\title{
Assessment of the clinical and electrophysiological characteristics of atrial fibrillation during and after cardiac surgery
}

Citation for published version (APA):

Bidar, E. (2018). Assessment of the clinical and electrophysiological characteristics of atrial fibrillation during and after cardiac surgery. [Doctoral Thesis, Maastricht University]. Maastricht University. https://doi.org/10.26481/dis.20181130eb

Document status and date:

Published: 01/01/2018

DOI:

10.26481/dis.20181130eb

Document Version:

Publisher's PDF, also known as Version of record

Please check the document version of this publication:

- A submitted manuscript is the version of the article upon submission and before peer-review. There can be important differences between the submitted version and the official published version of record.

People interested in the research are advised to contact the author for the final version of the publication, or visit the DOI to the publisher's website.

- The final author version and the galley proof are versions of the publication after peer review.

- The final published version features the final layout of the paper including the volume, issue and page numbers.

Link to publication

\footnotetext{
General rights rights.

- You may freely distribute the URL identifying the publication in the public portal. please follow below link for the End User Agreement:

www.umlib.nl/taverne-license

Take down policy

If you believe that this document breaches copyright please contact us at:

repository@maastrichtuniversity.nl

providing details and we will investigate your claim.
}

Copyright and moral rights for the publications made accessible in the public portal are retained by the authors and/or other copyright owners and it is a condition of accessing publications that users recognise and abide by the legal requirements associated with these

- Users may download and print one copy of any publication from the public portal for the purpose of private study or research.

- You may not further distribute the material or use it for any profit-making activity or commercial gain

If the publication is distributed under the terms of Article $25 \mathrm{fa}$ of the Dutch Copyright Act, indicated by the "Taverne" license above, 
Chapter 1 


\section{Assessment of the clinical and electrophysiological characteristics of atrial fibrillation during and after cardiac surgery}


Chapter 1

(C) copyright Elham Bidar, Maastricht 2018

Printing: ProefschriftMaken || www.proefschriftmaken.nl Lay-out: Elham Bidar

ISBN 978-94-6380-094-5 


\title{
Assessment of the clinical and electrophysiological characteristics of atrial fibrillation during and after cardiac surgery
}

\author{
DISSERTATION \\ to obtain the degree of Doctor at Maastricht University, \\ on the authority of the Rector Magnificus, Prof. Dr. Rianne M. Letschert \\ in accordance with the decision of the Board of Deans, \\ to be defended in public \\ on Friday 30 November 2018, at 12.00 hours
}

by

Elham Bidar 


\section{Promotores}

Prof. dr. U. Schotten

Prof. dr. J.G. Maessen

\section{Co-Promotor}

Dr. S. Verheule

\section{Assessment committee}

Prof. dr. H. J. G. M. Crijns, (Voorzitter)

Prof. dr. I. C. van Gelder, UMC Groningen

Dr. M. La Meir, Maastricht UMC

Prof. dr. W. J. L. Suyker, UMC Utrecht

Financial support for the publication of this thesis by: CARIM (Cardiovascular Research Institute Maastricht), ZonMw, HFL, Stichting Hartsvrienden RESCAR Maastricht are gratefully acknowledged, in addition to Krijnen Medical Innovations BV; Getinge Nederland BV; LivaNova Group Nederland NV; Edwards Lifesciences BV, PrivaZorg. Also financial support by the Dutch Heart Foundation for the publication of this thesis is gratefully acknowledged. 


\section{Contents}

Chapter 1 General Introduction

Part I Incidence and pathophysiology of late postoperative atrial fibrillation

Chapter 2 Postoperative Atrial Fibrillation - Pathophysiology, Treatment and Prevention

Chapter 3 A prospective randomized controlled trial on the incidence and predictors of late phase postoperative atrial fibrillation up to 30 days and the preventive value of bi-atrial pacing

Chpater 4 Assessment of clinical and electrophysiological predictors of late recurrences of postoperative atrial fibrillation detected by implantable loop recorder

Part II Importance of endo-epicardial dissociation of electrical activity for perpetuation of human atrial fibrillation

Chapter 5 A Novel Computer Model of Endo-epicardial Electrical Dissociation and Conduction during Human Atrial Fibrillation

Chapter 6 Application of Phase Coherence in Assessment of Spatial Alignment of Electrodes during Simultaneous Endocardial-epicardial Direct Contact Mapping of Atrial Fibrillation

Chapter 7 General Discussion

Valorization

Summary

Samenvatting

Dankwoord 
Dedicated to my parents. 
Chapter 1 
Chapter 1

General Introduction

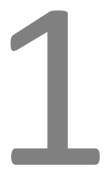

General Introduction 
Chapter 1 
Atrial fibrillation (AF) is the most common arrhythmia in human and its incidence is under-diagnosed because many episodes of AF are asymptomatic. ${ }^{1} A F$ is associated with an increased chance of stroke and thromboembolic events. ${ }^{2}$ Furthermore, because of its association with several age-related co-morbidities such as hypertension, diabetes mellitus, obesity and cardiac disease, its incidence is rising. ${ }^{3}$ In general, AF is categorized into paroxysmal (self-terminating), persistent (non-self-terminating, but pharmacological cardioversion still possible) and permanent (not amenable to pharmacological cardioversion) forms. ${ }^{4}$ In addition, postoperative AF (POAF) episodes occur after major surgery, mainly after cardiac surgery ${ }^{5}$ in patients with a comparable risk profile as in nonsurgical AF. ${ }^{6,7}$

The degree of atrial wall remodelling and occurrence of triggers determine the number and duration of AF episodes. Co-morbidities and advanced age contribute to structural heart disease, which leads to atrial wall remodelling and AF perpetuation., 9 This is illustrated for example in $\mathrm{CHADS}_{2} \mathrm{VA}_{2} \mathrm{SC}$ and HATCH scores ${ }^{10,11}$ both of which increase the chances of $A F$ progression. The resulting multifactorial aetiology of $A F$ includes abnormalities in calcium handling, ion-channel remodelling, fibrosis, oxidative stress, inflammation and others. ${ }^{12}$

Assessment of the atrial electrical activation during AF (Figure 1) has revealed that the fibrillation conduction pattern becomes more complex with AF persistence and is a reflection of the underlying structural changes. ${ }^{12-14}$ Moreover, different underlying diseases lead to distinctly different patterns of structural remodelling and fibrillation patterns in animal models. ${ }^{15}$ Two very interesting observations in human AF and AF animal models are dyssynchronous activation of the endo-epicardial surface (endo-epicardial dissociation) of the thin atrial wall, which leads to transmural conduction of wavelets (breakthrough). These conduction patterns have been shown to increase with complex substrates for AF in goat models ${ }^{16}$ and in humans, with high inter-individual variability (Figure 2). ${ }^{14}$

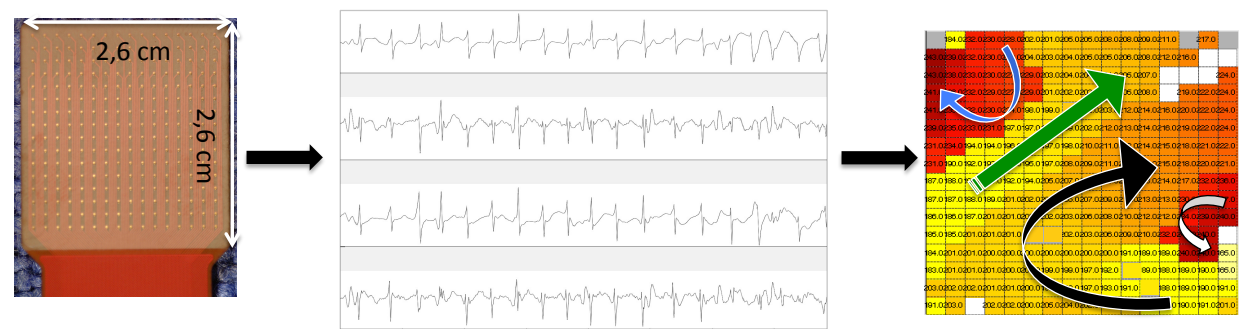

Figure 1 Different steps in epicardial mapping of fibrillation waves: From left to right: a unipolar electrode array $(26 \times 26 \mathrm{~mm})$ is used to record epicardial electrical activation by placing the electrode on the atrial wall surface during (induced) AF; unipolar electrograms are recorded and processed using an automated algorithm to filter out farfield deflections and detect steepest local deflections; finally, using the conduction velocity and wave tortuosity a wave map is created from the activation map (coloured arrows depict individual waves). 
Furthermore, AF itself can cause a gradual progression of structural changes such as myofiber rearrangement ${ }^{17}$ and endomysial fibrosis ${ }^{18}$ that contribute to AF perpetuation.

As expected, the traditional view of AF as a "one size fits all" disease does not suffice in classifying this complex disorder. This has become clearer from particularly two important findings of continuous rhythm monitoring devices (i.e. implanted pacemakers with atrial leads or implantable loop recorders). First, it has been shown that there is great discrepancy between the clinical classification of AF, which is often based on symptomatology, and the true temporal persistence of $A F .{ }^{19}$ In other words, patients classified in identical clinical categories may in reality have a wide variety in duration and incidence of AF episodes, which can lead to underestimation of the true AF burden. This finding may have important implications in clinical risk stratification, treatment strategies and their outcome measures in the abovementioned categories. Second, and perhaps even more importantly, subclinical atrial high rate episodes (AHRE) detected from implanted pacemakers, lasting up to 6 minutes contribute to enhanced risk of stroke. ${ }^{1,20,21}$ Consequently, even short lasting AF episodes may require oral anticoagulation treatment underscoring the need for rhythm monitoring in patients at risk for stroke. Thus, advanced monitoring strategies have led to a quest for re-evaluation of the clinical classifications of AF.
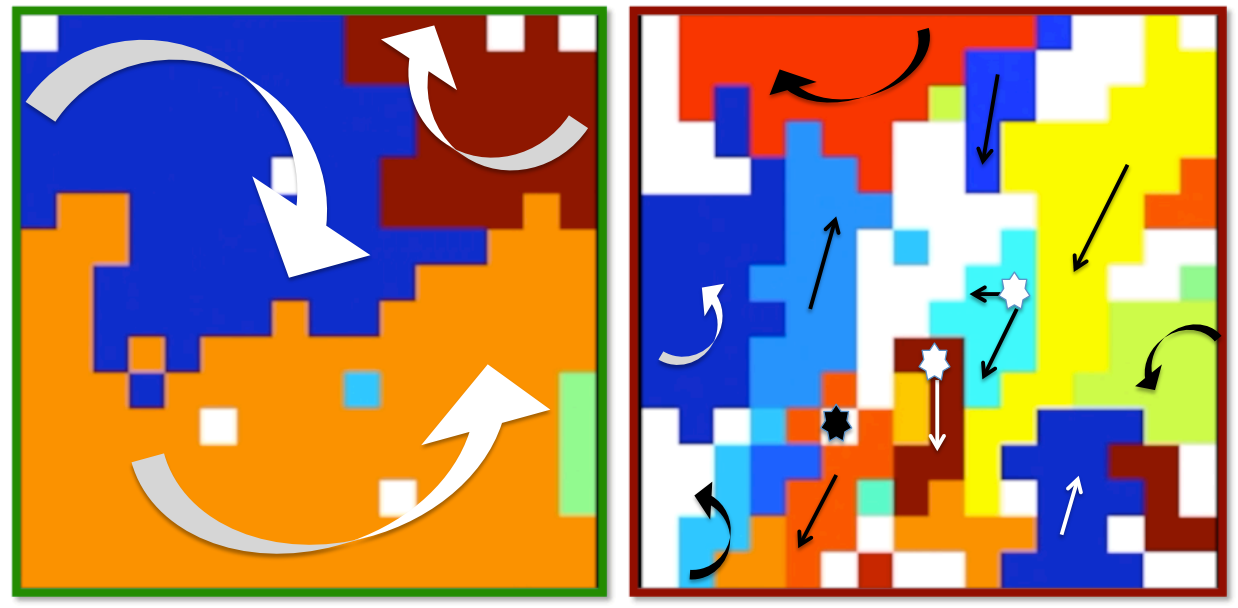

Figure 2 Two representative examples of activation patterns during electrically induced AF, acquired from patients without a history of AF: On the left, a 59 year old male patient with hypertension who underwent coronary artery bypass graft (CABG); On the right a 69 year old patient with hypertension who underwent CABG. Different colours depict different waves, arrows depict wave propagation direction, asterisks depict breakthrough waves. Clearly a more complex propagation pattern with wave narrowing and breakthroughs are seen in the older patient on the right (see also Chapter 4).

In this context, patients without a history of AF undergoing cardiac surgery represent a unique population. These patients carry on the one hand various degrees of potential substrates for AF caused by a variety of co-morbidities such as hypertension, cardiac 
failure and myocardial infarction. On the other hand, AF occurs in these patients during the acute postoperative phase by a large number of triggers including acute hemodynamic instability causing atrial stretch, a systemic inflammatory response to cardiopulmonary bypass, high levels of sympathetic activation, and others. ${ }^{5,22-26}$

Notably, while POAF is thought of as a transient arrhythmia after cardiac surgery, it is associated with increased long-term mortality and risk of stroke. ${ }^{6,7}$ This indicates that POAF may not be confined to the acute phase triggers but may show late recurrences, which is plausible if there is an underlying substrate. Also, whether the substrate for late POAF develops as a result of surgery or is pre-existent may differ from patient to patient. On the one hand, POAF occurs more frequently after cardiac surgery as opposed to general surgery, emphasizing the importance of cardiac surgical manipulation. ${ }^{27}$ On the other hand, analysis of right atrial appendages before and after surgery does not show histopathological differences. ${ }^{28}$ Furthermore up to $90 \%$ of patients with severe pre-existing myolysis develop POAF. ${ }^{28}$ These findings alongside the abovementioned co-morbidities in patients undergoing cardiac surgery, suggest a preexisting substrate that predisposes patients to POAF as opposed to an acute change during the operation (Figure 3).

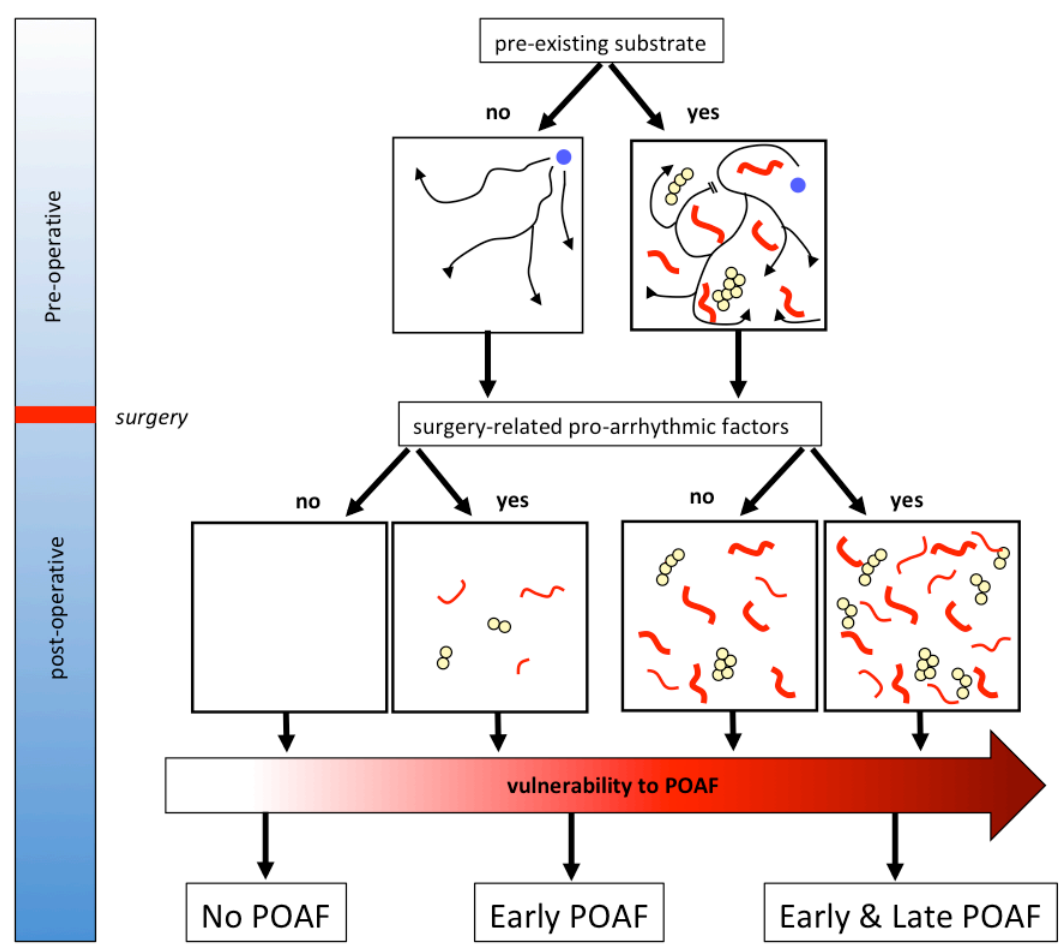

Figure 3 Schematic representation of a pre-existing structural substrate and its influence on vulnerability to POAF. Curved arrows depict electrical propagation, $P O A F=$ postoperative atrial fibrillation 


\section{Scope of this thesis}

In this thesis, we describe a number of studies undertaken to characterize the electrophysiological properties of the AF substrate during and after cardiac surgery, including a thorough quantification of true AF burden for an extended period of time after surgery. For this purpose we used continuous rhythm monitoring devices to detect AF episodes during follow-up periods of 1 month up to 3 years after cardiac surgery.

Previous studies quantifying late POAF mostly discuss clinical AF recurrences in populations who had a history of AF or show symptomatic and long lasting AF episodes. Here, we studied the relation between clinical predisposition at baseline and the electropathological substrate for $\mathrm{AF}$ on the one hand and $\mathrm{AF}$ recurrences including short lasting subclinical AF episodes on the other hand. Next to the invasive substrate quantification during surgery, we also highlight less invasive methods of substrate quantification such as P-wave morphology in electrocardiograms.

In the light of the above-mentioned inter-individual variability in AF substrates, detailed computational models can incorporate specific structural changes and atrial remodeling, to assess their effects on the propagation properties. In the last chapters of this thesis we describe the complex 3-dimensional electropathological substrate for AF in humans using a highly detailed computer model of AF, which showed the occurrences of transmural propagation of breakthrough waves as a result of endo-epicardial electrical uncoupling. To test this, we developed an invasive mapping technique, in which a clamp like electrode was inserted into the right atrium prior to venous cannulation during cardiac surgery to map the endo- and epicardium simultaneously. Using these techniques, we detected a new dimension in the electropathological substrate of AF.

In summary, we discuss the following subjects in the different chapters of this thesis:

- The prevalence of new onset AF in the acute postoperative phase (early POAF) and during prolonged follow-up (late POAF) using continuous rhythm monitoring devices (Chapters 3-4)

- Effect of co-morbidities on incidence of early and late POAF in the patients undergoing open chest cardiac surgery (Chapters 2-4,7)

- The underlying electropathological substrate assessed during electrically induced AF for POAF and late POAF in patients without a history of AF (Chapter 4).

- The 3-dimensional substrate for AF in patients undergoing open chest surgery (Chapter 5-6).

- ECG parameters for substrate detection and POAF prediction in patients undergoing cardiac surgery (Chapter 4). 


\section{References}

1. Freedman B, Camm J, Calkins H, Healey JS, Rosenqvist M, Wang J, Albert CM, Anderson CS, Antoniou S, Benjamin EJ, Boriani G, Brachmann J, Brandes A, Chao TF, Conen D, Engdahl J, Fauchier L, Fitzmaurice DA, Friberg L, Gersh BJ, Gladstone DJ, Glotzer TV, Gwynne K, Hankey GJ, Harbison J, Hillis GS, Hills MT, Kamel H, Kirchhof P, Kowey PR, Krieger D, Lee VWY, Levin LA, Lip GYH, Lobban T, Lowres N, Mairesse GH, Martinez C, Neubeck L, Orchard J, Piccini JP, Poppe K, Potpara TS, Puererfellner H, Rienstra M, Sandhu RK, Schnabel RB, Siu CW, Steinhubl S, Svendsen JH, Svennberg E, Themistoclakis S, Tieleman RG, Turakhia MP, Tveit A, Uittenbogaart SB, Van Gelder IC, Verma A, Wachter R, Yan BP and Collaborators AF-S. Screening for Atrial Fibrillation: A Report of the AF-SCREEN International Collaboration. Circulation. 2017;135:1851-1867.

2. Vanassche T, Lauw MN, Eikelboom JW, Healey JS, Hart RG, Alings M, Avezum A, Diaz R, Hohnloser SH, Lewis BS, Shestakovska O, Wang J and Connolly SJ. Risk of ischaemic stroke according to pattern of atrial fibrillation: analysis of 6563 aspirin-treated patients in ACTIVE-A and AVERROES. Eur Heart J. 2015;36:281-7a.

3. Huxley RR, Lopez FL, Folsom AR, Agarwal SK, Loehr LR, Soliman EZ, Maclehose R, Konety S and Alonso A. Absolute and attributable risks of atrial fibrillation in relation to optimal and borderline risk factors: the Atherosclerosis Risk in Communities (ARIC) study. Circulation. 2011;123:1501-8.

4. Kirchhof P, Benussi S, Kotecha D, Ahlsson A, Atar D, Casadei B, Castella M, Diener HC, Heidbuchel H, Hendriks J, Hindricks G, Manolis AS, Oldgren J, Popescu BA, Schotten U, Van Putte B, Vardas P, Agewall S, Camm J, Baron Esquivias G, Budts W, Carerj S, Casselman F, Coca A, De Caterina R, Deftereos S, Dobrev D, Ferro JM, Filippatos G, Fitzsimons D, Gorenek B, Guenoun M, Hohnloser SH, Kolh P, Lip GY, Manolis A, McMurray J, Ponikowski P, Rosenhek R, Ruschitzka F, Savelieva I, Sharma S, Suwalski P, Tamargo JL, Taylor CJ, Van Gelder IC, Voors AA, Windecker S, Zamorano JL and Zeppenfeld K. 2016 ESC Guidelines for the management of atrial fibrillation developed in collaboration with EACTS. Eur Heart J. 2016;37:28932962.

5. Vallurupalli S, Shanbhag A and Mehta JL. Controversies in postoperative atrial fibrillation after noncardiothoracic surgery: clinical and research implications. Clin Cardiol. 2017;40:329-332.

6. Mariscalco G, Biancari F, Zanobini M, Cottini M, Piffaretti G, Saccocci M, Banach M, Beghi C and Angelini GD. Bedside tool for predicting the risk of postoperative atrial fibrillation after cardiac surgery: the POAF score. J Am Heart Assoc. 2014;3:e000752.

7. Gialdini G, Nearing K, Bhave PD, Bonuccelli U, ladecola C, Healey JS and Kamel H. Perioperative atrial fibrillation and the long-term risk of ischemic stroke. JAMA. 2014;312:616-22.

8. Calkins H, Kuck KH, Cappato R, Brugada J, Camm AJ, Chen SA, Crijns HJ, Damiano RJ, Jr., Davies DW, DiMarco J, Edgerton J, Ellenbogen K, Ezekowitz MD, Haines DE, Haissaguerre M, Hindricks G, lesaka $Y$, Jackman W, Jalife J, Jais P, Kalman J, Keane D, Kim YH, Kirchhof P, Klein G, Kottkamp H, Kumagai K, Lindsay BD, Mansour M, Marchlinski FE, McCarthy PM, Mont JL, Morady F, Nademanee K, Nakagawa H, Natale A, Nattel S, Packer DL, Pappone C, Prystowsky E, Raviele A, Reddy V, Ruskin JN, Shemin RJ, Tsao HM and Wilber D. 2012 HRS/EHRA/ECAS Expert Consensus Statement on Catheter and Surgical Ablation of Atrial Fibrillation: recommendations for patient selection, procedural techniques, patient management and follow-up, definitions, endpoints, and research trial design. Europace. 2012;14:528606.

9. Chiang CE, Naditch-Brule L, Murin J, Goethals M, Inoue H, O'Neill J, Silva-Cardoso J, Zharinov O, Gamra H, Alam S, Ponikowski P, Lewalter T, Rosenqvist M and Steg PG. Distribution and risk profile of paroxysmal, persistent, and permanent atrial fibrillation in routine clinical practice: insight from the real-life global survey evaluating patients with atrial fibrillation international registry. Circ Arrhythm Electrophysiol. 2012;5:632-9.

10. de Vos CB, Pisters R, Nieuwlaat R, Prins MH, Tieleman RG, Coelen RJ, van den Heijkant AC, Allessie MA and Crijns HJ. Progression from paroxysmal to persistent atrial fibrillation clinical correlates and prognosis. J Am Coll Cardiol. 2010;55:725-31. 
11. Kirchhof P, Benussi S, Kotecha D, Ahlsson A, Atar D, Casadei B, Castella M, Diener HC, Heidbuchel H, Hendriks J, Hindricks G, Manolis AS, Oldgren J, Popescu BA, Schotten U, Van Putte B and Vardas P. [2016 ESC Guidelines for the management of atrial fibrillation developed in collaboration with EACTS]. Kardiol Pol. 2016;74:1359-1469

12. Schotten $U$, Verheule $S$, Kirchhof $P$ and Goette A. Pathophysiological mechanisms of atrial fibrillation: a translational appraisal. Physiol Rev. 2011;91:265-325.

13. Allessie MA, de Groot NM, Houben RP, Schotten U, Boersma E, Smeets JL and Crijns HJ. Electropathological substrate of long-standing persistent atrial fibrillation in patients with structural heart disease: longitudinal dissociation. Circ Arrhythm Electrophysiol. 2010;3:606-15.

14. de Groot NM, Houben RP, Smeets JL, Boersma E, Schotten U, Schalij MJ, Crijns H and Allessie MA. Electropathological substrate of longstanding persistent atrial fibrillation in patients with structural heart disease: epicardial breakthrough. Circulation. 2010;122:1674-82.

15. Everett THt, Wilson EE, Hulley GS and Olgin JE. Transmural characteristics of atrial fibrillation in canine models of structural and electrical atrial remodeling assessed by simultaneous epicardial and endocardial mapping. Heart Rhythm. 2010;7:506-17.

16. Eckstein J, Maesen B, Linz D, Zeemering S, van Hunnik A, Verheule S, Allessie M and Schotten U. Time course and mechanisms of endo-epicardial electrical dissociation during atrial fibrillation in the goat. Cardiovasc Res. 2011;89:816-24.

17. Maesen B, Zeemering S, Afonso C, Eckstein J, Burton RA, van Hunnik A, Stuckey DJ, Tyler D, Maessen J, Grau V, Verheule S, Kohl P and Schotten U. Rearrangement of atrial bundle architecture and consequent changes in anisotropy of conduction constitute the 3-dimensional substrate for atrial fibrillation. Circ Arrhythm Electrophysiol. 2013;6:967-75.

18. Verheule S, Tuyls E, Gharaviri A, Hulsmans S, van Hunnik A, Kuiper M, Serroyen J, Zeemering S, Kuijpers $\mathrm{NH}$ and Schotten $U$. Loss of continuity in the thin epicardial layer because of endomysial fibrosis increases the complexity of atrial fibrillatory conduction. Circ Arrhythm Electrophysiol. 2013;6:202-11.

19. Charitos El, Purerfellner H, Glotzer TV and Ziegler PD. Clinical classifications of atrial fibrillation poorly reflect its temporal persistence: insights from 1,195 patients continuously monitored with implantable devices. J Am Coll Cardiol. 2014;63:2840-8.

20. Camm AJ, Simantirakis E, Goette A, Lip GY, Vardas P, Calvert M, Chlouverakis G, Diener HC and Kirchhof P. Atrial high-rate episodes and stroke prevention. Europace. 2017;19:169-179.

21. Glotzer TV, Hellkamp AS, Zimmerman J, Sweeney MO, Yee R, Marinchak R, Cook J, Paraschos A, Love J, Radoslovich G, Lee KL, Lamas GA and Investigators M. Atrial high rate episodes detected by pacemaker diagnostics predict death and stroke: report of the Atrial Diagnostics Ancillary Study of the MOde Selection Trial (MOST). Circulation. 2003;107:1614-9.

22. Kannel WB, Wolf PA, Benjamin EJ and Levy D. Prevalence, incidence, prognosis, and predisposing conditions for atrial fibrillation: population-based estimates. Am J Cardiol. 1998;82:2N-9N.

23. Echahidi N, Pibarot P, O'Hara G and Mathieu P. Mechanisms, prevention, and treatment of atrial fibrillation after cardiac surgery. J Am Coll Cardiol. 2008;51:793-801.

24. Kalman JM, Munawar M, Howes LG, Louis WJ, Buxton BF, Gutteridge G and Tonkin AM. Atrial fibrillation after coronary artery bypass grafting is associated with sympathetic activation. Ann Thorac Surg. 1995;60:1709-15.

25. Frost L, Christiansen EH, Molgaard H, Jacobsen CJ, Allermand $\mathrm{H}$ and Thomsen PE. Premature atrial beat eliciting atrial fibrillation after coronary artery bypass grafting. J Electrocardiol. 1995;28:297-305.

26. Maisel WH, Rawn JD and Stevenson WG. Atrial fibrillation after cardiac surgery. Ann Intern Med. 2001;135:1061-73

27. Maesen B, Nijs J, Maessen J, Allessie M and Schotten U. Post-operative atrial fibrillation: a maze of mechanisms. Europace. 2012;14:159-74.

28. Ad N, Snir E, Vidne BA and Golomb E. Histologic atrial myolysis is associated with atrial fibrillation after cardiac operation. Ann Thorac Surg. 2001;72:688-93. 
Chapter 1 
Incidence and pathophysiology of late postoperative atrial fibrillation 


\section{Postoperative Atrial Fibrillation - Pathophysiology, Treatment and Prevention}




\section{Abstract}

Atrial fibrillation occurring after cardiac surgery has been the subject of intensive research over the past decades. However, the incidence remains high, despite numerous preventive and treatment strategies. In addition, several reports show that the impact of postoperative atrial fibrillation (POAF) is high. It is an independent risk factor for mortality after several years. These findings make clear that the pathophysiology of POAF is not fully understood and POAF-associated risks to some extent might be underestimated. On the one hand, excessive triggers during the acute post operative phase after cardiac surgery might initiate AF even in atria with low vulnerability. On the other hand, many patients undergoing surgery have an atrial substrate at the time of operation promoting AF not only in the postoperative phase but also in the days and weeks thereafter. Progress in our understanding of the AF mechanisms in general has provided valuable insights into processes involved in atrial structural remodeling due to advanced age, hypertension, obesity, and congestive heart failure. These patient characteristics strongly contribute to cardiac disease, predict POAF and likely have an impact on the risk of thrombus formation in the weeks and months after cardiac surgery. For a better understanding of the mechanisms involved, it is important to not only recognize the occurrence of POAF by continuous monitoring after surgery, but also to identity the extent of atrial vulnerability to AF in these patients. 


\section{Introduction and Incidence}

Postoperative atrial fibrillation (POAF) is an important complication after cardiac surgery, which increases short-term hospitalization costs ${ }^{1}$ and more importantly, decreases long-term survival. ${ }^{2,3}$ This makes POAF an important target for prevention and treatment.

Great discrepancy remains between reported incidences of POAF in different studies. Reported incidences vary between $10-60 \%$ depending on the type of surgery, with higher incidences in valve surgery compared to coronary artery bypass surgery (CABG). ${ }^{4}$ This is certainly affected by the more invasive structural changes arising from valvular diseases such as atrial dilatation and fibrosis, but also by the more prolonged and invasive nature of the surgical interventions in valve surgery. ${ }^{5}$ The incidence of POAF is however also influenced by the definition of AF. The minimal duration of AF needed to qualify as POAF varies in reports between minutes of $A F,{ }^{6,7}$ to sometimes only qualification as $A F$ if it requires therapy. ${ }^{1}$

In general, AF is defined as an episode with irregular RR-intervals without a traceable $\mathrm{p}$-wave, during at least 10 seconds. $^{8,9}$ It is important to acknowledge even the short episodes of $A F^{6}$, because of the progressive nature of the arrhythmia, ${ }^{10,11}$ but also because even a low AF burden significantly increases the stroke rate. ${ }^{12}$ The unpredictability of AF onset and duration poses a great challenge to the intermittent rhythm detectors such as ECG or Holter monitoring after discharge. ${ }^{13}$ Reports on long-term follow up after cardiac surgery suggest that POAF is an independent predictor of mortality, which might well be related to the fact that it is a recurrent arrhythmia. ${ }^{2,3,14}$ Of note, some of the AF episodes may remain unnoticed as they can be asymptomatic both during hospitalization and after discharge. ${ }^{15-17}$

Indeed, several studies in patients undergoing cardiac surgery have shown recurrence of AF after discharge. ${ }^{18,19}$ In a randomized trial of 124 patients on the effects of Amiodarone after cardiac surgery, $12 \%$ of the patients in the placebo group were in AF at a mean of 12 days after discharge. ${ }^{20}$ In a retrospective study of 305 patients undergoing cardiac surgery, the annual incidence of symptomatic AF during a 4 year follow up was $5.1 \%$ in patients who had developed POAF. ${ }^{21}$ Interestingly, multivariate analysis showed reduced left ventricular ejection fraction, which can cause atrial structural remodelling, to predict recurrences of POAF independently. ${ }^{21}$ In line with this, other predictors of POAF after discharge that have been reported are valve surgery, history of myocardial infarction and pulmonary hypertension. ${ }^{17}$

The value of continuous monitoring seems essential in detecting the true POAF burden, ${ }^{13}$ because the importance of asymptomatic "silent $A F^{\prime}$ in patients with a comparable risk profile as the POAF population, has recently been emphasized. ${ }^{12}$ Therefore, to be able to treat or at least to restrain the consequences of POAF, a better understanding of the pathophysiology of POAF is mandatory. 


\section{Pathophysiology}

Even in normal atria in sinus rhythm inter-atrial and site-specific conduction delays occur, leading to spatial non-uniformity of conduction anisotropy. ${ }^{22}$ In the presence of triggers with sufficient incidence, AF can be induced both in normal and in abnormal atria. The wave pattern and type of AF however, may vary in complexity ${ }^{9}$ depending on the severity of the underlying substrate. ${ }^{23}$ Although inducibility of AF by pacing in normal atrial structure is dependent on the protocol of pacing, ${ }^{24}$ it has predictive value for the occurrence of POAF. ${ }^{25,26}$ This suggests higher susceptibility for AF at least in some of the patients who subsequently develop POAF. ${ }^{27}$ Furthermore, AF occurring as a consequence of cardiac surgery in patients without a history of AF postulates a significant pathophysiological role for the surgical intervention itself.

\section{Early pro-arrhythmic environment}

In a recent review, we discussed the acute and chronic factors contributing to initiation of POAF, and emphasized that different mechanisms are responsible for $A F$ in the acute post operative setting. ${ }^{28}$

Inflammation in the postoperative phase has been subject of extensive research as it has been linked to several local and systemic pro-arrhythmic effects. First of all, direct atrial trauma, e.g. the venous cannulation through the right atrium, has been shown to induce an inflammatory reaction leading to inhomogeneity in conduction in a canine model. ${ }^{29}$ The canine sterile pericarditis model, in which application of sterile talc and subsequent pericarditis enhanced AF susceptibility, supports this hypothesis. ${ }^{30}$ Administration of prednisone in this model reduced inflammation and as expected prevented $A F .^{31}$ Similarly colchicine was able to reduce the incidence of POAF, as a result of a reduction of the post-cardiotomy syndrome in humans. ${ }^{32}$ Secondly, systemic inflammatory effects expressed as increased C-reactive protein levels, and therefore complement activation during cardio pulmonary bypass and during the acute post operative phase, were demonstrated to coincide with the peak POAF incidence, advocating a direct immune reaction mediated by the complement system. ${ }^{33}$ Indeed, the use of cardio pulmonary bypass is correlated with POAF incidence in most studies. ${ }^{5,34}$ Thus as expected, oral corticosteroids reduce not only the postoperative inflammatory markers, but also the incidence of POAF as demonstrated by an extensive meta-analysis. ${ }^{35}$

Furthermore, cardiopulmonary bypass might lead to insufficient cooling of the atria during the cardioplegic arrest. ${ }^{36}$ This may induce a temporary substrate to initiate AF as a consequence of ischemia reperfusion injury. ${ }^{36,37}$ Indeed, oxidative stress has been shown to cause a transient pro-arrhythmic effect in the postoperative setting. ${ }^{38}$ This can explain the anti-arrhythmic effects of statins in POAF prevention. Despite the antiinflammatory effects of the HMG-CoA enzyme inhibitors, statins had no effect in predetermined substrates for AF, such as enlarged left atria. ${ }^{39}$ In line with the effect of oxida- 
tive stress in the direct postoperative occurrence of AF, administration of ascorbate acid preserved the length of the effective refractory period (ERP) during rapid pacing in a canine model, and reduced POAF especially in the very early postoperative phase in humans. ${ }^{40}$ Similarly, the antioxidant $\mathrm{N}$-acetylcysteine reduced the incidence of POAF in the early postoperative phase. ${ }^{41}$ These findings suggest that independent of a preexisting vulnerability to AF, surgery itself can have several pro-arrhythmic consequences on the atrial tissue based on ischemic and inflammatory effects.

Postoperatively, as a counterbalance to anaesthesia induced hypotension, systemic inflammatory response and cardiac stunning after aortic cross clamping fluid administration is required to keep up the cardiac output. Especially in hypertrophic ventricles, e.g. in aortic valve stenosis, significant volume therapy is applied for hemodynamic stabilization in the acute post-operative phase. In this setting, atrial enlargement seems to be an important factor in predicting POAF. ${ }^{32}$ Acute atrial stretch decreases conduction velocity, increases conduction block and thereby the vulnerability of the atrial tissue to re-entry. ${ }^{42-44}$ In addition, premature atrial beats initiate postoperative $A F,{ }^{45}$ partly aggravated by high sympathetic activation. ${ }^{6}$ Possibly they are also due to increased Ltype calcium currents $\left(\mathrm{I}_{\mathrm{ca}}{ }^{2+}\right)$ in patients developing POAF. ${ }^{46}$ Indeed, milrinone, a phosphodiesterase inhibitor inotropic agent, increased the incidence of POAF significantly, presumably through a protein kinase-A activation leading to triggered activity. ${ }^{47}$

It can be concluded that transient local and systemic changes in the acute postoperative phase after cardiac surgery are linked to POAF. They cause conduction disturbances and may enhance triggers for AF both of which together will enhance the susceptibility to AF.

\section{Histopathological substrate}

In addition to postoperative acute phase triggers, several long-term mechanisms have been identified to also predict POAF. These mechanisms are known to produce a more sustained substrate for AF, which favors AF maintenance rather than initiating it. The complexity of AF in these patients is therefore higher and recurrences are more likely after discharge, compared to AF in the less pronounced substrates, which are confined to solely acute phase POAF.

First, POAF is a disease of advanced age. ${ }^{1,48}$ The atrial wall becomes fibrotic with age $^{49}$ and this has been identified as one of the most important structural substrates for AF perpetuation in the non-operative setting. ${ }^{10,23}$ Prolonged signal averaged $p$-wave duration may reflect atrial fibrosis resulting in conduction delays and has been reported to be a predictor of POAF. ${ }^{50-52}$ However, pre-operative AF was not excluded in all these studies. ${ }^{50,51}$ Nevertheless this finding suggests an increased AF vulnerability in patients with intra-atrial conduction delays particularly in a pro-arrhythmic environment.

Several co-morbidities have also been shown to increase the chances of POAF development, such as chronic obstructive pulmonary disease, ${ }^{48,53}$ hypertension, obesity 
and systolic dysfunction. ${ }^{1,53}$ The role of these co-morbidities in the perpetuation of AF has long been established. ${ }^{8,54}$ Obesity has been associated with ERP shortening in left atria, diastolic dysfunction and left atrial dilation, all of which predispose to AF. ${ }^{5}$

In congestive heart failure, Sanders et al. demonstrated increased vulnerability to AF due to prolonged P-wave duration, prolonged ERP duration at the right atrial wall and significantly longer sinus node recovery time. ${ }^{27}$ Accordingly, prolongation of conduction time with a higher percentage of double potentials and longer iso-electric intervals is linked to severely disturbed substrates. ${ }^{10,23}$ These pro-arrhythmic changes seem to occur due to chronic dilated atria, as a consequence of congestive heart failure or longstanding valve pathology for example. In line with these findings, left ventricular diastolic dysfunction was determined as an additional predictor of POAF. ${ }^{55}$ On the biochemical level, stretch activated channels (SAC's) increase intracellular $\mathrm{Na}^{+}$concentrations. As a consequence, the $\mathrm{Na}^{+} / \mathrm{Ca}^{2+}$ exchanger extrudes less $\mathrm{Ca}^{2+}$ to the extracellular space, thereby enhancing $\mathrm{Ca}^{2+}$ binding to the actin-myosin response. In this setting intracellular calcium overload causes a down regulation of $\mathrm{I}_{\mathrm{ca}}{ }^{2+}$-gene expression, subsequently shortening the ERP. ${ }^{56}$ Also chronic stretch has been associated with altered matrix metalloproteinase expression and angiotensin $\|$ mediated fibrosis. ${ }^{10}$ Thus as expected preoperative atrial enlargement has been shown to increase risk for POAF. ${ }^{57}$ Furthermore, preoperative dispersion of refractoriness and a prolonged $P R$ interval predicted POAF after $C A B G .{ }^{58}$ Atrial structural changes have also been attributed to the uncontrolled ventricular rate and congestive heart failure leading to atrial stretch, apoptosis and myolysis. ${ }^{59}$ Although apoptosis has not consistently been found in the atrial tissue of patients developing POAF, myolysis has been advocated as a pre-existing structural substrate in these patients. ${ }^{60,61}$

Another important structural abnormality, which is closely linked to the propagating abilities of the atrial wall, is the gap-junctional connexin $(C x)$ distribution. Higher and more heterogeneously distributed levels of $\mathrm{Cx} 40$ have been demonstrated in POAF patients. ${ }^{62}$ Also local inflammation caused a reduction in $C_{x} 40$ and 43 expressions in the epicardial level, compared to normal distribution in non-inflammatory circumstances. ${ }^{63}$ The exact role of connexin expression changes in POAF still needs to be defined.

From these findings it can be concluded that at least in some of the patients developing POAF after cardiac surgery, severely altered atrial architecture already is present before the operation. These structural alterations make the atria prone to not only POAF but also to AF in general. This is important because POAF might be an expression of the atrial vulnerability that is detected due to continuous monitoring in a period with excessive triggers, a "poor man's exercise" effect. This strongly implies close monitoring of these patients later on. Figure 1 gives a possible course of POAF development and perpetuation after cardiac surgery and after discharge.

Treatment strategies also provide additional information for the possible mechanism that is responsible for POAF. The positive effects of class III anti arrhythmic drugs for example, suggest a role for a re-entry mechanism, in which shortening of the excita- 
ble gap might be the key element in their effectiveness, while beta-adrenergic blockers advocate a more prominent role for the sympathetic activation and triggers for $A F^{5,64}$

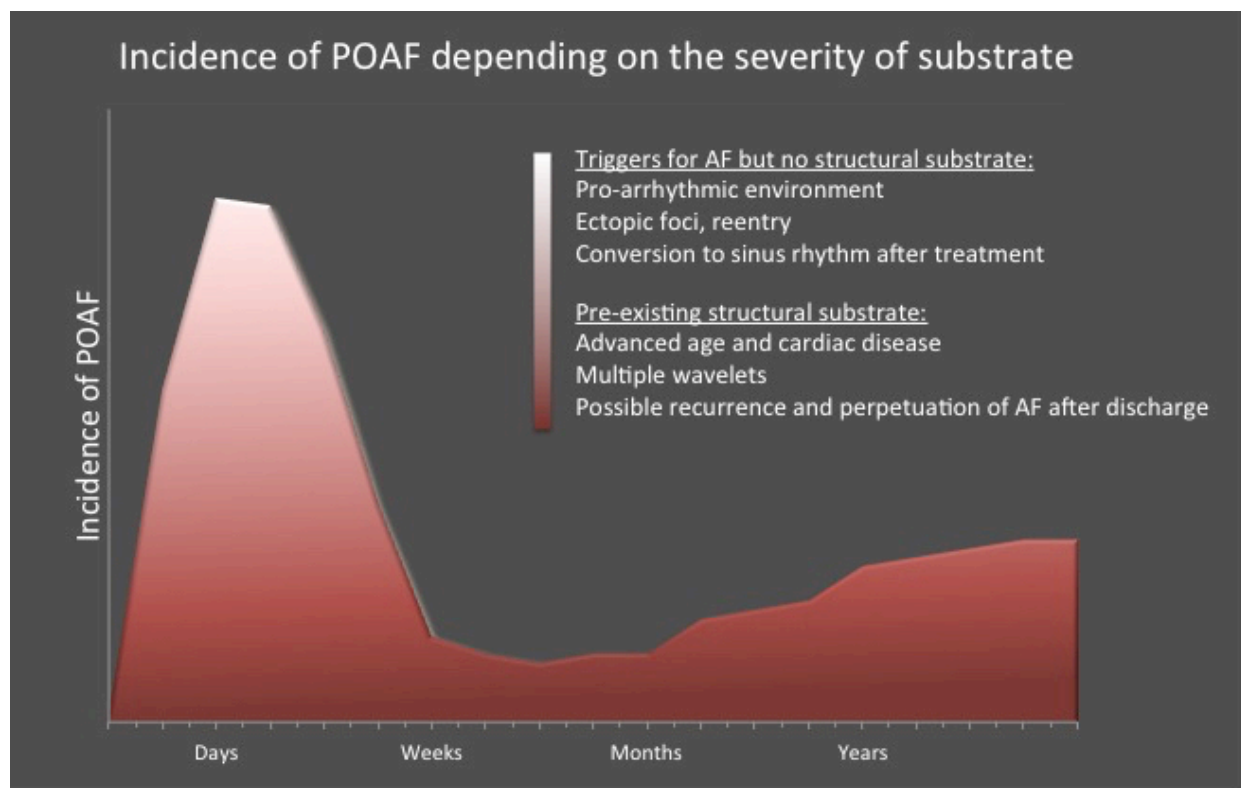

Figure $1 \mathrm{~A}$ schematic sketch of incidence of POAF in the early postoperative phase (i.e. the first postoperative week) and during the late postoperative phase (i.e. weeks to years following cardiac surgery) after discharge. In severely aggravated atrial substrates, POAF might continue to exist and reoccur. Red area under the curve represents patients with a preexistent structural substrate, e.g. atrial enlargement or heart failure, which is not easily reversible. White area under the curve represents patients with less severe structural substrate but who are exposed to the pro-arrhythmic environment of the acute-postoperative phase.

\section{Prevention}

\section{Beta-Blockers}

It has become clear from multiple meta-analyses, reviews, and large cohort studies, that the peri-operative use of $\beta$-blocking agents reduces the incidence of atrial fibrillation after cardiac surgery. ${ }^{65-67}$ Furthermore, it is evident that the peri-operative use of $\beta$ blockers reduces mortality. ${ }^{66}$ This knowledge has led to unambiguous recommendations of the use of $\beta$-blockers as standard of care in the prophylaxis of POAF in patients without contra-indications. 8 , 68-70

\section{Sotalol}

Sotalol has a greater efficacy in preventing POAF than standard $\beta$-blockers, ${ }^{65}$ but has possibly more unfavorable adverse event profile. The extent of side effects of sotalol, 
such as prolongation of the QT-interval, compared to standard $\beta$-blockers is debated. Because sotalol exposes patients to the risk for torsade des pointes, its use requires close monitoring, and under these conditions may be considered for the prevention of POAF. $^{8,54,68,70}$

\section{Amiodarone}

Amiodarone with its class III anti-arrhythmic effects is a strong preventive drug in the acute postoperative setting. ${ }^{20,71}$ Prophylactic amiodarone, with or without concomitant use of $\beta$-blockers also has a positive effect on duration of hospital stay, postoperative stroke, and postoperative ventricular tachyarrhythmia. ${ }^{20,65,71-73}$ However, in one trial the effects of amiodarone were not superior to placebo in patients with enlarged atria and in patients undergoing valve surgery. These are important characteristics of patients with a strong structural substrate ${ }^{43,71}$ suggesting its effectiveness relies on the prevention of triggers in the early pro-arrhythmic environment. Common adverse effects of amiodarone are bradycardia and hypotension, ${ }^{74,75}$ which lead- together with extra cardiac side effects- to cessation of the treatment in up to $20 \%$ of all patients. ${ }^{76}$ The pre-operative administration of amiodarone should be considered in patients with high risk for the development of POAF, according to the international guidelines, ${ }^{8,54}$ and should certainly be considered in patients with a contraindication for the use of $\beta$ blockers. $^{68,70}$

\section{Biatrial pacing}

Bi-atrial pacing significantly reduces the incidence of POAF, ${ }^{65}, 73$ although it has been reported to be difficult to apply. Some studies demonstrated even pro-arrhythmic side effects and also unintentional diaphragmatic or left ventricular pacing are common. ${ }^{52,77-}$

${ }^{79}$ However, when sensing and capture thresholds of the pacemaker leads are followed accurately, particularly simultaneous biatrial pacing effectively prevents POAF. 7, 80-84 The main effects of postoperative atrial pacing on the atria are still unclear. It has been proposed that simultaneous biatrial pacing reduces dispersion of refractoriness and reduces the P-wave duration and dispersion. ${ }^{52,85}$ Also, overdrive pacing might prevent ectopic activity. ${ }^{82}$ At the ventricular level, overdrive pacing after an ischemic episode has been shown to reduce infarct size, based on prevention of ischemic reperfusion injury. ${ }^{86}$ More research is required to define the exact mechanisms of AF prevention by pacing at the atrial level, and to determine the population in which pacing is effective.

\section{ACE-inhibitors}

Angiotensin concerting enzyme inhibitors (ACEI's) may be as effective in preventing POAF as they are in permanent AF in general population. ${ }^{87}$ Although administration of ACEI's have been associated with reduced POAF incidence, ${ }^{48,88}$ recent reports show conflicting results. Most importantly increased adverse effects are reported in some 
studies, including hypotension, renal failure, higher mortality and a paradoxical increased risk of POAF incidence, ${ }^{89,90}$ or at least no reduction of new onset AF after cardiac surgery. ${ }^{91}$ More research is required to find true effects of ACEl's in the acute and late postoperative setting for the prevention of POAF. ${ }^{8}$

Benefits from other prophylactic measures, such as the administration of corticosteroids, Colchicin, or vitamin C, are postulated in some reports, ${ }^{92}$ but lack sufficient evidence for standard practice. The use of statins as a prophylactic measure has shown conflicting results ${ }^{8}$ although a meta-analysis showed significant POAF reduction in statin treated arm. ${ }^{93}$ Intravenous administration of magnesium might reduce the incidence of POAF, although conflicting results on this issue are reported. ${ }^{65}$ In patients without renal dysfunction the probability of adverse effects is very low. In these patients some ${ }^{68}$ but not all guidelines recommend the perioperative use of magnesium. Further research on the usefulness, and applicability of these, and other preventive strategies is warranted.

\section{Treatment}

In the majority of patients, POAF will spontaneously convert to sinus rhythm within 24 hours after surgery. Correction of predisposing factors such as hypoxia, anemia, and electrolyte imbalance, should be the first step in the management of POAF. The superiority of a certain drug regarding rate control remains to be proven. Therefore the decision of the drug to be administered should be based on the side effect profile, contraindications, and local familiarity with the drug. ${ }^{94}$

In case of hemodynamic instability cardioversion to sinus rhythm by direct current (ECV) or pharmacologically with ibutilide or amiodarone, should be pursued. ${ }^{95}$ Also if patients are highly symptomatic or when rate control is difficult to achieve, electrical direct current cardioversion is recommended. ${ }^{8,54}$

\section{Oral anticoagulation}

Since the risk of stroke is increased in patients with $\mathrm{POAF}^{3}$ starting with oral anticoagulation within 48 hours of the onset of $A F$, is recommended. $8,54,6896$ In contrast to patients with $\mathrm{AF}$ in the general population, it has yet to be proven for patients with POAF that anticoagulation will decrease the risk of stroke. It is recommended to continue anticoagulation for at least 4 weeks after conversion to sinus rhythm, ${ }^{95}, 97$ although convincing evidence is lacking. 


\section{Conclusions}

The pathophysiology of POAF is not completely understood. In general, AF initiation and perpetuation has been attributed to (or a combination of) ectopic focal discharges and reentry primarily represented by multiple wavelets. ${ }^{10}$ In the postoperative setting, it is conceivable that in different patients, different mechanisms perpetuate AF. This is reflected by the fact that the preventive and therapeutic strategies are only helpful in some patients in the early phase after cardiac surgery. In patients with highly diseased atrial tissue e.g. due to chronic atrial stretch or advanced age, AF might not only occur in the early postoperative phase, but also during the days and weeks thereafter. Indeed, data on late POAF is accumulating and shows a potential role for prolonged monitoring in high-risk patients. ${ }^{2,14,98,99}$

Future research needs to address the incidence of 'late POAF' in the weeks and months after discharge. It is also of interest how this incidence depends on the heart disease and other clinical factors. Finally, the therapeutic implications of 'late POAF' need to be defined. As a first step towards these objectives more studies systematically studying 'late POAF' in different indication groups are urgently needed. 


\section{References}

1. Aranki SF, Shaw DP, Adams DH, Rizzo RJ, Couper GS, VanderVliet M, Collins JJ, Jr., Cohn LH and Burstin HR. Predictors of atrial fibrillation after coronary artery surgery. Current trends and impact on hospital resources. Circulation. 1996;94:390-7.

2. El-Chami MF, Kilgo P, Thourani V, Lattouf OM, Delurgio DB, Guyton RA, Leon AR and Puskas JD. Newonset atrial fibrillation predicts long-term mortality after coronary artery bypass graft. J Am Coll Cardiol. 2010;55:1370-6.

3. Villareal RP, Hariharan R, Liu BC, Kar B, Lee VV, Elayda M, Lopez JA, Rasekh A, Wilson JM and Massumi A. Postoperative atrial fibrillation and mortality after coronary artery bypass surgery. I Am Coll Cardiol. 2004;43:742-8.

4. Echahidi N, Pibarot P, O'Hara G and Mathieu P. Mechanisms, prevention, and treatment of atrial fibrillation after cardiac surgery. J Am Coll Cardiol. 2008;51:793-801.

5. Murphy GJ, Ascione R, Caputo M and Angelini GD. Operative factors that contribute to post-operative atrial fibrillation: insights from a prospective randomized trial. Card Electrophysiol Rev. 2003;7:136-9.

6. Kalman JM, Munawar M, Howes LG, Louis WJ, Buxton BF, Gutteridge G and Tonkin AM. Atrial fibrillation after coronary artery bypass grafting is associated with sympathetic activation. Ann Thorac Surg. 1995;60:1709-15.

7. Debrunner M, Naegeli B, Genoni M, Turina M and Bertel O. Prevention of atrial fibrillation after cardiac valvular surgery by epicardial, biatrial synchronous pacing. Eur J Cardiothorac Surg. 2004;25:16-20.

8. Camm AJ, Kirchhof P, Lip GY, Schotten U, Savelieva I, Ernst S, Van Gelder IC, Al-Attar N, Hindricks G, Prendergast B, Heidbuchel H, Alfieri O, Angelini A, Atar D, Colonna P, De Caterina R, De Sutter J, Goette A, Gorenek B, Heldal M, Hohloser SH, Kolh P, Le Heuzey JY, Ponikowski P, Rutten FH and Guidelines ESCCFP. Guidelines for the management of atrial fibrillation: the Task Force for the Management of Atrial Fibrillation of the European Society of Cardiology (ESC). Europace. 2010;12:1360-420.

9. Konings $\mathrm{KT}$, Kirchhof $\mathrm{CJ}$, Smeets JR, Wellens HJ, Penn $\mathrm{OC}$ and Allessie MA. High-density mapping of electrically induced atrial fibrillation in humans. Circulation. 1994;89:1665-80.

10. Schotten $U$, Verheule S, Kirchhof $P$ and Goette A. Pathophysiological mechanisms of atrial fibrillation: a translational appraisal. Physiol Rev. 2011;91:265-325.

11. Wijfels MC, Kirchhof CJ, Dorland R and Allessie MA. Atrial fibrillation begets atrial fibrillation. A study in awake chronically instrumented goats. Circulation. 1995;92:1954-68.

12. Healey JS, Connolly SJ, Gold MR, Israel CW, Van Gelder IC, Capucci A, Lau CP, Fain E, Yang S, Bailleul C, Morillo CA, Carlson M, Themeles E, Kaufman ES, Hohnloser SH and Investigators A. Subclinical atrial fibrillation and the risk of stroke. N Eng/ J Med. 2012;366:120-9.

13. Charitos El, Stierle U, Ziegler PD, Baldewig M, Robinson DR, Sievers HH and Hanke T. A comprehensive evaluation of rhythm monitoring strategies for the detection of atrial fibrillation recurrence: insights from 647 continuously monitored patients and implications for monitoring after therapeutic interventions. Circulation. 2012;126:806-14.

14. Saxena A, Dinh DT, Smith JA, Shardey GC, Reid CM and Newcomb AE. Usefulness of postoperative atrial fibrillation as an independent predictor for worse early and late outcomes after isolated coronary artery bypass grafting (multicenter Australian study of 19,497 patients). Am J Cardiol. 2012;109:219-25.

15. Landymore RW and Howell F. Recurrent atrial arrhythmias following treatment for postoperative atrial fibrillation after coronary bypass operations. Eur J Cardiothorac Surg. 1991;5:436-9.

16. Camm AJ, Corbucci $G$ and Padeletti L. Usefulness of continuous electrocardiographic monitoring for atrial fibrillation. Am J Cardiol. 2012;110:270-6.

17. Funk M, Richards SB, Desjardins J, Bebon $\mathrm{C}$ and Wilcox $\mathrm{H}$. Incidence, timing, symptoms, and risk factors for atrial fibrillation after cardiac surgery. Am J Crit Care. 2003;12:424-33; quiz 434-5.

18. Cioffi G, Cemin C, Russo TE, Pellegrini A, Terrasi F and Ferrario G. Post-discharge recurrences of newonset atrial fibrillation following cardiac surgery: impact of low-dose amiodarone and beta-blocker prophylaxis. Ital Heart J. 2000;1:691-7. 
19. D'Agostino RS, Jacobson J, Clarkson M, Svensson LG, Williamson C and Shahian DM. Readmission after cardiac operations: prevalence, patterns, and predisposing factors. J Thorac Cardiovasc Surg. 1999;118:823-32.

20. Daoud EG, Strickberger SA, Man KC, Goyal R, Deeb GM, Bolling SF, Pagani FD, Bitar C, Meissner MD and Morady F. Preoperative amiodarone as prophylaxis against atrial fibrillation after heart surgery. $N$ Eng/ J Med. 1997;337:1785-91.

21. Antonelli D, Peres D, Freedberg NA, Feldman A and Rosenfeld T. Incidence of postdischarge symptomatic paroxysmal atrial fibrillation in patients who underwent coronary artery bypass graft: long-term followup. Pacing Clin Electrophysiol. 2004;27:365-7.

22. Papageorgiou P, Monahan K, Boyle NG, Seifert MJ, Beswick P, Zebede J, Epstein LM and Josephson ME. Site-dependent intra-atrial conduction delay. Relationship to initiation of atrial fibrillation. Circulation. 1996;94:384-9.

23. Allessie MA, de Groot NM, Houben RP, Schotten U, Boersma E, Smeets JL and Crijns HJ. Electropathological substrate of long-standing persistent atrial fibrillation in patients with structural heart disease: longitudinal dissociation. Circ Arrhythm Electrophysiol. 2010;3:606-15.

24. Kumar S, Kalman JM, Sutherland F, Spence SJ, Finch S and Sparks PB. Atrial fibrillation inducibility in the absence of structural heart disease or clinical atrial fibrillation: critical dependence on induction protocol, inducibility definition, and number of inductions. Circ Arrhythm Electrophysiol. 2012;5:531-6.

25. Hakala T, Berg E, Hartikainen JE and Hippelainen MJ. Intraoperative high-rate atrial pacing test as a predictor of atrial fibrillation after coronary artery bypass surgery. Ann Thorac Surg. 2002;74:2072-5.

26. Kanagaratnam $P$, Kojodjojo $P$ and Peters NS. Electrophysiological abnormalities occur prior to the development of clinical episodes of atrial fibrillation: observations from human epicardial mapping. Pacing Clin Electrophysiol. 2008;31:443-53.

27. Sanders P, Morton JB, Davidson NC, Spence SJ, Vohra JK, Sparks PB and Kalman JM. Electrical remodeling of the atria in congestive heart failure: electrophysiological and electroanatomic mapping in humans. Circulation. 2003;108:1461-8.

28. Maesen B, Nijs J, Maessen J, Allessie M and Schotten U. Post-operative atrial fibrillation: a maze of mechanisms. Europace. 2012;14:159-74.

29. Ishii Y, Schuessler RB, Gaynor SL, Yamada K, Fu AS, Boineau JP and Damiano RJ, Jr. Inflammation of atrium after cardiac surgery is associated with inhomogeneity of atrial conduction and atrial fibrillation. Circulation. 2005;111:2881-8.

30. Page PL, Plumb VJ, Okumura K and Waldo AL. A new animal model of atrial flutter. J Am Coll Cardiol. 1986;8:872-9.

31. Goldstein RN, Ryu K, Khrestian C, van Wagoner DR and Waldo AL. Prednisone prevents inducible atrial flutter in the canine sterile pericarditis model. J Cardiovasc Electrophysiol. 2008;19:74-81.

32. Imazio M, Brucato A, Ferrazzi P, Rovere ME, Gandino A, Cemin R, Ferrua S, Belli R, Maestroni S, Simon C, Zingarelli E, Barosi A, Sansone F, Patrini D, Vitali E, Trinchero R, Spodick DH, Adler $Y$ and Investigators C. Colchicine reduces postoperative atrial fibrillation: results of the Colchicine for the Prevention of the Postpericardiotomy Syndrome (COPPS) atrial fibrillation substudy. Circulation. 2011;124:2290-5.

33. Bruins $P$, te Velthuis $H$, Yazdanbakhsh AP, Jansen PG, van Hardevelt FW, de Beaumont EM, Wildevuur CR, Eijsman L, Trouwborst A and Hack CE. Activation of the complement system during and after cardiopulmonary bypass surgery: postsurgery activation involves C-reactive protein and is associated with postoperative arrhythmia. Circulation. 1997;96:3542-8.

34. Ascione R, Caputo M, Calori G, Lloyd CT, Underwood MJ and Angelini GD. Predictors of atrial fibrillation after conventional and beating heart coronary surgery: A prospective, randomized study. Circulation. 2000;102:1530-5.

35. Ho KM and Tan JA. Benefits and risks of corticosteroid prophylaxis in adult cardiac surgery: a doseresponse meta-analysis. Circulation. 2009;119:1853-66.

36. Tchervenkov Cl, Wynands JE, Symes JF, Malcolm ID, Dobell AR and Morin JE. Persistent atrial activity during cardioplegic arrest: a possible factor in the etiology of postoperative supraventricular tachyarrhythmias. Ann Thorac Surg. 1983;36:437-43. 
37. Cox JL. A perspective of postoperative atrial fibrillation in cardiac operations. Ann Thorac Surg. 1993;56:405-9.

38. Reilly SN, Jayaram R, Nahar K, Antoniades C, Verheule S, Channon KM, Alp NJ, Schotten U and Casadei B. Atrial sources of reactive oxygen species vary with the duration and substrate of atrial fibrillation: implications for the antiarrhythmic effect of statins. Circulation. 2011;124:1107-17.

39. Patti G, Chello M, Candura D, Pasceri V, D'Ambrosio A, Covino E and Di Sciascio G. Randomized trial of atorvastatin for reduction of postoperative atrial fibrillation in patients undergoing cardiac surgery: results of the ARMYDA-3 (Atorvastatin for Reduction of MYocardial Dysrhythmia After cardiac surgery) study. Circulation. 2006;114:1455-61.

40. Carnes CA, Chung MK, Nakayama T, Nakayama H, Baliga RS, Piao S, Kanderian A, Pavia S, Hamlin RL, McCarthy PM, Bauer JA and Van Wagoner DR. Ascorbate attenuates atrial pacing-induced peroxynitrite formation and electrical remodeling and decreases the incidence of postoperative atrial fibrillation. Circ Res. 2001;89:E32-8.

41. Ozaydin M, Peker O, Erdogan D, Kapan S, Turker Y, Varol E, Ozguner F, Dogan A and Ibrisim E. Nacetylcysteine for the prevention of postoperative atrial fibrillation: a prospective, randomized, placebocontrolled pilot study. Eur Heart J. 2008;29:625-31.

42. Ravelli F, Mase M, del Greco M, Marini M and Disertori M. Acute atrial dilatation slows conduction and increases AF vulnerability in the human atrium. J Cardiovasc Electrophysiol. 2011;22:394-401.

43. Allessie M. Stretch and speed: a complicated couple. J Cardiovasc Electrophysiol. 2011;22:402-4.

44. Elvan A, Adiyaman A, Beukema RJ, Sie HT and Allessie MA. Electrophysiological effects of acute atrial stretch on persistent atrial fibrillation in patients undergoing open heart surgery. Heart Rhythm. 2013;10:322-30

45. Frost L, Christiansen EH, Molgaard H, Jacobsen CJ, Allermand $\mathrm{H}$ and Thomsen PE. Premature atrial beat eliciting atrial fibrillation after coronary artery bypass grafting. J Electrocardiol. 1995;28:297-305.

46. Van Wagoner DR, Pond AL, Lamorgese M, Rossie SS, McCarthy PM and Nerbonne JM. Atrial L-type Ca2+ currents and human atrial fibrillation. Circ Res. 1999;85:428-36.

47. Fleming GA, Murray KT, Yu C, Byrne JG, Greelish JP, Petracek MR, Hoff SJ, Ball SK, Brown NJ and Pretorius M. Milrinone use is associated with postoperative atrial fibrillation after cardiac surgery. Circulation. 2008;118:1619-25.

48. Mathew JP, Fontes ML, Tudor IC, Ramsay J, Duke P, Mazer CD, Barash PG, Hsu PH, Mangano DT, Investigators of the Ischemia R, Education F and Multicenter Study of Perioperative Ischemia Research $\mathrm{G}$. A multicenter risk index for atrial fibrillation after cardiac surgery. JAMA. 2004;291:1720-9.

49. Goette A, Juenemann G, Peters B, Klein HU, Roessner A, Huth C and Rocken C. Determinants and consequences of atrial fibrosis in patients undergoing open heart surgery. Cardiovasc Res. 2002;54:390-6.

50. Zaman AG, Archbold RA, Helft G, Paul EA, Curzen NP and Mills PG. Atrial fibrillation after coronary artery bypass surgery: a model for preoperative risk stratification. Circulation. 2000;101:1403-8.

51. Amar D, Shi W, Hogue CW, Jr., Zhang H, Passman RS, Thomas B, Bach PB, Damiano R and Thaler HT. Clinical prediction rule for atrial fibrillation after coronary artery bypass grafting. J Am Coll Cardiol. 2004;44:1248-53.

52. Goette A, Mittag J, Friedl A, Busk H, Jepsen MS, Hartung WM, Huth C and Klein HU. Pacing of Bachmann's bundle after coronary artery bypass grafting. Pacing Clin Electrophysiol. 2002;25:1072-8.

53. Zacharias A, Schwann TA, Riordan CJ, Durham SJ, Shah AS and Habib RH. Obesity and risk of new-onset atrial fibrillation after cardiac surgery. Circulation. 2005;112:3247-55.

54. Fuster V, Ryden LE, Cannom DS, Crijns HJ, Curtis AB, Ellenbogen KA, Halperin JL, Le Heuzey JY, Kay GN, Lowe JE, Olsson SB, Prystowsky EN, Tamargo JL, Wann S, Smith SC, Jr., Jacobs AK, Adams CD, Anderson $J L$, Antman EM, Halperin JL, Hunt SA, Nishimura R, Ornato JP, Page RL, Riegel B, Priori SG, Blanc JJ, Budaj A, Camm AJ, Dean V, Deckers JW, Despres C, Dickstein K, Lekakis J, McGregor K, Metra M, Morais J, Osterspey A, Tamargo JL, Zamorano JL, American College of Cardiology/American Heart Association Task Force on Practice G, European Society of Cardiology Committee for Practice G, European Heart Rhythm A and Heart Rhythm S. ACC/AHA/ESC 2006 Guidelines for the Management of Patients with Atrial Fibrillation: a report of the American College of Cardiology/American Heart Association Task Force on 
Practice Guidelines and the European Society of Cardiology Committee for Practice Guidelines (Writing Committee to Revise the 2001 Guidelines for the Management of Patients With Atrial Fibrillation): developed in collaboration with the European Heart Rhythm Association and the Heart Rhythm Society. Circulation. 2006;114:e257-354.

55. Melduni RM, Suri RM, Seward JB, Bailey KR, Ammash NM, Oh JK, Schaff HV and Gersh BJ. Diastolic dysfunction in patients undergoing cardiac surgery: a pathophysiological mechanism underlying the initiation of new-onset post-operative atrial fibrillation. J Am Coll Cardiol. 2011;58:953-61.

56. Savelieva I and John Camm A. Atrial fibrillation and heart failure: natural history and pharmacological treatment. Europace. 2004;5 Suppl 1:S5-19.

57. Asher CR, Miller DP, Grimm RA, Cosgrove DM, 3rd and Chung MK. Analysis of risk factors for development of atrial fibrillation early after cardiac valvular surgery. Am J Cardiol. 1998;82:892-5.

58. Soylu M, Demir AD, Ozdemir O, Soylu O, Topaloglu S, Kunt A, Sasmaz A, Korkmaz S and Tasdemir O. Increased dispersion of refractoriness in patients with atrial fibrillation in the early postoperative period after coronary artery bypass grafting. J Cardiovasc Electrophysiol. 2003;14:28-31.

59. De Jong AM, Maass AH, Oberdorf-Maass SU, Van Veldhuisen DJ, Van Gilst WH and Van Gelder IC. Mechanisms of atrial structural changes caused by stretch occurring before and during early atrial fibrillation. Cardiovasc Res. 2011;89:754-65.

60. Ad N, Snir E, Vidne BA and Golomb E. Histologic atrial myolysis is associated with atrial fibrillation after cardiac operation. Ann Thorac Surg. 2001;72:688-93.

61. Ak K, Akgun S, Tecimer T, Isbir CS, Civelek A, Tekeli A, Arsan S and Cobanoglu A. Determination of histopathologic risk factors for postoperative atrial fibrillation in cardiac surgery. Ann Thorac Surg. 2005;79:1970-5.

62. Dupont E, Ko Y, Rothery S, Coppen SR, Baghai M, Haw M and Severs NJ. The gap-junctional protein connexin40 is elevated in patients susceptible to postoperative atrial fibrillation. Circulation. 2001;103:842-9.

63. Ryu K, Li L, Khrestian CM, Matsumoto N, Sahadevan J, Ruehr ML, Van Wagoner DR, Efimov IR and Waldo AL. Effects of sterile pericarditis on connexins 40 and 43 in the atria: correlation with abnormal conduction and atrial arrhythmias. Am J Physiol Heart Circ Physiol. 2007;293:H1231-41.

64. Allessie MA, Boyden PA, Camm AJ, Kleber AG, Lab MJ, Legato MJ, Rosen MR, Schwartz PJ, Spooner PM, Van Wagoner DR and Waldo AL. Pathophysiology and prevention of atrial fibrillation. Circulation. 2001;103:769-77.

65. Crystal E, Connolly SJ, Sleik K, Ginger TJ and Yusuf S. Interventions on prevention of postoperative atrial fibrillation in patients undergoing heart surgery: a meta-analysis. Circulation. 2002;106:75-80.

66. Ferguson TB, Jr., Coombs LP, Peterson ED and Society of Thoracic Surgeons National Adult Cardiac Surgery D. Preoperative beta-blocker use and mortality and morbidity following CABG surgery in North America. JAMA. 2002;287:2221-7.

67. Omorphos S, Hanif $\mathrm{M}$ and Dunning J. Are prophylactic beta-blockers of benefit in reducing the incidence of AF following coronary bypass surgery? Interact Cardiovasc Thorac Surg. 2004;3:641-6.

68. Dunning J, Treasure T, Versteegh M, Nashef SA, Audit E and Guidelines C. Guidelines on the prevention and management of de novo atrial fibrillation after cardiac and thoracic surgery. Eur J Cardiothorac Surg. 2006;30:852-72.

69. Wann LS, Curtis AB, Ellenbogen KA, Estes NA, 3rd, Ezekowitz MD, Jackman WM, January CT, Lowe JE, Page RL, Slotwiner DJ, Stevenson WG and Tracy CM. 2011 ACCF/AHA/HRS focused update on the management of patients with atrial fibrillation (update on dabigatran): a report of the American College of Cardiology Foundation/American Heart Association Task Force on practice guidelines. J Am Coll Cardiol. 2011;57:1330-7.

70. Mitchell LB and Committee CCSAFG. Canadian Cardiovascular Society atrial fibrillation guidelines 2010: prevention and treatment of atrial fibrillation following cardiac surgery. Can J Cardiol. 2011;27:91-7.

71. Giri S, White CM, Dunn AB, Felton K, Freeman-Bosco L, Reddy P, Tsikouris JP, Wilcox HA and Kluger J. Oral amiodarone for prevention of atrial fibrillation after open heart surgery, the Atrial Fibrillation Suppression Trial (AFIST): a randomised placebo-controlled trial. Lancet. 2001;357:830-6. 
72. Bagshaw SM, Galbraith PD, Mitchell LB, Sauve R, Exner DV and Ghali WA. Prophylactic amiodarone for prevention of atrial fibrillation after cardiac surgery: a meta-analysis. Ann Thorac Surg. 2006;82:1927-37.

73. Burgess DC, Kilborn MJ and Keech AC. Interventions for prevention of post-operative atrial fibrillation and its complications after cardiac surgery: a meta-analysis. Eur Heart J. 2006;27:2846-57.

74. Patel AA, White CM, Gillespie EL, Kluger J and Coleman Cl. Safety of amiodarone in the prevention of postoperative atrial fibrillation: a meta-analysis. Am J Health Syst Pharm. 2006;63:829-37.

75. Butler J, Harriss DR, Sinclair M and Westaby S. Amiodarone prophylaxis for tachycardias after coronary artery surgery: a randomised, double blind, placebo controlled trial. Br Heart J. 1993;70:56-60.

76. Hohnloser SH, Meinertz T, Dammbacher T, Steiert K, Jahnchen E, Zehender M, Fraedrich G and Just $H$. Electrocardiographic and antiarrhythmic effects of intravenous amiodarone: results of a prospective, placebo-controlled study. Am Heart J. 1991;121:89-95.

77. Kurz DJ, Naegeli B, Kunz M, Genoni M, Niederhauser U and Bertel O. Epicardial, biatrial synchronous pacing for prevention of atrial fibrillation after cardiac surgery. Pacing Clin Electrophysiol. 1999;22:721-6.

78. Gerstenfeld EP, Hill MR, French SN, Mehra R, Rofino K, Vander Salm TJ and Mittleman RS. Evaluation of right atrial and biatrial temporary pacing for the prevention of atrial fibrillation after coronary artery bypass surgery. J Am Coll Cardiol. 1999;33:1981-8.

79. Chung MK, Augostini RS, Asher CR, Pool DP, Grady TA, Zikri M, Buehner SM, Weinstock M and McCarthy PM. Ineffectiveness and potential proarrhythmia of atrial pacing for atrial fibrillation prevention after coronary artery bypass grafting. Ann Thorac Surg. 2000;69:1057-63.

80. Gerstenfeld EP, Khoo M, Martin RC, Cook JR, Lancey R, Rofino K, Vander Salm TJ and Mittleman RS. Effectiveness of bi-atrial pacing for reducing atrial fibrillation after coronary artery bypass graft surgery. $J$ Interv Card Electrophysiol. 2001;5:275-83.

81. Levy T, Fotopoulos G, Walker S, Rex S, Octave M, Paul V and Amrani M. Randomized controlled study investigating the effect of biatrial pacing in prevention of atrial fibrillation after coronary artery bypass grafting. Circulation. 2000;102:1382-7.

82. Daoud EG, Dabir R, Archambeau M, Morady F and Strickberger SA. Randomized, double-blind trial of simultaneous right and left atrial epicardial pacing for prevention of post-open heart surgery atrial fibrillation. Circulation. 2000;102:761-5.

83. Blommaert D, Gonzalez M, Mucumbitsi J, Gurne O, Evrard P, Buche M, Louagie Y, Eucher P, Jamart J, Installe $E$ and De Roy L. Effective prevention of atrial fibrillation by continuous atrial overdrive pacing after coronary artery bypass surgery. J Am Coll Cardiol. 2000;35:1411-5.

84. Neto VA, Costa R, Da Silva KR, Martins AL, Escobar LF, Moreira LF, Costa RV, Santos LB and Melo RF. Temporary atrial pacing in the prevention of postoperative atrial fibrillation. Pacing Clin Electrophysiol. 2007;30 Suppl 1:S79-83.

85. Fan K, Lee KL, Chiu CS, Lee JW, He GW, Cheung D, Sun MP and Lau CP. Effects of biatrial pacing in prevention of postoperative atrial fibrillation after coronary artery bypass surgery. Circulation. 2000;102:755-60.

86. Vanagt WY, Cornelussen RN, Baynham TC, Van Hunnik A, Poulina QP, Babiker F, Spinelli J, Delhaas T and Prinzen FW. Pacing-induced dyssynchrony during early reperfusion reduces infarct size. J Am Coll Cardiol. 2007;49:1813-9.

87. Mayson SE, Greenspon AJ, Adams S, Decaro MV, Sheth M, Weitz HH and Whellan DJ. The changing face of postoperative atrial fibrillation prevention: a review of current medical therapy. Cardiol Rev. 2007;15:231-41.

88. Ozaydin M, Dede O, Varol E, Kapan S, Turker Y, Peker O, Duver H and Ibrisim E. Effect of reninangiotensin aldosteron system blockers on postoperative atrial fibrillation. Int J Cardiol. 2008;127:362-7.

89. Miceli A, Capoun R, Fino C, Narayan P, Bryan AJ, Angelini GD and Caputo M. Effects of angiotensinconverting enzyme inhibitor therapy on clinical outcome in patients undergoing coronary artery bypass grafting. J Am Coll Cardiol. 2009;54:1778-84.

90. Rouleau JL, Warnica WJ, Baillot R, Block PJ, Chocron S, Johnstone D, Myers MG, Calciu CD, Dalle-Ave S, Martineau P, Mormont C, van Gilst WH and Investigators I. Effects of angiotensin-converting enzyme inhibition in low-risk patients early after coronary artery bypass surgery. Circulation. 2008;117:24-31. 
91. Rader F, Van Wagoner DR, Gillinov AM and Blackstone EH. Preoperative angiotensin-blocking drug therapy is not associated with atrial fibrillation after cardiac surgery. Am Heart J. 2010;160:329-336 e1.

92. Eslami M, Badkoubeh RS, Mousavi M, Radmehr H, Salehi M, Tavakoli N and Avadi MR. Oral ascorbic acid in combination with beta-blockers is more effective than beta-blockers alone in the prevention of atrial fibrillation after coronary artery bypass grafting. Tex Heart Inst J. 2007;34:268-74.

93. Liakopoulos OJ, Choi YH, Kuhn EW, Wittwer T, Borys M, Madershahian N, Wassmer G and Wahlers T. Statins for prevention of atrial fibrillation after cardiac surgery: a systematic literature review. J Thorac Cardiovasc Surg. 2009;138:678-686 e1.

94. Dunning J, Khasati N and Prendergast B. What is the optimal medical treatment for stable cardiac surgical patients who go into atrial fibrillation after their operation? Interact Cardiovasc Thorac Surg. 2004;3:46-51.

95. Fernando HC, Jaklitsch MT, Walsh GL, Tisdale JE, Bridges CD, Mitchell JD and Shrager JB. The Society of Thoracic Surgeons practice guideline on the prophylaxis and management of atrial fibrillation associated with general thoracic surgery: executive summary. Ann Thorac Surg. 2011;92:1144-52.

96. Daoud EG. Management of atrial fibrillation in the post-cardiac surgery setting. Cardiol Clin. 2004;22:159-66.

97. Epstein AE, Alexander JC, Gutterman DD, Maisel W, Wharton JM and American College of Chest P. Anticoagulation: American College of Chest Physicians guidelines for the prevention and management of postoperative atrial fibrillation after cardiac surgery. Chest. 2005;128:24S-27S.

98. Filardo G, Hamilton C, Hamman B, Hebeler RF, Jr., Adams J and Grayburn P. New-onset postoperative atrial fibrillation and long-term survival after aortic valve replacement surgery. Ann Thorac Surg. 2010;90:474-9.

99. Bramer S, van Straten AH, Soliman Hamad MA, Berreklouw E, Martens EJ and Maessen JG. The impact of preoperative atrial fibrillation on early and late mortality after coronary artery bypass grafting. Eur $J$ Cardiothorac Surg. 2010;38:373-9. 
Postoperative Atrial Fibrillation - Pathophysiology, Treatment and Prevention 
Chapter 2 
A prospective randomized controlled trial on the incidence and predictors of late phase postoperative atrial fibrillation up to 30 days and the preventive value of bi-atrial pacing 


\section{Abstract}

Background Postoperative atrial fibrillation (POAF) is considered to be a transient arrhythmia in the first week after surgery.

Objectives The aim of this study was to determine the 30-day incidence and predictors of POAF and the value of postoperative overdrive biatrial pacing in prevention of POAF.

Methods Patients ( $n=148$ ) without a history of AF undergoing aortic valve replacement (AVR) or coronary artery bypass graft (CABG) were randomized into a pacing group $(n=75)$ and a control group. Patients were treated with standardized Sotalol postoperatively. Rhythm was continuously monitored for 30 days by a trans-telephonic event recorder.

Results POAF occurred in 73 patients (49.3\%) of whom 60 patients (40.5\%) showed POAF during postoperative days (POD) $0-5$ and 37 patients (25\%) during POD 6-30. Prolonged aortic cross clamp time (ACCT) was an important univariate predictor of 30day and of late POAF (POD 6-30) ( $p=0.017, p=0.03$ respectively). Best-fit model analysis using 15 predetermined risk factors for POAF showed different positive interactive effects for early POAF (i.e. baseline C-reactive protein (CRP) levels with a history of myocardial infarction or low body mass index (BMI)) and late POAF (i.e. high BMI, diabetes mellitus, baseline CRP, early POAF, creatinine levels, type of operation, smoking and male gender). Biatrial pacing reduced the late POAF incidence in patients with ACCT > 50 minutes $(p=0.006)$.

Conclusion POAF is not limited to the first week after cardiac surgery but also occurs frequently in the postoperative month. It is desirable to regularly follow POAF patients for AF recurrences after discharge. 


\section{Introduction}

Historically, postoperative atrial fibrillation (POAF) has been defined as a transient arrhythmia in the first week after cardiac surgery, with a peak incidence between the second and third postoperative days. A growing body of evidence has identified POAF as an important risk factor for increased late mortality. ${ }^{1,2}$ Data on the incidence of POAF after discontinuation of in-hospital continuous telemetric monitoring are rare but increasingly important because POAF may show later occurrences. ${ }^{3}$

In addition, despite the several treatment and preventive strategies, the reported incidence of POAF remains high. ${ }^{4,5}$ Overdrive atrial pacing has shown conflicting results in previous studies when tested for POAF prevention. ${ }^{6-9}$ To our knowledge, long-term effects of strategies to prevent POAF have not yet been studied. We hypothesize that episodes of $A F$ frequently recur after the first postoperative week and aimed to determine the preventive value of synchronized biatrial overdrive pacing on the 30-day POAF incidence.

\section{Methods}

\section{Population}

Between October 2009 and July 2011, patients undergoing elective coronary artery bypass graft (CABG) or aortic valve replacement (AVR), without a known history of AF or any treatment for that purpose were enrolled in the study. Exclusion criteria were a history of AF, sick sinus syndrome or AV-block. The local medical ethical committee approved this trial.

\section{Study protocol}

All patients underwent elective CABG or AVR using cardiopulmonary bypass, through a median sternotomy, with the use of cold crystalloid antegrade cardioplegic support. Perioperatively two pairs of unipolar temporary atrial pacemaker wires (Flexon ${ }^{\mathrm{TM}}$ ) were placed on the epicardium of the right atrial wall and on the Bachmann bundle in all patients (figure 1). Patients were randomized into a pacing and non-pacing group and all were treated with Sotalol during the first postoperative week, unless contraindicated (dosage and discontinuation left to the discretion of the attending resident and the cardiologist).

The rhythm of patients was monitored by daily review of the continuous telemetric monitoring (POD 0-3). Twelve lead ECGs were obtained on the first, second and fourth postoperative days. In addition, from the moment of cessation of in-hospital telemetric monitoring, continuous trans-telephonic monitoring was started for a total of 4 weeks. For this purpose an external one-lead trans-telephonic loop recorder (Vitaphone 3100 $B T^{~}{ }^{M}$ ) with an autotrigger for $A F$, was used. It detects conversion of sinus rhythm (SR) 
into AF and AF into SR. Clinical and rhythm-monitoring data were collected and analysed by blinded investigators.

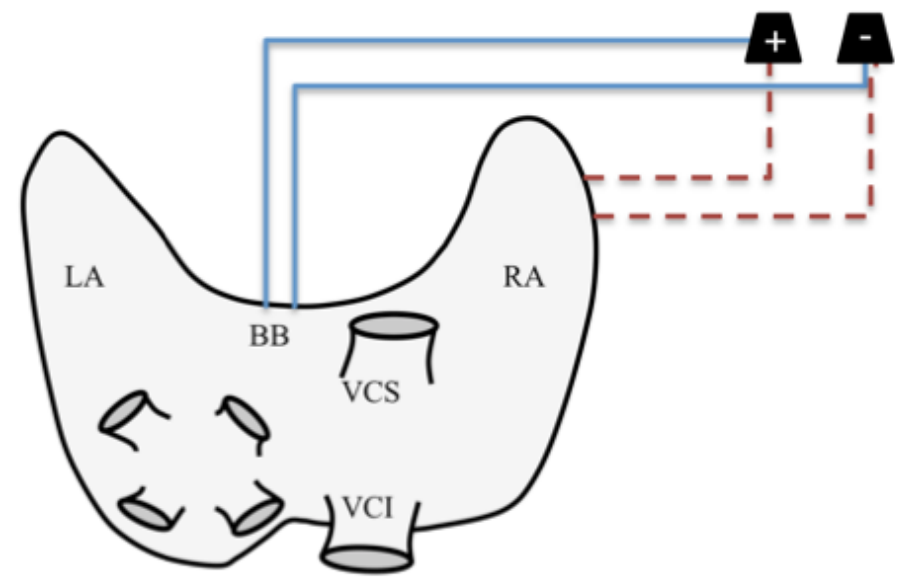

Figure 1. Schematic representation of the electrode placement. The right atrial (red line) and the Bachmann bundle (blue line) wire placement. BB= Bachmann's bundle; $R A=$ right atrium; $L A=$ left atrium; VCS= superior caval vein; $\mathrm{VCl}=$ inferior caval vein

\section{Pacing protocol}

After arrival at the cardiovascular intensive care unit, pacing wires in the pacing group were connected to the output of an external pacemaker and pacing protocol was initiated. The sensing and stimulus threshold of all wires were tested prior to chest closure and on a daily basis after surgery. The output was set at 2 times greater than the stimulation threshold of the pacing site with the highest threshold (i.e. Bachmann's bundle or right atrium). The sensitivity was set at half of the sensing threshold of the location with the lowest threshold. Pacing was maintained for 72 hours in AAl mode, 10 beats per minute (bpm) above the intrinsic heart rate (minimum of 80 and maximum of 120 bpm). Pacing was stopped during AF or sinus tachycardia $>110 \mathrm{bpm}$, and resumed after conversion to normal sinus rhythm (SR) to complete the 72-hour protocol. Uni-atrial right atrial pacing in the non-pacing group ( $P O D$ ) in response to bradycardia was not considered a protocol violation $(n=7)$. In case of loss of capture and/or failure of sensing, the anode and cathode connections to the pacemaker were exchanged. The same was done when phrenic nerve pacing occurred. All pacemaker wires were removed after 72 hours.

\section{Outcomes}

Atrial fibrillation was defined as an irregular RR interval during at least 10 seconds, without a detectable $\mathrm{p}$-wave. ${ }^{10,11}$ The event rate and duration of POAF was compared between study groups for early POAF (POD 0-5), late POAF (POD 6-30) and total POAF 
(POD 0-30). Secondly, we aimed to determine demographic and clinical risk factors confounding the net effect of pacing on all outcome measures.

\section{Statistical analysis}

Metric variables are characterized by means and standard deviations, if they are normally distributed as tested by the Shapiro-Wilk test. Baseline patient characteristics between both randomized groups were tested by the Student t-test (if normally distributed), the Mann-Whitney test (if not) or the log-likelihood chi-square test (for categorical data).

Univariate analysis to examine the relationship of risk factors or variables with early POAF, late POAF and overall 30 day POAF are provided by means of absolutes and percentages, log-likelihood chi-square $\left(\chi_{L}^{2}\right)$, p-values of $\chi_{L}^{2}$, odds ratios $(O R)$ and $95 \%$ Confidence Intervals (C.I.) of the OR. Multivariate analysis on the three POAF incidence measures (early, late and total POAF) was performed by Cox regression analysis. At first, a univariate Cox regression analysis was performed using the experimental groups factor (non-pacing vs. pacing), in addition to a per protocol analysis for three groups (nonpaced vs. sufficiently paced vs. insufficiently paced). Next, a direct-effects Cox regression model with only statistically significant effects on each of the three outcome measures was searched for by means of the backward elimination log-likelihood chisquare technique using a predetermined list of 15 risk factors for POAF in addition to the experimental factor. All first-order interactive effects of these risk factors between themselves and that of each risk factor with the experimental groups factor (nonpacing vs pacing) were group-wise and hierarchically tested by backward elimination loglikelihood chi-square. Finally, for each of the three measures separately a final Cox regression model was searched for containing only statistically significant effects. A pvalue of less than 0.05 was considered to be statistically significant. All types of analysis were performed using SPSS-pc version 20.0.

\section{Results}

\section{Patient characteristics}

Of 163 patients who had given informed consent to participate, 15 patients (9.2\%) were excluded due to surgical complications or difficulty of placement of the Bachmann bundle wires. Patients $(n=148)$ were followed for an average of $22.26( \pm 9.98)$ days (range 4 - 42). Protocol violations occurred in the pacing group (i.e. pacing stopped before the end of the 72 hour protocol left to the discretion of the attending physician: 48 hours pacing $n=6 ; 24$ hour pacing $n=8$ and no pacing at all $n=6$ ). Due to its potential proarrhythmic effects Sotalol was discontinued during the early postoperative phase in 55 patients $(37.0 \%)$ by the attending cardiologist. Two patients required amiodarone for 
persistence of AF and no patients underwent electrical cardioversion. None of the patients died during the follow-up. Baseline characteristics in both groups were comparable except for COPD and DM. (Table 1)

Table 1. Patient characteristics

\begin{tabular}{llll}
\hline & Pacing $(\mathrm{n}=75)$ & Non-Pacing $(\mathrm{n}=73)$ & $\mathrm{P}$ \\
\hline Age & $66.5 \mathrm{y}(9.8144-87)$ & $68.3 \mathrm{y}(9.1444-82)$ & $\mathrm{P}=0.198^{\mathrm{b}}$ \\
Male & $61(81.3)$ & $59(80.8)$ & $\mathrm{P}=0.937^{\mathrm{a}}$ \\
BMI & $26.6(3.82)$ & $27.8(3.57)$ & $\mathrm{P}=0.050^{\mathrm{c}}$ \\
LVEF $<50 \%$ & $18(24.0)$ & $15(20.5)$ & $\mathrm{P}=0.614^{\mathrm{a}}$ \\
Hypertension & $70(93.3)$ & $67(91.8)$ & $\mathrm{P}=0.719^{\mathrm{a}}$ \\
COPD & $2(2.7)$ & $8(11.0)$ & $\mathrm{P}=0.038^{\mathrm{a}}$ \\
Preop $\beta$-blocker use & $57(76.0)$ & $54(74.0)$ & $\mathrm{P}=0.776^{\mathrm{a}}$ \\
Diabetes Mellitus & $14(18.7)$ & $24(32.9)$ & $\mathrm{P}=0.047^{\mathrm{a}}$ \\
History of smoking & $23(30.7)$ & $20(27.4)$ & $\mathrm{P}=0.661^{\mathrm{a}}$ \\
Hypercholesterolemia & $70(93.3)$ & $68(93.2)$ & $\mathrm{P}=0.965^{\mathrm{a}}$ \\
Myocardial infarction & $13(17.3)$ & $14(19.2)$ & $\mathrm{P}=0.771^{\mathrm{a}}$ \\
Creatinine & $92.3(27.4450-243)$ & $94.1(24.5256-194)$ & $\mathrm{P}=0.525^{\mathrm{b}}$ \\
ACCT & $49.1(15.5225-95)$ & $49.9(17.5219-115)$ & $\mathrm{P}=0.808^{\mathrm{b}}$ \\
CABG & $66(88.0)$ & $61(83.6)$ & $\mathrm{P}=0.439^{\mathrm{a}}$ \\
Number of anastomoses & $3.1(0-6)$ & $2.8(0-5)$ & $\mathrm{P}=0.141^{\mathrm{b}} 9$ \\
\hline
\end{tabular}

BMI: body mass index; ACCT: aortic cross clamp time; CABG: coronary artery bypass graft; COPD: chronic obstructive pulmonary disease; LVEF: left ventricular ejection fraction. $a=$ Log-likelihood chi-square test, $b=$ Mann-Whitney test, $c=$ Student t-test; Means with standard deviations and minima-maxima in brackets or numbers with percentages for both randomized groups.

\section{POAF incidence}

POAF occurred in 73 patients (49.3\%) within the total 30-day follow-up period. The dayto-day prevalence of $\mathrm{AF}$ is shown in figure $2 \mathrm{a}$ and stratified by pacing and control group in figure $2 \mathrm{~b}$. In the early postoperative period (POD $0-5), 40.5 \%$ of the patients $(n=60)$ developed POAF, while the prevalence was $25.0 \%(n=37)$ in the POD 6- 30. The durations of AF episodes during each day were added together and the total time in AF per day (AF burden) was calculated. Early POAF caused a larger AF burden (average $32.51 \mathrm{~min}$, 0- 451 min) compared to late POAF (average $10.6 \mathrm{~min}, 0-450 \mathrm{~min}, \mathrm{p}<0.001$ ). Notably, AF burden of early POAF in patients $(n=24)$ developing additional late POAF was significantly larger (63.34 min in early POAF) compared to the AF burden in patients $(n=36)$ who only had early POAF (35.06 min in early POAF, $p=0.013)$. In thirteen patients $(8.8 \%)$ the first episode of AF was detected during POD 6-30 (average duration $13.09 \mathrm{~min}$ ). 


\section{Univariate analysis}

In the univariate analysis only aortic cross clamp time (ACCT) was a statistically significant predictor of overall POAF (POD 0-30) $(p=0.01)$. We found no significant predictors of early POAF. On the other hand, early POAF itself was a strong predictor of late POAF $(p<0.001)$. Also, patients with ACCT> 50min and patients who underwent AVR showed significantly higher incidence of late POAF.

\section{Multivariate analysis}

A high level of baseline CRP combined with a history of myocardial infarction or with low $\mathrm{BMI}$ was associated with higher chances of getting early POAF $(p=0.030$ and $p=0.022$ respectively) (Table 2 ). Seven interactive effects and one direct effect were found for the prediction of late POAF. In patients with ACCT> 50min, pacing reduced late POAF ( $p=$ 0.006 ) while it did not in the overall patient population. Pacing in patients with high preoperative levels of creatinine ( $>129 \mathrm{umol} / \mathrm{L})$ increased the risk of late POAF $(p=0.041)$. These results have been corrected for the remaining 5 interactive effects (Table 3 ).

The highest significant interactive effect for prediction of total 30-day POAF was the combination of high (> $1.0 \mathrm{mg} / \mathrm{L})$ level of baseline CRP and a history of $\mathrm{MI}(\mathrm{p}=0.008)$. In addition, a high ( $>60 \mathrm{~min})$ ACCT $(p=0.017)$ and smoking tended to be associated with overall POAF ( $p=0.051)$ (Table 4$)$. No effects of Sotalol in the prevention of POAF were seen in the final models.

\section{Per protocol analysis}

To determine the true effect of 72 hour pacing on POAF, a per-protocol analysis was performed. For this purpose we compared patients who were biatrially paced for a total of 72 hours post surgery $(n=52)$, with the non-pacing group $(n=73)$. In this approach the patients who were insufficiently paced were excluded $(n=23,15.5 \%)$. No significant effect of pacing on POAF was seen in this analysis.

Table 2: Multivariate analysis for early POAF

\begin{tabular}{lllllll}
\hline Predictors & Ln. Regression & S.E. & Loss in $\chi_{L}^{2}$ & $p$ & Cox reg & $95 \%$ C.I. \\
\hline BMI & 0.086 & 0.057 & & & 1.090 & $0.974-1.220$ \\
CRP & 0.830 & 0.419 & & & 2.293 & $1.009-5.213$ \\
MI & -0.367 & 0.493 & & 0.693 & $0.264-1.820$ \\
Pacing & 0.013 & 0.266 & 0.002 & 0.961 & 1.013 & $0.602-1.706$ \\
BMI*CRP & -0.034 & 0.016 & 5.217 & 0.022 & 0.967 & $0.937-0.998$ \\
MI*CRP $^{*}$ & 0.248 & 0.110 & 4.708 & 0.030 & 1.281 & $1.033-1.589$ \\
\hline
\end{tabular}

Results of the final, best-fitting Cox-regression model for early POAF (POD 0-5): The model comprises one (non-significant) direct effect for Pacing and two interactive effects. $n=148$. BMI: body mass index; CRP: Creactive protein; $\mathrm{Ml}$; myocardial infarction; 

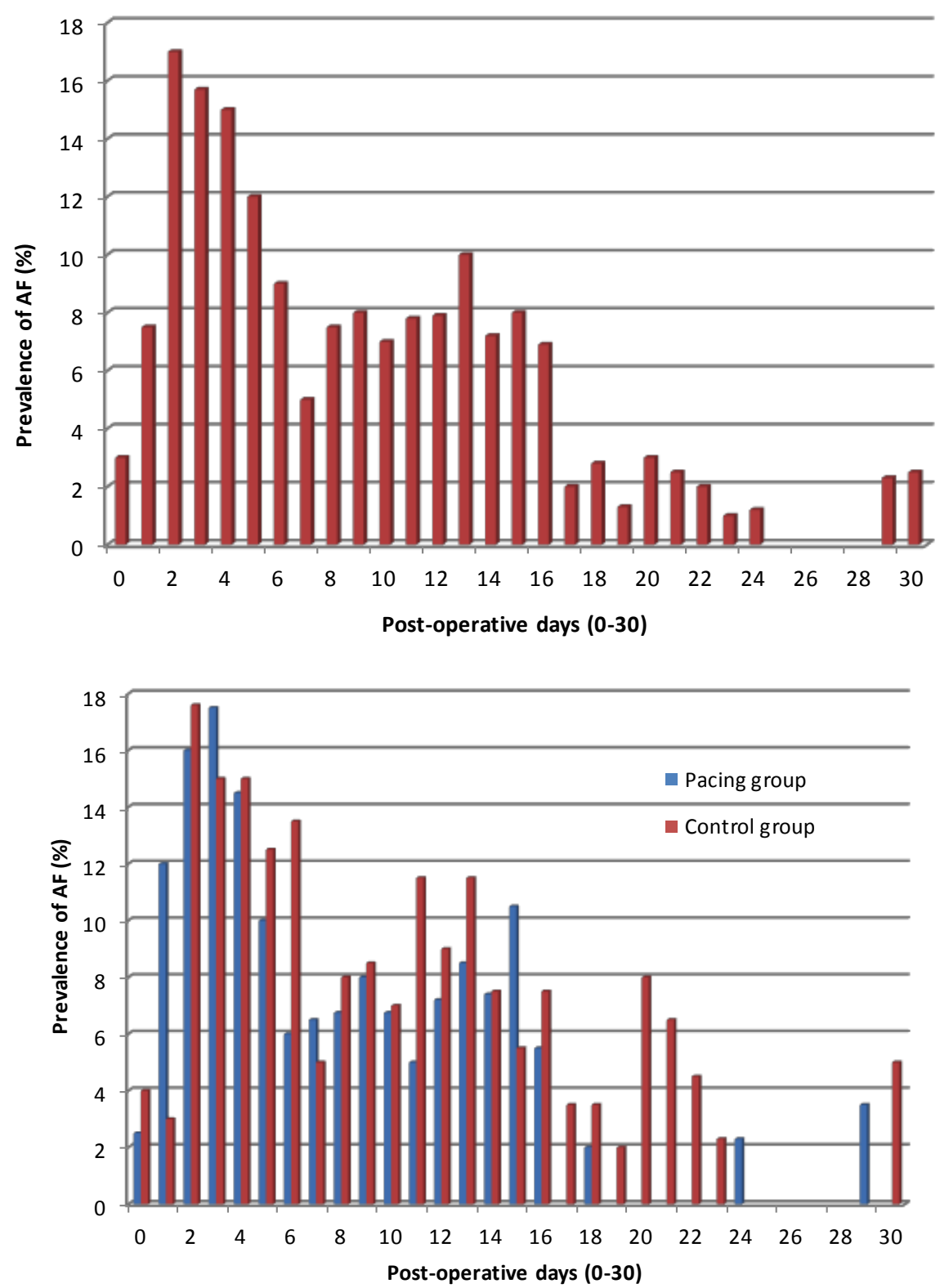

Figure $2 \mathrm{a}$ (top). Daily prevalence of POAF and Figure $2 \mathrm{~b}$ (bottom) Incidence of POAF as stratified by pacing and control group. 
Table 3. Multivariate analysis for late POAF

\begin{tabular}{|c|c|c|c|c|c|c|}
\hline Predictors & Ln. Regression & S.E. & Loss in $\chi^{2}$ & $p$ & Cox reg & 95\%C.I. \\
\hline BMI & 0.048 & 0.060 & & & 1.050 & $0.934-1.180$ \\
\hline АCCT & 0.038 & 0.014 & & & 1.039 & $1.010-1.068$ \\
\hline Baseline Creatinine & -0.054 & 0.020 & & & 0.947 & $0.912-0.984$ \\
\hline $\operatorname{CABG}(0) \rightarrow \operatorname{AVR}(1)$ & 3.736 & 2.282 & & & 0.024 & $0.000-2.089$ \\
\hline Diabetes Mellitus & -18.859 & 5.060 & & & 0.000 & $0.000-0.000$ \\
\hline Smoking & -2.881 & 2.039 & & & 0.056 & $0.001-3.049$ \\
\hline Baseline CRP & -0.382 & 0.148 & & & 0.682 & $0.510-0.912$ \\
\hline Early POAF & 0.441 & 0.214 & & & 1.555 & $1.022-2.366$ \\
\hline Pacing $(0 \rightarrow 1)$ & -1.339 & 1.946 & & & 0.262 & $0.006-1.882$ \\
\hline Gender & 2.088 & 0.760 & 11.352 & 0.001 & 8.068 & $1.818-5.805$ \\
\hline $\mathrm{BMI} * \mathrm{DM}$ & 0.605 & 0.159 & 14.372 & $<0.001$ & 1.830 & $1.341-2.498$ \\
\hline ACCT * Pacing & -0.061 & 0.023 & 7.453 & 0.006 & 0.941 & $0.899-0.984$ \\
\hline Creat* Operation & 0.061 & 0.026 & 6.083 & 0.014 & 1.063 & $1.011-1.118$ \\
\hline Creat * Smoking & 0.040 & 0.022 & 3.826 & 0.050 & 1.041 & $0.997-1.087$ \\
\hline DM * early POAF & 1.011 & 0.503 & 4.210 & 0.040 & 2.747 & $1.025-7.361$ \\
\hline Creat * Pacing & 0.035 & 0.018 & 4.178 & 0.041 & 1.035 & $1.000-1.072$ \\
\hline CRP * Early POAF & 0.132 & 0.049 & 6.486 & 0.011 & 1.141 & $1.036-1.256$ \\
\hline
\end{tabular}

Results of the final, best-fitting Cox-regression model for late (6-30 days follow-up) post- operative AF. The model comprises one direct effect for Gender and six interactive effects including one involving a specification for Pacing. $\mathrm{N}=148$. (Abbreviations as in Tables 1 and 2)

Table 4. Multivariate analysis for total 30-day POAF

\begin{tabular}{lllllll}
\hline Predictors & Ln. Reg & S.E. & Loss in $\chi_{L}^{2}$ & $p$ & Cox reg & 95\% C.I. \\
\hline History of MI & -0.891 & 0.512 & & & 0.410 & $0.150-1.120$ \\
Baseline CRP & -0.087 & 0.042 & & & 0.917 & $0.844-0.995$ \\
Pacing (0-1) & -0.052 & 0.242 & 0.046 & 0.829 & 0.949 & $0.591-1.524$ \\
ACCT & 0.017 & 0.007 & 5.658 & 0.017 & 1.017 & $1.003-1.031$ \\
(Ex)smoker (0-1) & 0.527 & 0.264 & 3.818 & 0.051 & 1.694 & $1.011-2.841$ \\
MI*Baseline CRP & 0.325 & 0.118 & 7.089 & 0.007 & 1.384 & $1.098-1.744$ \\
\hline
\end{tabular}

Results of the final, best-fitting Cox-regression model for total (0-30 days) follow-up postoperative AF. The model comprises one (non-significant) direct effect for Pacing and two interactive effects. $\mathrm{N}=148$. (Abbreviations as in Tables 1 and 2)

\section{Discussion}

Previous studies have demonstrated that POAF is associated with an increase in longterm mortality. ${ }^{1,2,12,13}$ This observation suggests that POAF does not only occur during the first postoperative days but also in the weeks and months thereafter. If this is the case, early discontinuation of oral anticoagulation may have adverse effects. Notably, 
continuation of warfarin after discharge showed protective effects against long-term mortality in one report. ${ }^{1}$

However, information on incidence and prevalence of 'late' POAF is very limited. To our knowledge, this is the first trial using continuous monitoring to detect late episodes of POAF after discharge. We demonstrate that POAF is not transient in the first week, but has $25 \%$ prevalence between day 6 and day 30 after the operation.

\section{Early POAF}

We demonstrate an important predictive effect of baseline CRP levels in patients with a previous $\mathrm{MI}$ and in low BMI patients for early POAF incidence. This is in line with the established role of systemic and local inflammation in early POAF. Higher baseline CRP levels before cardiac surgery have been hypothesized to start early complement activation during cardiopulmonary bypass, aggravating the acute postoperative systemic inflammation, which may lead to POAF. ${ }^{14}$ Local inflammation has shown pro-arrhythmic effects in the sterile pericarditis model in dogs, in which sustained atrial flutter was inducible. ${ }^{15}$ Also in a canine model of direct atrial trauma, activation maps revealed inhomogeneous conduction, which was diminished by treatment with methylprednisolone. $^{16}$

Our results are in line with previous findings suggesting a postoperative transient pro-arrhythmic environment e.g. due to inflammation, oxidative stress, ${ }^{17}$ acute atrial stretch due to hemodynamic changes, ${ }^{18}$ and high sympathetic activity ${ }^{19}$ consequently elicits AF in a fairly large population with limited structural heart disease. ${ }^{10}$

Furthermore, we demonstrate that the combination of low BMI with higher baseline CRP levels predicts early POAF, while high BMI levels predict late POAF. The vulnerability of low BMI patients has been demonstrated by increased short and long term mortality in patients undergoing CABG. ${ }^{20}$ On the other hand, several pro-arrhythmic electrophysiological and mechanical changes in obese patients may contribute to a pro-arrhythmic substrate for $\mathrm{AF}^{21}$ and high $\mathrm{BMI}$ has been shown to predict POAF. ${ }^{22}$

\section{Late POAF}

Early POAF consisted of longer episodes in patients who later on had additional late POAF, compared to patients who developed early POAF only. Also predictors for late POAF differed from factors predicting early POAF. Late POAF predictors include renal dysfunction (measured by creatinine levels) in smokers or in patients undergoing AVR, obesity and DM, early POAF both in combination with DM and high baseline CRP levels $(>3 \mathrm{mg} / \mathrm{L})$ and finally male gender. Although some of the interactions may not have a causal effect in the postoperative setting, these morbidities have been identified as risk factors for AF in general. ${ }^{23-26}$

Despite the fact that the substrate for POAF is partly caused by the surgery itself, ${ }^{27}$ the similarity in risk factors of late POAF and AF in general suggest common mecha- 
nisms enhancing AF susceptibility in this group of patients. ${ }^{28}$ Furthermore several structural abnormalities which potentially contribute to AF in general, have also been demonstrated in POAF patients, e.g. atrial enlargement, ${ }^{29}$ fibrosis, ${ }^{30}$ heterogeneous connexin distribution ${ }^{31}$ and myolysis. ${ }^{32}$

\section{Pacing in POAF}

Overdrive pacing has been successfully used to treat sick sinus syndrome ${ }^{33}$ and paroxysmal AF. ${ }^{34}$ Biatrial pacing (i.e., $80-100$ bpm, during 5 minutes) also produces favorable hemodynamic changes and shortens the P-wave duration. ${ }^{35,}{ }^{36}$ In the postoperative setting, biatrial overdrive pacing has been hypothesized to reduce dispersion of refractoriness and prevent ectopic activity. ${ }^{9,35,37}$ Although previous studies showed promising effects of this strategy in early POAF, ${ }^{4}$ their results have not been fully comparable, because of differences in pacing protocol and definitions of AF varying between minutes ${ }^{35}$ to hours of AF. ${ }^{38}$ Also the pacing sites have not been consistent. In our study, the pacing wires were placed on the right atrial free wall and on the Bachmann bundle. Some studies used posterior left atrial wall instead of the Bachmann bundle, ${ }^{9}$ and the right atrial free wall is used in most reports. ${ }^{39}$ However, the Bachmann bundle is not only easily accessible by the surgeon, but also seems to be the preferred site for pacing in atrial fibrillation. ${ }^{40,41}$ This is partly explained by the anatomical position of the bundle as a major pathway between right and left atrium. ${ }^{42}$ In addition, biatrial pacing in POAF has shown superior results when compared to other pacing modalities (eg. right or left atrial pacing alone). ${ }^{39}$

In this study, biatrial pacing reduced the risk of late POAF incidence in patients with ACCT > 50 minutes, but did not affect early POAF. This effect may be explained by prevention of higher levels of oxidative stress which occur due to atrial ischemia in prolonged ACCT. ${ }^{43}$ The effects of reperfusion injury are carried out beyond the first week and may affect late POAF more significantly. However, more research is required to address this question.

\section{Study Limitations}

The incidence of late POAF may be underestimated due to the required patient compliance in Vitaphone $3100{ }^{\mathrm{TM}}$ device handling. Despite this limitation, we detected a high incidence of POAF after discharge. Known AF predictors such as hypertension, heart failure and age had no predictive value in this relatively small study. This is due to a high prevalence of hypertension and low prevalence of heart failure in this population (i.e. more than $90 \%$ of our population had hypertension and less than $4 \%$ had an LVEF $<35 \%$ ) and low variation in age amongst participants. 


\section{Conclusions and clinical implications}

POAF is not limited to the early postoperative phase, but recurs in some patients at least in the first postoperative month. In current clinical practice oral anticoagulation (OAC) is often discontinued after conversion of POAF to SR. ${ }^{24,44,45}$ According to our results and previous studies, it is desirable to regularly follow POAF patients for AF recurrence and treat the high-risk patients accordingly. 


\section{References}

1. El-Chami MF, Kilgo P, Thourani V, Lattouf OM, Delurgio DB, Guyton RA, Leon AR and Puskas JD. Newonset atrial fibrillation predicts long-term mortality after coronary artery bypass graft. J Am Coll Cardiol. 2010;55:1370-6.

2. Saxena A, Dinh DT, Smith JA, Shardey GC, Reid CM and Newcomb AE. Usefulness of Postoperative Atrial Fibrillation as an Independent Predictor for Worse Early and Late Outcomes After Isolated Coronary Artery Bypass Grafting (Multicenter Australian Study of 19,497 Patients). AJC. 2012;109:219-225.

3. Bidar E, Bramer S, Maesen B, Maessen JG and Schotten U. Post-operative Atrial Fibrillation : Pathophysiology, Treatment and Prevention. Journal of Atrial Fibrillation. 2013;5:136-145.

4. Crystal E, Connolly SJ, Sleik K, Ginger TJ and Yusuf S. Interventions on prevention of postoperative atrial fibrillation in patients undergoing heart surgery: a meta-analysis. Circulation. 2002;106:75-80.

5. Dunning J, Treasure T, Versteegh M, Nashef SA, Audit E and Guidelines C. Guidelines on the prevention and management of de novo atrial fibrillation after cardiac and thoracic surgery. Eur J Cardiothorac Surg. 2006;30:852-72.

6. Chung MK, Augostini RS, Asher CR, Pool DP, Grady TA, Zikri M, Buehner SM, Weinstock M and McCarthy PM. Ineffectiveness and potential proarrhythmia of atrial pacing for atrial fibrillation prevention after coronary artery bypass grafting. The Annals of Thoracic Surgery. 2000;69:1057-1063.

7. Gerstenfeld EP, Hill MR, French SN, Mehra R, Rofino K, Vander Salm TJ and Mittleman RS. Evaluation of right atrial and biatrial temporary pacing for the prevention of atrial fibrillation after coronary artery bypass surgery. J Am Coll Cardiol. 1999;33:1981-8.

8. Greenberg MD, Katz NM, Iuliano S, Tempesta BJ and Solomon AJ. Atrial pacing for the prevention of atrial fibrillation after cardiovascular surgery. JAC. 2000;35:1416-1422.

9. Daoud EG, Dabir R, Archambeau M, Morady F and Strickberger SA. Randomized, Double-Blind Trial of Simultaneous Right and Left Atrial Epicardial Pacing for Prevention of Post-Open Heart Surgery Atrial Fibrillation. Circulation. 2000;102:761-765.

10. Konings KT, Kirchhof $\mathrm{CJ}$, Smeets JR, Wellens HJ, Penn OC and Allessie MA. High-density mapping of electrically induced atrial fibrillation in humans. Circulation. 1994;89:1665-1680.

11. European Heart Rhythm A, European Association for Cardio-Thoracic S, Camm AJ, Kirchhof P, Lip GY, Schotten U, Savelieva I, Ernst S, Van Gelder IC, Al-Attar N, Hindricks G, Prendergast B, Heidbuchel H, Alfieri O, Angelini A, Atar D, Colonna P, De Caterina R, De Sutter J, Goette A, Gorenek B, Heldal M, Hohloser SH, Kolh P, Le Heuzey JY, Ponikowski P and Rutten FH. Guidelines for the management of atrial fibrillation: the Task Force for the Management of Atrial Fibrillation of the European Society of Cardiology (ESC). Eur Heart J. 2010;31:2369-429.

12. Villareal RP, Hariharan R, Liu BC, Kar B, Lee V-V, Elayda M, Lopez JA, Rasekh A, Wilson JM and Massumi A. Postoperative atrial fibrillation and mortality after coronary artery bypass surgery. Journal of the American College of Cardiology. 2004;43:742-748.

13. Filardo G, Hamilton C, Hamman B, Hebeler RF, Adams J and Grayburn P. New-Onset Postoperative Atrial Fibrillation and Long-Term Survival After Aortic Valve Replacement Surgery. ATS. 2010;90:474-479.

14. Bruins $P$, te Velthuis $H$, Yazdanbakhsh AP, Jansen $P G$, van Hardevelt FW, de Beaumont EM, Wildevuur $C R$, Eijsman L, Trouwborst A and Hack CE. Activation of the complement system during and after cardiopulmonary bypass surgery: postsurgery activation involves C-reactive protein and is associated with postoperative arrhythmia. Circulation. 1997;96:3542-3548.

15. Page PL, Plumb VJ, Okumura K and Waldo AL. A new animal model of atrial flutter. J Am Coll Cardiol. 1986;8:872-9.

16. Ishii Y, Schuessler RB, Gaynor SL, Yamada K, Fu AS, Boineau JP and Damiano RJ, Jr. Inflammation of atrium after cardiac surgery is associated with inhomogeneity of atrial conduction and atrial fibrillation. Circulation. 2005;111:2881-8. 
17. Reilly SN, Jayaram R, Nahar K, Antoniades C, Verheule S, Channon KM, Alp NJ, Schotten U and Casadei B. Atrial Sources of Reactive Oxygen Species Vary With the Duration and Substrate of Atrial Fibrillation: Implications for the Antiarrhythmic Effect of Statins. Circulation. 2011;124:1107-1117.

18. Echahidi N, Pibarot P, O'Hara G and Mathieu P. Mechanisms, prevention, and treatment of atrial fibrillation after cardiac surgery. J Am Coll Cardiol. 2008;51:793-801.

19. Kalman JM, Munawar M, Howes LG, Louis WJ, Buxton BF, Gutteridge G and Tonkin AM. Atrial fibrillation after coronary artery bypass grafting is associated with sympathetic activation. The Annals of Thoracic Surgery. 1995;60:1709-1715.

20. Shahian DM, O'Brien SM, Sheng S, Grover FL, Mayer JE, Jacobs JP, Weiss JM, Delong ER, Peterson ED, Weintraub WS, Grau-Sepulveda MV, Klein LW, Shaw RE, Garratt KN, Moussa ID, Shewan CM, Dangas GD and Edwards FH. Predictors of long-term survival after coronary artery bypass grafting surgery: results from the Society of Thoracic Surgeons Adult Cardiac Surgery Database (the ASCERT study). Circulation. 2012;125:1491-500.

21. Munger TM, Dong Y-X, Masaki M, Oh JK, Mankad SV, Borlaug BA, Asirvatham SJ, Shen W-K, Lee H-C, Bielinski SJ, Hodge DO, Herges RM, Buescher TL, Wu J-H, Ma C, Zhang Y, Chen P-S, Packer DL and Cha YM. Electrophysiological and hemodynamic characteristics associated with obesity in patients with atrial fibrillation. Journal of the American College of Cardiology. 2012;60:851-860.

22. Zacharias A, Schwann TA, Riordan CJ, Durham SJ, Shah AS and Habib RH. Obesity and risk of new-onset atrial fibrillation after cardiac surgery. Circulation. 2005;112:3247-55.

23. Camm AJ, Corbucci G and Padeletti L. Usefulness of Continuous Electrocardiographic Monitoring for Atrial Fibrillation. AJC. 2012;110:270-276.

24. Fuster V, Rydén LE, Cannom DS, Crijns HJ, Curtis AB, Ellenbogen KA, Halperin JL, Le Heuzey J-Y, Kay GN, Lowe JE, Olsson SB, Prystowsky EN, Tamargo JL, Wann S, Smith SC, Jacobs AK, Adams CD, Anderson JL, Antman EM, Halperin JL, Hunt SA, Nishimura R, Ornato JP, Page RL, Riegel B, Priori SG, Blanc J-J, Budaj A, Camm AJ, Dean V, Deckers JW, Despres C, Dickstein K, Lekakis J, McGregor K, Metra M, Morais J, Osterspey A, Tamargo JL, Zamorano JL, Guidelines ACoCAHATFoP, Guidelines ESoCCfP, Association EHR and Society HR. ACC/AHA/ESC 2006 Guidelines for the Management of Patients with Atrial Fibrillation: a report of the American College of Cardiology/American Heart Association Task Force on Practice Guidelines and the European Society of Cardiology Committee for Practice Guidelines (Writing Committee to Revise the 2001 Guidelines for the Management of Patients With Atrial Fibrillation): developed in collaboration with the European Heart Rhythm Association and the Heart Rhythm Society. Circulation. 2006;114:e257-354.

25. Baber U, Howard VJ, Halperin JL, Soliman EZ, Zhang X, McClellan W, Warnock DG and Muntner P. Association of chronic kidney disease with atrial fibrillation among adults in the United States: REasons for Geographic and Racial Differences in Stroke (REGARDS) Study. Circ Arrhythm Electrophysiol. 2011;4:26-32.

26. Chamberlain AM, Agarwal SK, Folsom AR, Duval S, Soliman EZ, Ambrose M, Eberly LE and Alonso A. Smoking and incidence of atrial fibrillation: Results from the Atherosclerosis Risk in Communities (ARIC) Study. Heart Rhythm. 2011;8:1160-1166.

27. Maesen B, Nijs J, Maessen J, Allessie M and Schotten U. Post-operative atrial fibrillation: a maze of mechanisms. Europace. 2012;14:159-174.

28. Mayson SE, Greenspon AJ, Adams S, Decaro MV, Sheth M, Weitz HH and Whellan DJ. The changing face of postoperative atrial fibrillation prevention: a review of current medical therapy. Cardiol Rev. 2007; 15:231-41

29. Asher CR, Miller DP, Grimm RA, Cosgrove DM, 3rd and Chung MK. Analysis of risk factors for development of atrial fibrillation early after cardiac valvular surgery. Am J Cardiol. 1998;82:892-5.

30. Goette A, Juenemann G, Peters B, Klein HU, Roessner A, Huth C and Röcken C. Determinants and consequences of atrial fibrosis in patients undergoing open heart surgery. Cardiovascular Research. 2002;54:390-396. 
31. Dupont E, Ko Y, Rothery S, Coppen SR, Baghai M, Haw M and Severs NJ. The gap-junctional protein connexin40 is elevated in patients susceptible to postoperative atrial fibrillation. Circulation. 2001;103:842-849.

32. Ad N, Snir E, Vidne BA and Golomb E. Histologic atrial myolysis is associated with atrial fibrillation after cardiac operation. Ann Thorac Surg. 2001;72:688-93.

33. Andersen HR, Thuesen L, Bagger JP, Vesterlund T and Thomsen PE. Prospective randomised trial of atrial versus ventricular pacing in sick-sinus syndrome. Lancet. 1994;344:1523-8.

34. Mirza I, James $\mathrm{S}$ and Holt P. Biatrial pacing for paroxysmal atrial fibrillation: a randomized prospective study into the suppression of paroxysmal atrial fibrillation using biatrial pacing. Journal of the American College of Cardiology. 2002;40:457-63.

35. Goette A, Mittag J, Friedl A, Busk H, Jepsen MS, Hartung WM, Huth C and Klein HU. Pacing of Bachmann's bundle after coronary artery bypass grafting. Pacing Clin Electrophysiol. 2002;25:1072-8.

36. Doi A, Takagi M, Toda I, Yoshiyama M, Takeuchi K and Yoshikawa J. Acute Hemodynamic Benefits of BiAtrial Atrioventricular Sequential Pacing With the Optimal Atrioventricular Delay. Journal of the American College of Cardiology. 2005;46:320-326.

37. Fan K, Lee KL, Chiu CS, Lee JW, He GW, Cheung D, Sun MP and Lau CP. Effects of biatrial pacing in prevention of postoperative atrial fibrillation after coronary artery bypass surgery. Circulation. 2000;102:755-760.

38. Levy T, Fotopoulos G, Walker S, Rex S, Octave M, Paul V and Amrani M. Randomized Controlled Study Investigating the Effect of Biatrial Pacing in Prevention of Atrial Fibrillation After Coronary Artery Bypass Grafting. Circulation. 2000;102:1382-1387.

39. Crystal E, Garfinkle MS, Connolly SS, Ginger TT, Sleik K and Yusuf SS. Interventions for preventing postoperative atrial fibrillation in patients undergoing heart surgery. The Cochrane database of systematic reviews. 2004:CD003611.

40. Bailin SJ. Is Bachmann's Bundle the only right site for single-site pacing to prevent atrial fibrillation? Results of a multicenter randomized trial. Card Electrophysiol Rev. 2003;7:325-8.

41. Goette A. Pacing to prevent atrial fibrillation after coronary artery bypass grafting. What works, what doesn't: insights from Bachmann's Bundle pacing. Card Electrophysiol Rev. 2003;7:154-7.

42. Schotten $U$, Verheule S, Kirchhof P and Goette A. Pathophysiological mechanisms of atrial fibrillation: a translational appraisal. Physiol Rev. 2011;91:265-325.

43. Tchervenkov Cl, Wynands JE, Symes JF, Malcolm ID, Dobell AR and Morin JE. Persistent atrial activity during cardioplegic arrest: a possible factor in the etiology of postoperative supraventricular tachyarrhythmias. Ann Thorac Surg. 1983;36:437-43.

44. Fernando HC, Jaklitsch MT, Walsh GL, Tisdale JE, Bridges CD, Mitchell JD and Shrager JB. The Society of Thoracic Surgeons Practice Guideline on the Prophylaxis and Management of Atrial Fibrillation Associated With General Thoracic Surgery: Executive Summary. ATS. 2011;92:1144-1152.

45. Epstein AE, Alexander JC, Gutterman DD, Maisel W, Wharton JM and American College of Chest $P$. Anticoagulation: American College of Chest Physicians guidelines for the prevention and management of postoperative atrial fibrillation after cardiac surgery. Chest. 2005;128:24S-27S. 
Chapter 3 


\section{4}

Assessment of clinical and electrophysiological predictors of late recurrences of postoperative atrial fibrillation detected by implantable loop recorder 


\section{Abstract}

Background Postoperative atrial fibrillation (POAF) is a common complication of cardiac surgery. While early POAF occurs during the acute postoperative phase, late POAF can re-occur in the months thereafter, increasing the risk of stroke and mortality. Given the clinical risk profile of cardiac surgery patients, a predisposing structural and electrophysiological substrate for AF is likely to exist. Using epicardial mapping to determine the complexity of $\mathrm{AF}$, we assessed the clinical and electro-pathological profile predicting early and late POAF.

Methods Patients without a history of AF undergoing cardiac surgery were included. Prior to cardiopulmonary bypass, electrically induced AF was mapped epicardially using a high-density 256-unipolar electrode plaque on the right atrial (RA) wall. Electrophysiological parameters such as the number of waves per cycle, fractionation index and breakthrough/cycle (BT/cycle) were quantified. P-wave analysis of the preoperative 12-lead electrocardiogram was conducted in all patients and correlated to POAF development. After surgery, patients were followed for 3 years using a continuous rhythm monitoring implantable loop recorder for AF detection and a remote monitoring system. Early POAF was defined as AF detected during the first 5 postoperative days, late POAF was defined as an irregular RR interval detected on a 2-minute ECG lead between postoperative day (POD) 6 until end of follow up. Clinical and electrophysiological data were compared between patients developing early and/or late POAF and those without POAF.

Results All patients ( $N=79,75 \%$ male) had hypertension and underwent either coronary artery bypass graft $(72.2 \%)$, aortic valve replacement $(22.8 \%)$, or mitral valve replacement (5.1\%), with an average aortic cross clamp time of 60 minutes. POAF occurred in 46 patients (58.2\%); early POAF in 27 patients (34.2\%) and late POAF in 37 patients (46.8\%), with an average duration per episode of $218.6 \pm 284 \mathrm{~min}$ vs $91.3 \pm 173.3 \mathrm{~min}$ respectively ( $p$ $=0.04$ ). Daily early POAF burden was significantly longer when additional late POAF occurred ( $370 \pm 276.9$ vs $165.7 \pm 169.8 \mathrm{~min}, \mathrm{p}=0.05$ ). Age and $\mathrm{CHA}_{2} \mathrm{DS}_{25}$ VASc score were significantly higher in POAF patients and early POAF was a predictor of late POAF. P-wave amplitude was significantly lower in patients with early POAF; $P Q$ time was prolonged in late POAF and P-wave duration shorter in patients developing both early and late POAF. Multivariate analysis of clinical an electrophysiological data revealed age as an independent predictor in all POAF and $\mathrm{CHA}_{2} \mathrm{DS}_{2}$ VASc score as an independent predictor of early POAF. In addition, RA volume, RA waves/cycle and age were independent predictors of late POAF.

Conclusion After cardiac surgery, late POAF recurrences are common, with a higher $\mathrm{CHA}_{2} \mathrm{DS}_{2}$ VASc score, advanced age and RA volume as predictors. Besides, a pre-existing electrophysiological substrate predisposes patients to POAF and its recurrences. $\mathrm{Pa}$ tients with high $\mathrm{CHA}_{2} \mathrm{DS}_{2}$ VASc score developing early POAF should be followed intensively for late POAF recurrences. 


\section{Introduction}

Postoperative atrial fibrillation (POAF) after cardiac surgery is prevalent in up to $50 \%$ of patients in the first postoperative days and reoccurs in up to $30 \%$ in the following year. ${ }^{1,2}$ Early POAF occurring during the first postoperative days is a predictor of AF after discharge, ${ }^{2-4}$ and predicts increased late mortality and stroke rate in the months to years following the initial operation. ${ }^{5-9}$ In addition, long-term protective effects of antiarrhythmic drugs ${ }^{5}$ and oral anticoagulation ${ }^{8}$ in patients developing POAF suggests that indeed late POAF recurrences contribute to increased risk of stroke. ${ }^{10}$ However, data on incidence and burden of POAF in the years following cardiac surgery are scarce.

The clinical risk profile of patients developing POAF includes risk factors such as valvular heart disease, coronary artery disease, advanced age, hypertension, and heart failure, ${ }^{11,12}$ closely resembling that of AF in the general population. ${ }^{13,14}$ Although the surgical trauma and the acute postoperative phase contribute to a transient phase of prevalent early POAF, ${ }^{15}$ the predisposing co-morbidities in POAF suggest that atrial structural remodelling predisposes to POAF and presumably contribute to its recurrences on a longer term. ${ }^{10}$ Direct contact epicardial mapping of the atrial wall is a wellestablished technique for assessing the substrate for AF, varying from a low complexity of fibrillation patterns in acutely induced AF in normal atria ${ }^{16}$ to more complex patterns with higher number of simultaneous wavelets and breakthrough waves in persistent $\mathrm{AF}^{17}{ }^{17}$ The relation between substrate complexity and late POAF incidence is yet unknown.

We hypothesized that POAF occurs more frequently in patients with a pre-existing substrate, which also predisposes patients to late POAF. We also aimed to determine the electrophysiological substrate of early and late POAF assessed by direct contact epicardial high-density mapping of the right atrium during cardiac surgery.

\section{Methods}

\section{Study population}

Between May 2012 and September 2014, patients without a history of AF, undergoing open chest cardiac surgery using cardiopulmonary bypass were included. All available electrocardiograms, rhythm monitoring data and data obtained from the general practitioner were reviewed for AF episodes prior to hospitalization. Patients had to be 18 years of age and able to sign informed consent. Exclusion criteria were sick sinus syndrome and AV-block. The local ethical committee approved of this protocol. 


\section{Epicardial mapping protocol}

Under general anaesthesia, after sternotomy, epicardial atrial pacemaker wires (Flex$\mathrm{on}^{\mathrm{TM}}$ ) were placed on the right atrial appendage. Atrial fibrillation was induced by atrial burst pacing (max 800 beats per minute (bpm) and/or incremental/decremental pacing. Induction attempts were stopped in case of hemodynamic instability, or when AF was not inducible after 10 minutes of atrial burst pacing. A custom-made high-density square electrode array (FlexMEA, Maastricht Instruments BV, Maastricht, The Netherlands $-26 \times 26 \mathrm{~mm}$, 256 electrodes, electrode diameter $0.1 \mathrm{~mm}$ and inter-electrode spacing $1.5 \mathrm{~mm}$ ) was used for direct contact epicardial mapping. Unipolar AF electrograms were recorded from the right atrial wall using an amplifier (filtering bandwidth 0.1$400 \mathrm{~Hz}$, sampling rate $1 \mathrm{kHz}$ ). After epicardial mapping was completed, cardiopulmonary bypass was initiated.

All files were analysed using an automated analysis described previously. ${ }^{18}$ In short, electrograms were filtered through a $0.5 \mathrm{~Hz}$ high-pass filter with cancellation of far-field ventricular complexes followed by a probabilistic algorithm detecting steepest negative local deflections per electrode, accounting for AFCL distribution. From the local deflections, waves were constructed using wave conduction likelihood method based on the normal distributions of conduction velocity (CV) and conduction deviation. We considered a $\mathrm{CV}<20 \mathrm{~cm} / \mathrm{s}$ as conduction block. Non-local deflections were considered farfield activity if they were larger than $25 \%$ of the median of intrinsic deflections. Fractionation index was calculated as the ratio between these large non-intrinsic and intrinsic deflections.

\section{ECG P-wave analysis}

The day prior to the operation a 10-second ECG was digitally recorded in all patients with a sampling frequency of $250 \mathrm{~Hz}$, and analysed in Matlab (The Mathworks, Inc., Natick, Massachusetts, United States). The ECGs were filtered using a bandpass filter 1$100 \mathrm{~Hz}$. Parameters used for analysis included: averaged P-wave duration, dispersion, area, amplitude and PQ-time.

\section{AF detection during follow up}

After the operation all patients underwent continuous telemetric monitoring in the nursing ward until discharge (minimum 3 days). At least 2 ECGs were recorded during the first postoperative week. Following the closure of the sternotomy, a Reveal $X T^{\mathrm{TM}}$ (Medtronic Minneapolis, MN, USA) ${ }^{19}$ was inserted at the left parasternal area. This implantable loop recorder (ILR) classifies brady- and tachy-arrhythmias based on a specific algorithm for detection of irregular RR intervals lasting at least 2 minutes. All patients received a remote monitoring system (CareLink ${ }^{\circ}$ ) at postoperative day 3 for a period of 3 years. Patients were instructed to interrogate the ILR once in two weeks. 
The interrogated episodes were stored in a protected central database (Medtronic Minneapolis, MN, USA). Each interrogated event contained episodes that were stored between the last session and the current interrogation. Only episodes containing an ECG recording were included in the analysis. Events stored as text only were excluded. Patients were contacted at 3 months, 1 year and 2 years and at detection of AF episodes and asked for any symptoms of palpitations, changes in medication or hospitalisations. Recurrent AF episodes were discussed with the patient's cardiologist and treatment or initiation of oral anticoagulation was left at the discretion of the cardiologist.

In this study, early POAF was defined as an irregular RR-interval, without evident Pwaves, detected during the first postoperative days (POD) usually on telemetric monitoring or ECG lead. Late POAF was defined as an AF episode detected by the ILR on a one lead ECG of at least 2 minutes, between POD 6 until the end of the 3-year follow-up period.

\section{Statistics}

Analysis was performed using SPSS (IBM SPSS statistics version 21.0). Data are expressed as mean \pm SD or percentages. Patients developing POAF at different time points were compared to patients without POAF using an unpaired Student's-t-test or analysis of variance (ANOVA). For differences between early and late POAF a paired Student's-ttest was used if normally distributed or Wilcoxon Rank sum test if not. Categorical data were analysed using Pearson's chi-square test. P-values $<0.05$ were considered statistically significant. For multivariate analysis we first conducted a univariate logistic regression analysis of 10 predetermined clinical and electrophysiological variables using total POAF, early POAF, late POAF and early AND late POAF as dependent variables. Afterwards we used the variables with $p<0.05$ in a multivariate logistic regression analysis (backward elimination, assessing goodness-of-fit with a Hosmer-Lemeshow test). For the multivariate analysis we excluded the electrophysiological data from the epicardial mapping (due to loss of power) but conducted a subgroup multivariate analysis including these data.

\section{Results}

\section{Clinical data}

Seventy-nine patients were included and received a Reveal $\mathrm{XT}^{\mathrm{TM}}$ (Medtronic Minneapolis, MN, USA) of whom 6 were explanted during follow-up due to pain or infection. Patients were on average 65 years of age, all had hypertension, with an average $\mathrm{CHA}_{2} \mathrm{DS}_{2}$ VASc score of $2.4 \pm 1.3$. In this population $72.2 \%$ underwent CABG alone with an aortic cross-clamp time of $60 \pm 25 \mathrm{~min}$. Right atrial volume was on average $52 \pm 15.7 \mathrm{ml}$. 
Pre-operatively, most patients were treated with a beta-blocking agent $(72.2 \%)$ and statins (84.8\%) (Table 1). Postoperatively all patients received standardised betablockers for POAF prevention unless contraindicated, although this was left at the discretion of the treating physicians.

Table 1: Basic clinical characteristics

\begin{tabular}{|c|c|}
\hline Clinical parameter & $N=79$ \\
\hline Age (years) & $65( \pm 9.0)$ \\
\hline $\mathrm{BMI}$ & $27.5( \pm 4.5)$ \\
\hline RA-volume (ml) & $51.87( \pm 15.68)$ \\
\hline RAVI & $25.2( \pm 8)$ \\
\hline LA-volume (ml) & $79( \pm 24.5)$ \\
\hline LAVI & $40.2( \pm 14.4)$ \\
\hline LVEF & $60 \%( \pm 5 \%)$ \\
\hline Creatinine & $90.1( \pm 21.2)$ \\
\hline COPD & $11(13.9 \%)$ \\
\hline HATCH score & $1.7( \pm 1.1)$ \\
\hline $\mathrm{CHA}_{2} \mathrm{DS}_{2}$ VASC & $2.4( \pm 1.3)$ \\
\hline$-\mathrm{CHF}$ & $10(12.70 \%)$ \\
\hline - Hypertension & 79 (100\%) \\
\hline - Age $>75 / 65-75$ & $13(16.46 \%) / 23(29.11 \%)$ \\
\hline - Diabetes & $16(20.25 \%)$ \\
\hline - Stroke/TIA & $6(7.59 \%)$ \\
\hline - Vascular disease & 15 (18.99\%) \\
\hline- Sex & 20 female \\
\hline CABG & $57(72.2 \%)$ \\
\hline$A V R \pm C A B G$ & $18(22.8 \%)$ \\
\hline$M V R \pm C A B G$ & $4(5.1 \%)$ \\
\hline ACCT & $60 \min ( \pm 25)$ \\
\hline ICU-stay (days) & $1.5( \pm 1.6)$ \\
\hline B-blockers & $57(72.2 \%)$ \\
\hline ACE inhibitors & $27(34.2 \%)$ \\
\hline Statins & $67(84.8 \%)$ \\
\hline
\end{tabular}

$B M I=$ body mass index; $R A=$ right atrium; $C A B G=$ coronary artery bypass graft; $A V R=$ aortic valve replacement; $M V P=$ mitral valve repair/replacement; $L A V I / R A V I=l e f t$ and right atrial volume index; $L V E F=$ left ventricular ejection fraction; $\mathrm{CHA}_{2} \mathrm{DS}_{2}$ VASc score = CHF, congestive heart failure/ hypertension/ age/ diabetes/ sex/vascular disease; HATCH score= hypertension/ age $>75 y e a r s /$ transient ischemic attack (TIA) or stroke/ chronic obstructive pulmonary disease (COPD) /heart failure; ACCT=aortic cross clamp time.

\section{POAF-prevalence}

During a follow-up of 3 years (range 5 days - 36 months), 3605 device interrogations were sent to the Carelink central database for analysis (mean 48 per patient, range 3- 
150). Forty-six patients (58.2\%) developed POAF. Early POAF was detected in 27 patients (34.2\%). Interestingly, two thirds of this group (18 patients, $22.8 \%$ of total) had additional late POAF episodes. In addition, 19 patients (24.1\%) developed only late POAF without any early POAF episodes. Nine patients (11.4\%) developed only early POAF without any late POAF episodes (Table 2).

Table 2. POAF incidence $n=79(\%)$

\begin{tabular}{llll}
\hline & late POAF - & late POAF + & Total \\
\hline early POAF - & $33(41.77)$ & $19(24.05)$ & $52(65.82)$ \\
early POAF + & $9(11.39)$ & $18(22.78)$ & $27(34.18)$ \\
& $42(53.16)$ & $37(46.84)$ & $79(100)$ \\
\hline
\end{tabular}

Cross tabulation between early and late POAF.

$\%$

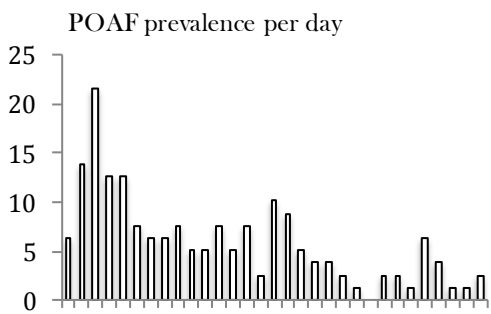

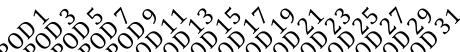

POAF prevalence per month

$\%$

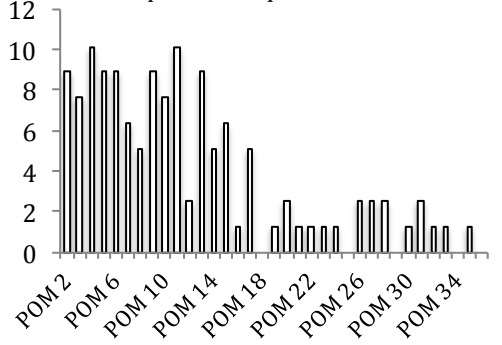

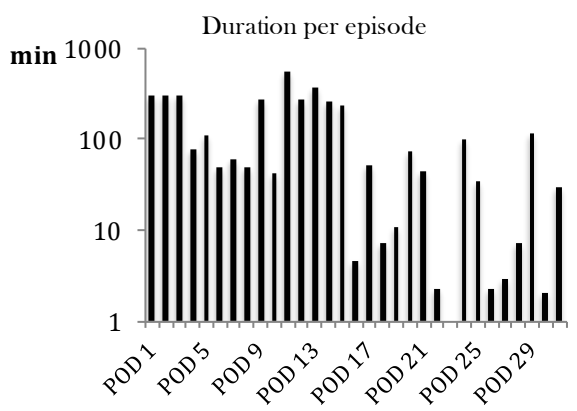

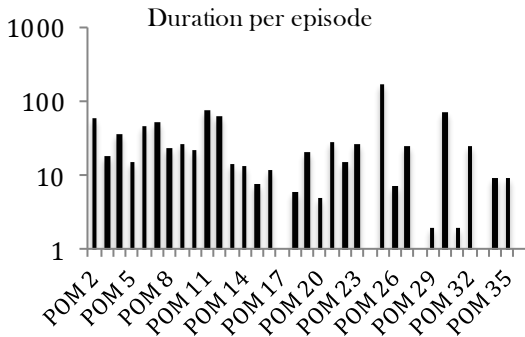

Figure 1. Prevalence of POAF in the first postoperative month (top left) and the following months excluding the first month (bottom left) and the average duration per episode on a logarithmic scale in the first postoperative month (top right) and the following months (bottom right). POD=postoperative day, POM=postoperative month.

The temporal variation in POAF incidence is presented in figure 1. As expected, the peak incidence of POAF occurred during the first few days after the operation with a notable decline after POD 5. However, after this period, there is a steady incidence of $5-10 \%$ in the following 17 months, slowly declining in the months thereafter, presumably due to decreased intensity of rhythm follow-up (inherent memory limitations of ILR, patient compliance and loss to follow-up). On the other hand, the average duration per episode on a daily basis remained consistent ranging between 10-100 minutes until the end of 
the follow-up period. On average, the duration per episode in early POAF was longer than in late POAF (219 $\pm 284 \mathrm{~min}$ vs $91 \pm 173 \mathrm{~min}, \mathrm{p}=0.02)$ (Figure 2$)$. Daily early POAF burden was also significantly longer in patients developing additional late POAF, compared to early POAF only $(370 \pm 277$ vs $166 \pm 170 \mathrm{~min}, \mathrm{p}=0.05)$. In late POAF, 3 patients developed $>24$ hours of AF. Patients were contacted after recurrent late POAF episodes were diagnosed with the loop recorder.

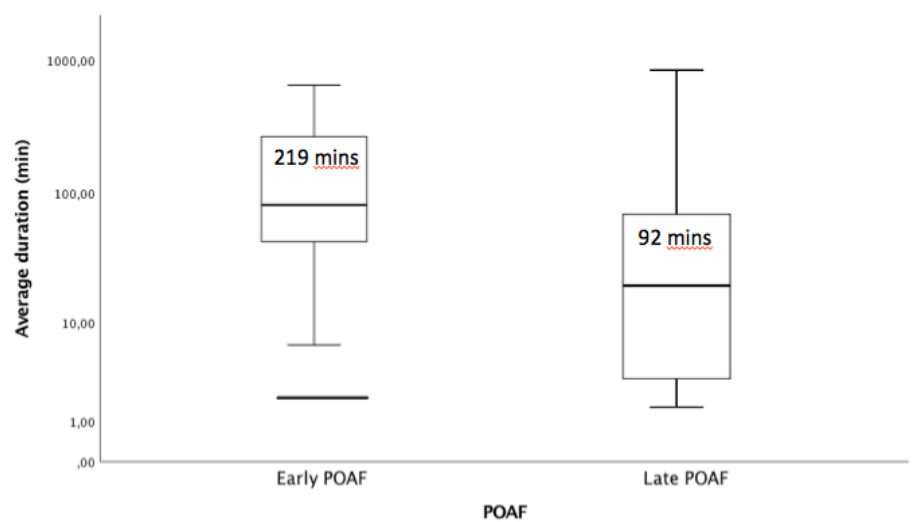

Figure 2. Boxplot of average duration of early and late POAF.

Interestingly, as depicted in figures $3 a$ and $b$, the first episode of AF occurred between 10-40 weeks up to 100 weeks in 1 patient. Sixteen patients (20\%) received oral anticoagulation by their treating cardiologist.

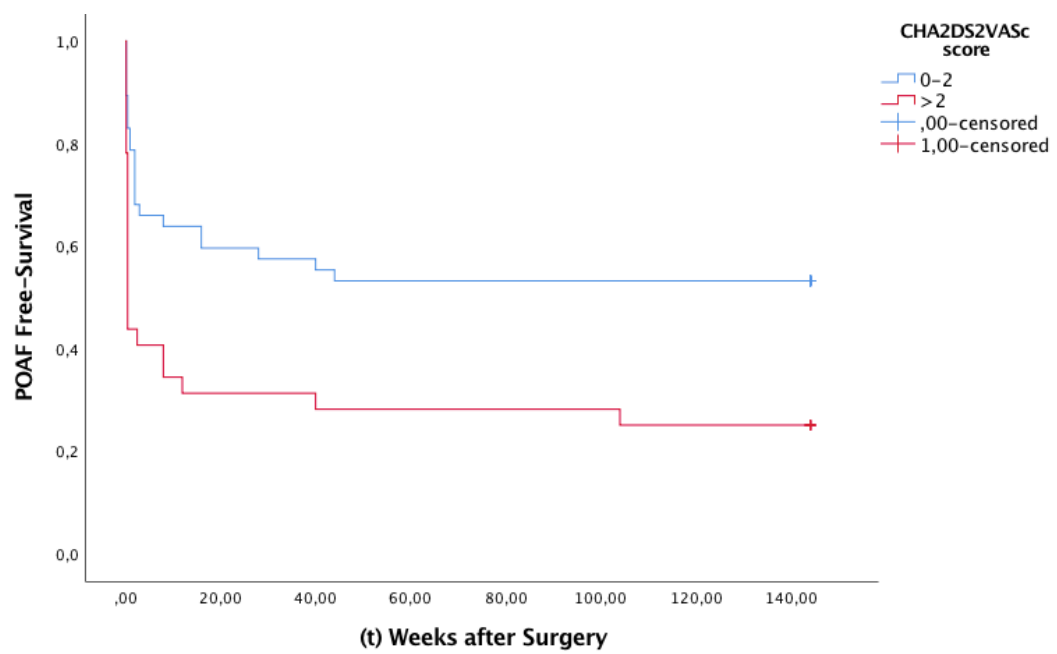

Figure 3a. Kaplan-Meier survival comparison between patients with $\mathrm{CHA}_{2} \mathrm{DS}_{2} \mathrm{VASc}$ score of $0-2(n=47)$ and 3 $6(n=32) . P=0.002$. 


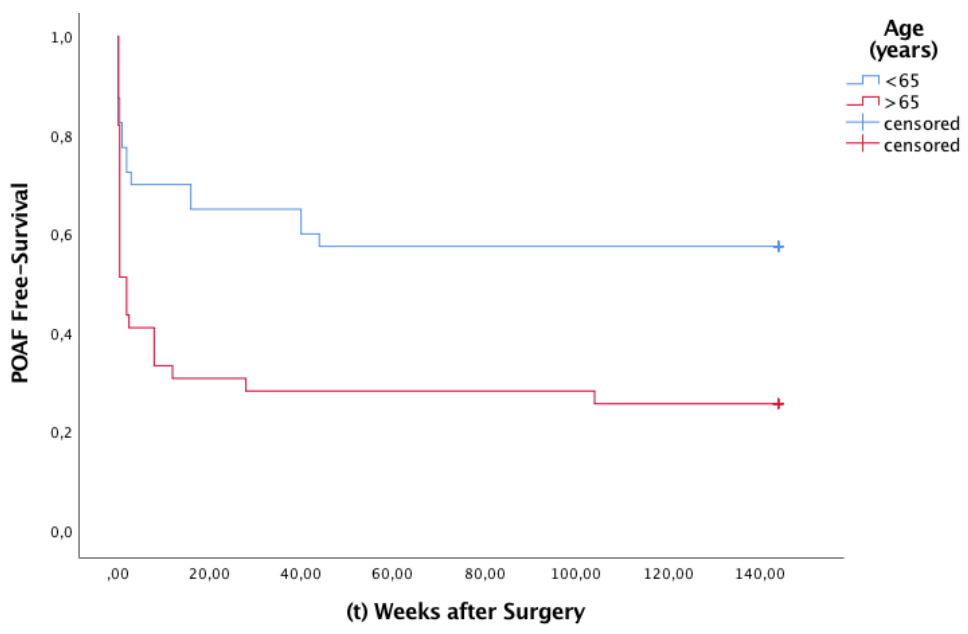

Figure 3b. Kaplan-Meier survival comparison between patients with Age>65 years $(n=40)$ and $<65$ years $(n=39)$. $P=0.004$.

\section{Clinical characteristics of patients developing POAF}

To assess a potential substrate for AF in POAF patients, we analysed the predisposing co-morbidities known to affect AF substrates in the general population. Univariate characteristics of different POAF subgroups are presented in table 3.

Age was consistently higher in all POAF subgroups (in years, $68.3 \pm 8.5$ vs $60.9 \pm 8.3$ in total POAF; $69.6 \pm 9.2$ vs $62.9 \pm 8.3$ for early POAF and $68.7 \pm 8.4$ vs $62.1 \pm 8.8$ for late POAF, $\mathrm{p}<0.05$ for all). $\mathrm{CHA}_{2} \mathrm{DS}_{2}$ VASc score was higher in total POAF (2.8 \pm 1.4 vs $2.0 \pm 1.2, \mathrm{P}$ $=0.01)$ and in early POAF $(3.2 \pm 1.4$ vs $2.2 \pm 1.2, p=0.01)$. In addition, HATCH score was also higher in early POAF (2.1 \pm 1.1 vs $1.5 \pm 1.1, p=0.04)$. Early POAF itself was a predictor of late POAF ( $p=0.01)$. In multivariate analysis age remained an independent predictor of total POAF, late POAF and of early and late POAF, while $\mathrm{CHA}_{2} \mathrm{DS}_{2}$ VASc score was the only independent predictor of early POAF (Table 4).

\section{Atrial electrophysiological characteristics of patients developing POAF}

To test the hypothesis that the underlying structural substrate for POAF results from atrial conduction disturbances we performed direct contact mapping of electrically induced AF in the right atrium. In 9 patients sustained AF was not inducible after completing the AF induction protocol of incremental and burst pacing during 10 minutes. Also epicardial mapping could not be performed in another 17 patients because of hemodynamic instability during AF $(n=4)$, for logistic reasons due to changes in operation time schedule $(n=7)$ or poor quality of the electrograms due to electrical noise $(n=6)$. 
A total of 53 mapping files were obtained from the right atrium ranging between 7 to 45 seconds. Basic electrophysiological characteristics are presented in table 5. AFCL was significantly longer in patients who subsequently developed POAF (181 \pm 3 vs $166 \pm 2$, $\mathrm{p}=0.03$ ). In accordance with the pre-existing clinical substrate for POAF, fibrillatory propagation in the right atrium was clearly more complex in all POAF groups.

Univariate analysis is presented in table 3. Patients with POAF showed a significantly higher number of RA waves/cycle (POAF $5.0 \pm 1.4$ vs $4.0 \pm 1.6$; early POAF $5.3 \pm 1.5$ vs 4.3 \pm 1.5 ; late POAF $5.1 \pm 1.6$ vs $4.2 \pm 1.4$ for patients that did not develop POAF, all $p<0.05$ ). The preoperative ECG showed significantly smaller P-wave amplitude for the early POAF group (0.07 \pm 0.03 vs $0.08 \pm 0.02, p=0.03$ ), a prolonged $P Q$ time for late POAF (171.7 \pm 19.1 vs $160.5 \pm 18.0 \mathrm{~ms}, \mathrm{p}=0.01)$ and a smaller P-wave area (3.0 \pm 0.8 vs $3.6 \pm 1.1, p$ $=0.04)$ and amplitude (0.06 \pm 0.03 vs $0.08 \pm 0.02, p<0.05)$ and RAFI (total POAF $2.1 \pm 1.0$ vs $1.7 \pm 0.7$; early POAF $2.5 \pm 0.8$ vs $1.7 \pm 0.7$; early AND late POAF $2.4 \pm 0.8$ vs $1.8 \pm 0.8 p$ $<0.05$ for all comparisons).

Table 3. Clinical, electrophysiological and ECG characteristics results of analysis of variance (ANOVA)

\begin{tabular}{|c|c|c|c|c|c|c|c|c|c|c|c|c|}
\hline & $\begin{array}{l}\text { POAF- } \\
(n=33)\end{array}$ & $\begin{array}{l}\text { POAF+ } \\
(n=46)\end{array}$ & $P$ & $\begin{array}{c}\text { Early } \\
\text { POAF- } \\
(n=52)\end{array}$ & $\begin{array}{c}\text { Early } \\
\text { POAF+ } \\
(n=27)\end{array}$ & $\mathrm{P}$ & $\begin{array}{l}\text { Late } \\
\text { POAF- } \\
(n=42)\end{array}$ & $\begin{array}{c}\text { Late } \\
\text { POAF+ } \\
(n=37)\end{array}$ & $P$ & $\begin{array}{c}E \& L \\
\text { POAF- } \\
(n=61)\end{array}$ & $\begin{array}{c}E \& L \\
\text { POAF+ } \\
(n=18)\end{array}$ & $P$ \\
\hline 3MI & 7.91 & 27.28 & 0.55 & .62 & 27.39 & 0.84 & 7.40 & 27.70 & 0.78 & 7.32 & 28.30 & 0.43 \\
\hline Age $(y$ & 60.88 & 68.33 & 0.00 & 62.92 & 69.63 & 0.00 & 2.14 & 68.70 & 0.01 & 3.48 & 71.11 & 0.00 \\
\hline $\mathrm{AoCC}$ & 60.34 & 60.22 & 0.98 & 58.98 & 62.70 & 0.55 & 58.68 & 62.03 & 0.58 & 58.13 & 67.39 & 0.19 \\
\hline CRP & 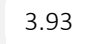 & $\perp$ & 0.87 & 34 & $T$ & 0.94 & 4 & 4 & 0.67 & 64 & 4.33 & 0.67 \\
\hline $\mathrm{HA}_{2} \mathrm{DS}_{2}$ & 2.03 & 283 & 1 0 & 215 & 315 & 0.00 & 279 & 2.79 & 0.14 & 2.28 & 3.22 & 0.01 \\
\hline HATCH score & 48 & 1.89 & 0.10 & & 2.07 & 0.04 & 1.67 & 1.78 & 0.64 & .66 & 1.94 & 0.34 \\
\hline RA volume (ml) & 46.46 & 55.50 & 0.0 & 9 & 49 & 0.4 & 8 & 55 & 8 & 38 & 00 & 0.20 \\
\hline RA BT/cycle & 1.05 & 13 & 0.18 & 1.13 & 132 & 0.31 & 1.09 & 1.30 & 0.24 & 1.12 & 1.50 & 0.12 \\
\hline A wav & & & 0.05 & 31 & & 0.04 & 4.19 & 5.06 & 0.04 & 4.34 & 5.62 & 0.01 \\
\hline RA FI & 1.6 & 2.2 & 0.02 & 1.66 & 2.53 & 0.00 & 1.84 & 2.02 & 0.43 & 1.80 & 2.40 & 0.04 \\
\hline Duration(ms) & 113.58 & 112.06 & 0.66 & 114.00 & 110.00 & 0.27 & 111.33 & 114.44 & 0.36 & 113.39 & 110.00 & 0.43 \\
\hline P dispersion & 40.56 & 40.72 & 0.97 & 41.85 & 38.04 & 0.50 & 39.69 & 41.83 & 0.67 & 41.31 & 37.95 & 0.59 \\
\hline$P Q$-tim & 162.71 & 167.61 & 0.27 & 165.57 & 165.30 & 0.95 & 160.45 & 171.69 & 0.01 & 164.77 & 168.38 & 0.52 \\
\hline $\mathrm{P}$ area & 3.46 & 3.45 & 0.95 & 3.52 & 330 & 0.40 & 1.12 & 0.91 & 0.43 & 3.57 & 2.96 & 0.04 \\
\hline amplitude & 0.08 & 0.08 & 0.24 & 0.08 & 0.07 & 0.03 & 0.081 & 0.083 & 0.42 & 0.08 & 0.06 & 0.00 \\
\hline
\end{tabular}

ANOVA of patients developing early POAF, late PAOF, early AND late (E\&L) POAF: BMI=body mass index; AoCCT=aortic cross clamp time; $\mathrm{CRP}=\mathrm{C}$-reactive protein; $\mathrm{CHA}_{2} \mathrm{DS}_{2}$ VASc score = congestive heart failure/ hypertension/age/ diabetes/ sex/vascular disease; HATCH score= hypertension/ age $>75 y$ years/ (TIA) transient ischemic attack or stroke/ (COPD) chronic obstructive pulmonary disease/heart failure; RA=right atrium; $\mathrm{BT}=$ breakthrough wave; $\mathrm{FI}=$ fractionation index; $\mathrm{LA}=$ left atrium; $E C G=$ electrocardiography; $\mathrm{P}=\mathrm{P}$-wave

The number of breakthrough waves (BT) per AFCL (BT/cycle) was not significantly different between these groups but a trend towards more BT with POAF recurrence was seen. The substrate complexity parameters remained significantly different between 
POAF and non-POAF groups in the final multivariate model. In addition to age, RA volume, and $\mathrm{CHA}_{2} \mathrm{DS}_{2}$ VASc score, independent predictors for POAF were RA waves/cycle in total and for late POAF and RA FI for early POAF.

Table 4a-d. Results multivariate logistic regression analysis

\begin{tabular}{|c|c|c|}
\hline $\begin{array}{l}\text { A. POAF } \\
(n=46)\end{array}$ & Adjust OR $(95 \% \mathrm{Cl})$ & $P$ \\
\hline Age & $1.11(1.04-1.20)$ & 0.03 \\
\hline \multicolumn{3}{|l|}{ Subgroup analysis } \\
\hline RA volume & 1.10 (1.03-1.18) & 0.008 \\
\hline $\mathrm{CHA}_{2} \mathrm{DS}_{2}$ VASC & 3.38 (1.47-7.75) & 0.004 \\
\hline RA waves/cycle & $2.06(1.09-3.90)$ & 0.026 \\
\hline $\begin{array}{l}\text { B. Early POAF } \\
(n=27)\end{array}$ & Adjust OR $(95 \% \mathrm{Cl})$ & $\mathrm{P}$ \\
\hline $\mathrm{CHA}_{2} \mathrm{DS}_{2}$ VASC & $1.80(1.22-2.66)$ & 0.003 \\
\hline \multicolumn{3}{|l|}{ Subgroup analysis } \\
\hline $\mathrm{CHA}_{2} \mathrm{DS}_{2}$ VASC & $2.19(1.17-4.08)$ & 0.014 \\
\hline $\mathrm{RA}-\mathrm{FI}$ & $4.17(1.41-12.36)$ & 0.010 \\
\hline $\begin{array}{l}\text { C. Late POAF } \\
(n=37)\end{array}$ & Adjust OR $(95 \% \mathrm{Cl})$ & $P$ \\
\hline Age & $1.10(1.03-1.16)$ & 0.003 \\
\hline \multicolumn{3}{|l|}{ Subgroup analysis } \\
\hline Age & $1.15(1.03-1.30)$ & 0.02 \\
\hline RA volume & $1.08(1.02-1.14)$ & 0.01 \\
\hline RA waves/cycle & $1.88(1.07-3.32)$ & 0.03 \\
\hline $\begin{array}{l}\text { D. E\&L POAF } \\
(n=18)\end{array}$ & Adjust OR $(95 \% \mathrm{Cl})$ & $P$ \\
\hline Age & $1.13(1.04-1.22)$ & 0.005 \\
\hline
\end{tabular}

$\mathrm{BMI}=$ body mass index; $\mathrm{AoCCT}=$ aortic cross clamp time; $\mathrm{CRP}=\mathrm{C}$-reactive protein; $\mathrm{CHA}_{2} \mathrm{DS}_{2}$ VASc score = congestive heart failure/ hypertension/ age/ diabetes/ sex/vascular disease; HATCH score= hypertension/ age>75years/ (TIA) transient ischemic attack or stroke/ (COPD) chronic obstructive pulmonary disease/heart failure; $\mathrm{RA}=$ right atrium; $\mathrm{BT}=$ breakthrough wave; $\mathrm{FI}=$ fractionation index; $\mathrm{LA}=$ left atrium; $\mathrm{ECG}=$ electrocardiography;

By adding the RA waves/cycle to the clinical predictors of late POAF (age, RA volume and early POAF) the predictive value of the Receiver Operator Curve- model increased from area under the curve of 0.78 to 0.86 (Figure 3). 
Table 5. Electrophysiological characteristics of epicardial mapping

\begin{tabular}{lllll}
\hline Mean & $\begin{array}{l}\text { POAF } \\
(n=53)\end{array}$ & $\begin{array}{l}\text { No-POAF } \\
(n=23)\end{array}$ & $p$ \\
\hline $\mathrm{AFCL}(\mathrm{ms})$ & $177( \pm 31)$ & $181( \pm 30)$ & $166( \pm 24)$ & 0.05 \\
$\mathrm{CV}(\mathrm{m} / \mathrm{s})$ & $0.58( \pm 0.1)$ & $0.57( \pm 0.1)$ & $0.58( \pm 0.1)$ & 0.7 \\
$\mathrm{BT} / \mathrm{CL}$ & $1.1( \pm 0.6)$ & $1.3( \pm 0.6)$ & $1.0( \pm 0.5)$ & 0.09 \\
$\mathrm{RA}-\mathrm{FI}$ & $1.9( \pm 0.8)$ & $2.2( \pm 0.9)$ & $1.6( \pm 0.7)$ & 0.02 \\
waves/CL & $4.6( \pm 1.6)$ & $5.0( \pm 1.5)$ & $4.1( \pm 1.6)$ & 0.05 \\
\hline
\end{tabular}

$\mathrm{RA}=$ right atrium; $\mathrm{AFCL}=$ Atrial fibrillation cycle length; $\mathrm{ms}=$ milliseconds; $\mathrm{CV}=$ conduction velocity (meters/seconds); $\mathrm{BT}=$ breakthrough waves; $\mathrm{CL}=$ cycle length; $\mathrm{FI}=$ fractionation index.

\section{Discussion}

Previous reports on incidence of late POAF or the effect of interventions on AF recurrences did not exclude patients with a history of paroxysmal $\mathrm{AF}^{7,20}$ and focused on clinically symptomatic $A F$, relying on electrocardiogram recordings in patient reporting symptoms of AF. ${ }^{2,4,21}$ However, a high percentage of subclinical AF may exist in highrisk patients ${ }^{22}$ and "snapshot" monitoring strategies are insufficient for quantifying AF burden. ${ }^{23}$ To our knowledge, this is the first prospective study with prolonged continuous rhythm monitoring with ILR, in patients without a clinical history of AF undergoing cardiac surgery. We found subclinical late POAF recurrences in $47 \%$ of patients during a 3-year follow-up. In our population, late POAF duration was 1.5 hours per episode on average. Atrial high rate episodes (AHRE), lasting minutes to hours, detected by cardiac implantable electronic devices have been reported to be associated with an increased risk for ischemic stroke in general population. ${ }^{22,24,25}$ The ASSERT trial for example, included 2580 patients with hypertension without a history of AF and demonstrated AHRE in $35 \%$ of patients during continuous rhythm follow-up of 2.5 years. ${ }^{26}$ As expected, the risk of stroke in these patients was higher especially in patients with elevated $\mathrm{CHADS}_{2}$ score $(>2.1) .{ }^{25,26}$ In line with this, AHRE in the absence of a history of AF has been associated with significantly higher incidence of silent ischemic brain lesions detected on computed tomography scans. ${ }^{27}$ Furthermore, 15 minutes of AF or rapid pacing have been shown to increase amounts of platelet activation and thrombin generation compared to sinus rhythm, ${ }^{28}$ emphasizing the potential prothrombotic effects of short lasting episodes of atrial arrhythmias.

Hence, there is a significant amount of data supporting oral anticoagulation (OAC) treatment in patients with short lasting AF episodes. Of note, a sub-analysis of the ASSERT trial recently showed that only episodes of subclinical AF lasting longer than 24 hours were associated with an increased risk of stroke ${ }^{29}$ and elevated stroke risk in AHRE in different reports may have been driven by longer episodes. ${ }^{25}$ Patients developing late POAF in our study had an average $\mathrm{CHA}_{2} \mathrm{DS}_{2}$ VASc score of 2.8, which is known to 
go along with an increased risk of stroke also in short lasting AF episodes. ${ }^{30}$ Still, more research is required to determine the risk-benefit ratio of oral anticoagulation in late POAF.

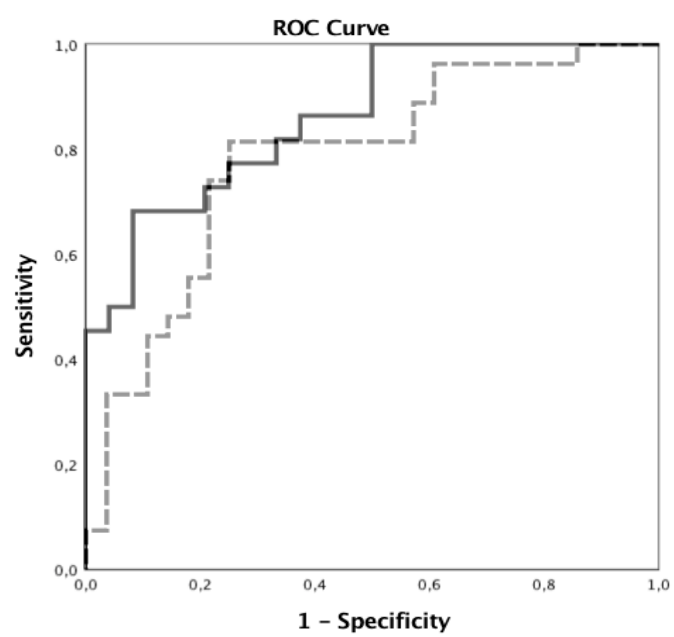

Figure 3. Receiver Operator Curve- model of predictors of late POAF. Dashed line: Age, RA volume, early POAF, AUC 0.78; Black line: Age, right atrial volume, early POAF and RA waves/cycle AUC: 0.86

We further determined the underlying clinical and electropathological substrate for POAF. In our patient population, a higher $\mathrm{CHA}_{2} \mathrm{DS}_{2}$ VASc score was an independent predictor of early POAF and advanced age and large RA volume were independent predictors of late POAF. In addition, others have reported predisposing factors to POAF including COPD, obesity, systolic dysfunction, and valvular disease. ${ }^{7,11,31}$ These co-morbidities may contribute to atrial remodelling through fibrosis ${ }^{32}$ and heterogeneous gap-junction protein distribution $^{33}$ resulting into a structural substrate for $A F .^{34,35}$ In line with this, patients developing POAF showed more complex propagating properties, including higher RA/FI and higher number of RA waves/cycle compared to patients without POAF.

The complexity of atrial activation pattern during $A F$ is a reflection of the underlying structural substrate for AF. ${ }^{17,36-38}$ Also in patients without a history of AF some degree of remodelling may already exist as previously demonstrated by Konings et al., in patients undergoing ablation for Wolf-Parkinson-White (WPW) syndrome. ${ }^{16}$ Similarly, RA local conduction slowing and enhanced AF inducibility were seen in patients without a history of AF with RA dilatation as a result of an atrial septal defect ${ }^{39}$ or as a result of chronic hypertension. ${ }^{40}$ Patients with persistent $A F$, on the other hand, show a much more complex wave pattern with a high number of simultaneous fibrillation waves and high number of breakthrough waves as compared to the WPW patients. ${ }^{17,38}$

These findings alongside our epicardial mapping results suggest that some patients without a history of AF may have a predisposition to AF as a result of their underlying 
co-morbidities. Of note, perioperative characteristics such as aortic cross clamp time and ICU stay did not differ in patients developing POAF. Patients developing additional late POAF showed significantly higher early POAF burden. This suggests that at least in this population, the pre-existing substrate resulted in prolonged early POAF development, also predisposing to late POAF that potentially requires rhythm follow-up.

Considering the pre-existing substrate, POAF can thus be predicted by substrate quantification in patients undergoing cardiac surgery. The 12-lead ECG has been shown to capture AF complexity and propagation properties of the atria. Previously, specific ECG parameters such as $\mathrm{P}$-wave dispersion ${ }^{41}$ and prolonged $\mathrm{P}$-wave duration on signal averaged ECG ${ }^{42,43}$ have been described to predict POAF. Also, the number of peaks within the P-wave and the terminal force in lead V1 has been shown to detect patients with a history of AF. The P-wave area has been described as a predictor for AF and risk of stroke in general population. ${ }^{44}$ However, these results are not solely based on the standardised 12 lead ECG and not all previous studies excluded patients with a history of $A F$ including patients with lower left ventricular ejection fraction. ${ }^{41-43}$ In the current study, using the standardised (filtered) preoperative ECGs, we found that P-wave amplitude and $\mathrm{P}$-wave area were significantly lower in patients developing both early and late POAF. Although the filtered 12 lead ECG is known to smoothen most irregularities and peaks compared to signal averaged high-resolution ECGs, ${ }^{45}$ these findings are easily available on a broad scale. The clinical use of the $p$-wave analysis for POAF prediction will have to be shown in future studies.

\section{Conclusion}

We found that $47 \%$ of cardiac surgery patients in our population developed late POAF at least once during 3 years of follow-up with an average duration of 1.5 hours per episode. Advanced age, $\mathrm{CHA}_{2} \mathrm{DS}_{2}$ VASc score, RA volume and complex epicardial propagation patterns were important predictors of early and late POAF. Our data indicate that patients developing early POAF are likely to have an underlying structural substrate for $A F$, which predisposes them to late POAF recurrences. Because late POAF has been related to increased mortality and stroke, patients with high $\mathrm{CHA}_{2} \mathrm{DS}_{2} \mathrm{VASc}$ score developing early POAF should be followed intensively for late POAF recurrences. Furthermore, due to the existence of a clinical and electro-pathological substrate, predictive efforts should be evaluated in the future studies. 12-lead ECG P-wave characteristics may help to identify patients at risk for late POAF. 


\section{Study limitations}

One important limitation in using Reveal $\mathrm{XT}^{\mathrm{TM}}$ device is the fact that the device has a short storage capacity. At the same time, the device has a relatively low specificity and positive predictive value for AF detection ( $85.6 \%$ and $79.3 \%$ respectively). ${ }^{46}$ The problem arises when the device is used for longer periods and AF episodes are overwritten by more recent episodes. This limitation, along with the patient dependent interrogation, leads to relatively high false positive episodes and low frequency of device interrogations towards the end of follow-up. However, we regularly contacted the patients to keep the time between interrogations short and analysed more than 3000 interrogations of the implanted devices with an average of 48 interrogations per patient. Another important limitation in this study is the fact that patients did not have continuous rhythm monitoring prior to the surgery. Therefore, although all medical records of all patients were reviewed, it is plausible that at least some of the patients developing late POAF may have had episodes of (asymptomatic) AF prior to surgery. 


\section{References}

1. Bidar E, Maesen B, Nieman F, Verheule S, Schotten U and Maessen JG. A prospective randomized controlled trial on the incidence and predictors of late-phase postoperative atrial fibrillation up to 30 days and the preventive value of biatrial pacing. Heart Rhythm. 2014;11:1156-62.

2. Lee SH, Kang DR, Uhm JS, Shim J, Sung JH, Kim JY, Pak HN, Lee MH and Joung B. New-onset atrial fibrillation predicts long-term newly developed atrial fibrillation after coronary artery bypass graft. $\mathrm{Am}$ Heart J. 2014;167:593-600 e1.

3. Melduni RM, Schaff HV, Bailey KR, Cha SS, Ammash NM, Seward JB and Gersh BJ. Implications of newonset atrial fibrillation after cardiac surgery on long-term prognosis: a community-based study. Am Heart J. 2015;170:659-68.

4. Ahlsson A, Fengsrud E, Bodin L and Englund A. Postoperative atrial fibrillation in patients undergoing aortocoronary bypass surgery carries an eightfold risk of future atrial fibrillation and a doubled cardiovascular mortality. Eur J Cardiothorac Surg. 2010;37:1353-9.

5. Villareal RP, Hariharan R, Liu BC, Kar B, Lee VV, Elayda M, Lopez JA, Rasekh A, Wilson JM and Massumi A. Postoperative atrial fibrillation and mortality after coronary artery bypass surgery. I Am Coll Cardiol. 2004;43:742-8.

6. Bramer S, van Straten AH, Soliman Hamad MA, van den Broek KC, Maessen JG and Berreklouw E. Newonset postoperative atrial fibrillation predicts late mortality after mitral valve surgery. Ann Thorac Surg. 2011;92:2091-6.

7. Mariscalco G, Klersy C, Zanobini M, Banach M, Ferrarese S, Borsani P, Cantore C, Biglioli P and Sala A. Atrial fibrillation after isolated coronary surgery affects late survival. Circulation. 2008;118:1612-8.

8. El-Chami MF, Kilgo P, Thourani V, Lattouf OM, Delurgio DB, Guyton RA, Leon AR and Puskas JD. Newonset atrial fibrillation predicts long-term mortality after coronary artery bypass graft. J Am Coll Cardiol. 2010;55:1370-6

9. Gialdini G, Nearing K, Bhave PD, Bonuccelli U, ladecola C, Healey IS and Kamel H. Perioperative atrial fibrillation and the long-term risk of ischemic stroke. JAMA. 2014;312:616-22.

10. Bidar E, Bramer S, Maesen B, Maessen JG and Schotten U. Postoperative Atrial Fibrillation Pathophysiology, Treatment and Prevention. J Atr Fibrillation. 2013;5:781.

11. Mathew JP, Fontes ML, Tudor IC, Ramsay J, Duke P, Mazer CD, Barash PG, Hsu PH, Mangano DT, Investigators of the Ischemia R, Education $\mathrm{F}$ and Multicenter Study of Perioperative Ischemia Research $\mathrm{G}$. A multicenter risk index for atrial fibrillation after cardiac surgery. JAMA. 2004;291:1720-9.

12. Zaman AG, Archbold RA, Helft G, Paul EA, Curzen NP and Mills PG. Atrial fibrillation after coronary artery bypass surgery: a model for preoperative risk stratification. Circulation. 2000;101:1403-8.

13. Chiang CE, Naditch-Brule L, Murin J, Goethals M, Inoue H, O'Neill J, Silva-Cardoso J, Zharinov O, Gamra H, Alam S, Ponikowski P, Lewalter T, Rosenqvist M and Steg PG. Distribution and risk profile of paroxysmal, persistent, and permanent atrial fibrillation in routine clinical practice: insight from the real-life global survey evaluating patients with atrial fibrillation international registry. Circ Arrhythm Electrophysiol. 2012;5:632-9.

14. de Vos CB, Pisters R, Nieuwlaat R, Prins MH, Tieleman RG, Coelen RJ, van den Heijkant AC, Allessie MA and Crijns HJ. Progression from paroxysmal to persistent atrial fibrillation clinical correlates and prognosis. J Am Coll Cardiol. 2010;55:725-31.

15. Maesen B, Nijs J, Maessen J, Allessie M and Schotten U. Post-operative atrial fibrillation: a maze of mechanisms. Europace. 2012;14:159-74.

16. Konings KT, Kirchhof $\mathrm{CJ}$, Smeets JR, Wellens HJ, Penn OC and Allessie MA. High-density mapping of electrically induced atrial fibrillation in humans. Circulation. 1994;89:1665-80.

17. Allessie MA, de Groot NM, Houben RP, Schotten U, Boersma E, Smeets JL and Crijns HJ. Electropathological substrate of long-standing persistent atrial fibrillation in patients with structural heart disease: longitudinal dissociation. Circ Arrhythm Electrophysiol. 2010;3:606-15. 
18. Zeemering S, Maesen B, Nijs J, Lau DH, Granier M, Verheule S and Schotten U. Automated quantification of atrial fibrillation complexity by probabilistic electrogram analysis and fibrillation wave reconstruction. Conf Proc IEEE Eng Med Biol Soc. 2012;2012:6357-60.

19. Krahn AD, Klein GJ, Yee R, Takle-Newhouse T and Norris C. Use of an extended monitoring strategy in patients with problematic syncope. Reveal Investigators. Circulation. 1999;99:406-10.

20. Pokushalov E, Kozlov B, Romanov A, Strelnikov A, Bayramova S, Sergeevichev D, Bogachev-Prokophiev A, Zheleznev S, Shipulin V, Lomivorotov VV, Karaskov A, Po SS and Steinberg JS. Long-Term Suppression of Atrial Fibrillation by Botulinum Toxin Injection Into Epicardial Fat Pads in Patients Undergoing Cardiac Surgery: One-Year Follow-Up of a Randomized Pilot Study. Circ Arrhythm Electrophysiol. 2015;8:133441.

21. Gillinov AM, Bagiella E, Moskowitz AJ, Raiten JM, Groh MA, Bowdish ME, Ailawadi G, Kirkwood KA, Perrault LP, Parides MK, Smith RL, 2nd, Kern JA, Dussault G, Hackmann AE, Jeffries NO, Miller MA, Taddei-Peters WC, Rose EA, Weisel RD, Williams DL, Mangusan RF, Argenziano M, Moquete EG, O'Sullivan KL, Pellerin M, Shah KJ, Gammie JS, Mayer ML, Voisine P, Gelijns AC, O'Gara PT, Mack MJ and Ctsn. Rate Control versus Rhythm Control for Atrial Fibrillation after Cardiac Surgery. N Eng/ J Med. 2016;374:1911-21.

22. Freedman B, Camm J, Calkins H, Healey JS, Rosenqvist M, Wang J, Albert CM, Anderson CS, Antoniou S, Benjamin EJ, Boriani G, Brachmann J, Brandes A, Chao TF, Conen D, Engdahl J, Fauchier L, Fitzmaurice DA, Friberg L, Gersh BJ, Gladstone DJ, Glotzer TV, Gwynne K, Hankey GJ, Harbison J, Hillis GS, Hills MT, Kamel H, Kirchhof P, Kowey PR, Krieger D, Lee VWY, Levin LA, Lip GYH, Lobban T, Lowres N, Mairesse GH, Martinez C, Neubeck L, Orchard J, Piccini JP, Poppe K, Potpara TS, Puererfellner H, Rienstra M, Sandhu RK, Schnabel RB, Siu CW, Steinhubl S, Svendsen JH, Svennberg E, Themistoclakis S, Tieleman RG, Turakhia MP, Tveit A, Uittenbogaart SB, Van Gelder IC, Verma A, Wachter R, Yan BP and Collaborators AF-S. Screening for Atrial Fibrillation: A Report of the AF-SCREEN International Collaboration. Circulation. 2017;135:1851-1867.

23. Charitos EI, Purerfellner H, Glotzer TV and Ziegler PD. Clinical classifications of atrial fibrillation poorly reflect its temporal persistence: insights from 1,195 patients continuously monitored with implantable devices. J Am Coll Cardiol. 2014;63:2840-8.

24. Kirchhof P, Benussi S, Kotecha D, Ahlsson A, Atar D, Casadei B, Castella M, Diener HC, Heidbuchel H, Hendriks J, Hindricks G, Manolis AS, Oldgren J, Popescu BA, Schotten U, Van Putte B, Vardas P, Agewall S, Camm J, Baron Esquivias G, Budts W, Carerj S, Casselman F, Coca A, De Caterina R, Deftereos S, Dobrev D, Ferro JM, Filippatos G, Fitzsimons D, Gorenek B, Guenoun M, Hohnloser SH, Kolh P, Lip GY, Manolis A, McMurray J, Ponikowski P, Rosenhek R, Ruschitzka F, Savelieva I, Sharma S, Suwalski P, Tamargo JL, Taylor CJ, Van Gelder IC, Voors AA, Windecker S, Zamorano JL and Zeppenfeld K. 2016 ESC Guidelines for the management of atrial fibrillation developed in collaboration with EACTS. Eur Heart J. 2016;37:28932962.

25. Mahajan R, Perera T, Elliott AD, Twomey DJ, Kumar S, Munwar DA, Khokhar KB, Thiyagarajah A, Middeldorp ME, Nalliah CJ, Hendriks JML, Kalman JM, Lau DH and Sanders P. Subclinical device-detected atrial fibrillation and stroke risk: a systematic review and meta-analysis. Eur Heart J. 2018.

26. Healey JS, Connolly SJ, Gold MR, Israel CW, Van Gelder IC, Capucci A, Lau CP, Fain E, Yang S, Bailleul C, Morillo CA, Carlson M, Themeles E, Kaufman ES, Hohnloser SH and Investigators A. Subclinical atrial fibrillation and the risk of stroke. N Eng/ J Med. 2012;366:120-9.

27. Benezet-Mazuecos J, Rubio JM, Cortes M, Iglesias JA, Calle S, de la Vieja JJ, Quinones MA, SanchezBorque $\mathrm{P}$, de la Cruz E, Espejo A and Farre J. Silent ischaemic brain lesions related to atrial high rate episodes in patients with cardiac implantable electronic devices. Europace. 2015;17:364-9.

28. Lim HS, Willoughby SR, Schultz C, Gan C, Alasady M, Lau DH, Leong DP, Brooks AG, Young GD, Kistler PM, Kalman JM, Worthley MI and Sanders P. Effect of atrial fibrillation on atrial thrombogenesis in humans: impact of rate and rhythm. J Am Coll Cardiol. 2013;61:852-60.

29. Van Gelder IC, Healey JS, Crijns H, Wang J, Hohnloser SH, Gold MR, Capucci A, Lau CP, Morillo CA, Hobbelt $\mathrm{AH}$, Rienstra $\mathrm{M}$ and Connolly SJ. Duration of device-detected subclinical atrial fibrillation and occurrence of stroke in ASSERT. Eur Heart J. 2017;38:1339-1344. 
30. Botto GL, Padeletti L, Santini M, Capucci A, Gulizia M, Zolezzi F, Favale S, Molon G, Ricci R, Biffi M, Russo $G$, Vimercati $M$, Corbucci $G$ and Boriani $G$. Presence and duration of atrial fibrillation detected by continuous monitoring: crucial implications for the risk of thromboembolic events. J Cardiovasc Electrophysiol. 2009;20:241-8.

31. Zacharias A, Schwann TA, Riordan CJ, Durham SJ, Shah AS and Habib RH. Obesity and risk of new-onset atrial fibrillation after cardiac surgery. Circulation. 2005;112:3247-55.

32. Goette A, Juenemann G, Peters B, Klein HU, Roessner A, Huth C and Rocken C. Determinants and consequences of atrial fibrosis in patients undergoing open heart surgery. Cardiovasc Res. 2002;54:3906.

33. Dupont E, Ko Y, Rothery S, Coppen SR, Baghai M, Haw M and Severs NJ. The gap-junctional protein connexin40 is elevated in patients susceptible to postoperative atrial fibrillation. Circulation. 2001;103:842-9.

34. Schotten $U$, Verheule S, Kirchhof P and Goette A. Pathophysiological mechanisms of atrial fibrillation: a translational appraisal. Physiol Rev. 2011;91:265-325.

35. Burstein B, Comtois P, Michael G, Nishida K, Villeneuve L, Yeh YH and Nattel S. Changes in connexin expression and the atrial fibrillation substrate in congestive heart failure. Circ Res. 2009;105:1213-22.

36. Verheule S, Tuyls $E$, van Hunnik A, Kuiper M, Schotten $U$ and Allessie M. Fibrillatory conduction in the atrial free walls of goats in persistent and permanent atrial fibrillation. Circ Arrhythm Electrophysiol. 2010;3:590-9.

37. Lee G, Kumar S, Teh A, Madry A, Spence S, Larobina M, Goldblatt J, Brown R, Atkinson V, Moten S, Morton JB, Sanders P, Kistler PM and Kalman JM. Epicardial wave mapping in human long-lasting persistent atrial fibrillation: transient rotational circuits, complex wavefronts, and disorganized activity. Eur Heart J. 2014;35:86-97.

38. de Groot NM, Houben RP, Smeets JL, Boersma E, Schotten U, Schalij MJ, Crijns H and Allessie MA. Electropathological substrate of longstanding persistent atrial fibrillation in patients with structural heart disease: epicardial breakthrough. Circulation. 2010;122:1674-82.

39. Morton JB, Sanders P, Vohra JK, Sparks PB, Morgan JG, Spence SJ, Grigg LE and Kalman JM. Effect of chronic right atrial stretch on atrial electrical remodeling in patients with an atrial septal defect. Circulation. 2003;107:1775-82.

40. Medi C, Kalman JM, Spence SJ, Teh AW, Lee G, Bader I, Kaye DM and Kistler PM. Atrial electrical and structural changes associated with longstanding hypertension in humans: implications for the substrate for atrial fibrillation. J Cardiovasc Electrophysiol. 2011;22:1317-24.

41. Chandy J, Nakai T, Lee RJ, Bellows WH, Dzankic S and Leung JM. Increases in P-wave dispersion predict postoperative atrial fibrillation after coronary artery bypass graft surgery. Anesth Analg. 2004;98:303-10, table of contents.

42. Aytemir K, Aksoyek S, Ozer N, Aslamaci S and Oto A. Atrial fibrillation after coronary artery bypass surgery: P wave signal averaged ECG, clinical and angiographic variables in risk assessment. Int J Cardiol. 1999;69:49-56

43. Steinberg JS, Zelenkofske S, Wong SC, Gelernt M, Sciacca R and Menchavez E. Value of the P-wave signalaveraged ECG for predicting atrial fibrillation after cardiac surgery. Circulation. 1993;88:2618-22.

44. Soliman EZ, Prineas RJ, Case LD, Zhang ZM and Goff DC, Jr. Ethnic distribution of ECG predictors of atrial fibrillation and its impact on understanding the ethnic distribution of ischemic stroke in the Atherosclerosis Risk in Communities (ARIC) study. Stroke. 2009;40:1204-11.

45. Potse M, Lankveld TA, Zeemering S, Dagnelie PC, Stehouwer CD, Henry RM, Linnenbank AC, Kuijpers NH and Schotten U. P-wave complexity in normal subjects and computer models. J Electrocardiol. 2016;49:545-53.

46. Hindricks G, Pokushalov E, Urban L, Taborsky M, Kuck KH, Lebedev D, Rieger G, Purerfellner H and Investigators XT. Performance of a new leadless implantable cardiac monitor in detecting and quantifying atrial fibrillation: Results of the XPECT trial. Circ Arrhythm Electrophysiol. 2010;3:141-7. 
Clinical and Electrophysiological Predictors of ILR Detected Late POAF 
Chapter 4 


\section{part II}

Importance of endo-epicardial dissociation of electrical activity for perpetuation of human atrial fibrillation 


\section{A Novel Computer Model of Endo-epicardial Electrical Dissociation and Conduction during Human Atrial Fibrillation}




\section{Abstract}

Background: Recent studies have demonstrated dissociation of electrical activity between the subepicardial layer and the endocardial bundle network frequently leading to transmural conduction (breakthrough) during experimental and human atrial fibrillation (AF). However, this phenomenon has not been studied in mathematical models.

Objective: The goal of this study was to assess the effect of epicardial fibrosis on endo-epicardial dissociation and breakthroughs during AF.

Methods: We developed a 3-dimensional model of the human atria, based on MR images and histo-anatomical studies, consisting of a thin epicardial layer and an endocardial bundle network. We studied the effect of fibrosis in the epicardial layer on endoepicardial dissociation and breakthrough. The simulation results were validated by simultaneous endo-epicardial mapping of AF in the right atrium of 4 patients with longstanding persistent AF and in 3 patients without a history of AF.

Results: In both measured and simulation data, endo-epicardial dissociation occurred that frequently resulted in breakthroughs. The AF cycle length, conduction velocity, and endo-epicardial dissociation were comparable in the mapping studies and the simulations. Fibrosis increased the average number of fibrillation waves per cycle. Endoepicardial dissociation increased from $28.4 \pm 1.52 \%$ to $57 \pm 2.62 \%$ and $60.3 \pm 2.87 \%$ $(p<0.05)$, while breakthroughs increased from $1.16 \pm 0.45$ to $3.80 \pm 1.13$ to $8.60 \pm 1.75$ in control, moderate, and severe fibrosis $(\mathrm{p}<0.05)$. In both mapping data and simulations endo-epicardial dissociation correlated with prevalence of breakthrough.

Conclusion: Using a detailed model of human atria, we successfully simulated endoepicardial dissociation resulting from increased fibrosis, culminating in breakthroughs, which emphasizes the 3-dimensional character of AF in humans.

Keywords: Atrial fibrillation, computer models, transmural conduction, endoepicardial dissociation, breakthrough waves. 


\section{Introduction}

The progression of atrial fibrillation (AF) is mediated by a complex process of ion channel remodeling and structural alterations including atrial fibrosis. ${ }^{1}$ Both processes together result in an increase in conduction block in the atrial wall resulting in narrower wavefronts and increasing dissociation of electrical activity between the epicardial layer and the endocardial bundle network. ${ }^{2-5}$ Verheule et al. demonstrated that transition from persistent to permanent $\mathrm{AF}$ in goats is characterized by an increase in endomysial fibrosis, particularly in the outer millimeter of the atrial wall, leading to loss of side to side connections in the subepicardial layer ${ }^{6}$ explaining the decline in the electrical coupling between the subepicardial layer and the endocardial bundle network. As such, increased fibrosis may contribute to dissociation of electrical activity between these two layers (endo-epicardial dissociation of electrical activity) giving rise to transmural propagation in both directions. These transmurally propagating waves become visible as "breakthroughs" and add to the overall complexity of fibrillatory conduction, and thereby to the stability of AF. ${ }^{8}$ Endo-epicardial dissociation greatly increases the effective surface area available to fibrillation waves to propagate and causes the atrial walls to behave as a 3-dimensional substrate. ${ }^{8}$

While experimental studies have demonstrated a clear association between structural remodeling, endo-epicardial dissociation of electrical activity, and breakthrough incidence, the causal role of endomysial atrial fibrosis for the occurrence of 3dimensional conduction is still not clear. ${ }^{4,6}$

We hypothesized that isolated epicardial fibrosis is sufficient to enhance dissociation and increase breakthrough incidence. To test this hypothesis, we developed a novel highly detailed computer model of the atria, which includes an epicardial layer and an endocardial bundle network based on a large variety of human imaging and anatomical studies. The epicardial layer had varying wall thickness and two to three sub-layers with different fiber orientations depending on the atrial region. ${ }^{9}$ To validate the model and the observed correlation between endo-epicardial dissociation of electrical activity and breakthrough rates, we performed simultaneous endo-epicardial high-density mapping in human right atria during cardiac surgery.

\section{Methods}

\subsection{Patient characteristics}

In total 7 patients, 4 with longstanding persistent AF (persAF) and 3 without a history of AF (sinus rhythm group, SR), were included. All patients underwent on-pump cardiac surgery through median sternotomy at Maastricht University Hospital (MUMC), Maas- 
tricht, The Netherlands. The local medical ethical committee approved this study and written informed consent was obtained from each patient.

Table 1: Patient characteristics

\begin{tabular}{lllllll}
\hline Gender & BMI & Age (years) & Operations & LA-d $(\mathrm{mm})$ & EF(\%) & Rhythm \\
\hline Male & 23,5 & 75 & AVR & 45 & 35 & persAF \\
Female & 24 & 72 & MVR & 100 & 50 & persAF \\
Male & 30 & 66 & CABG & 69 & 60 & persAF \\
Male & 26,5 & 77 & AVR & 72 & 30 & persAF \\
Male & 30 & 71 & CABG & 37 & 60 & SR \\
Male & 18,7 & 70 & CABG & 28 & 60 & SR \\
Male & 24,2 & 60 & AVR & 40 & 30 & SR \\
\hline
\end{tabular}

$\mathrm{Pt}=$ patient number; $\mathrm{AVR}=$ aortic valve replacement; $\mathrm{MVR}=$ mitral valve replacement; $\mathrm{CABG}=$ coronary artery bypass graft; $L A-d=$ left atrial diameter in $\mathrm{mm}$; $E F=$ left ventricular ejection fraction; persAF= longstanding persistent $\mathrm{AF} ; \mathrm{SR}=$ sinus rhythm.

\subsubsection{Simultaneous Endo-epicardial mapping}

Simultaneous endo-epicardial mapping of the right atrium was performed as described previously. $8,10,11$ In short, we developed a tongs-shaped mapping device (Figure 1) with both arms ending in a square plaque containing 64 unipolar electrodes $(8 \times 8$; interelectrode distance $1.5 \mathrm{~mm}$ ), directly facing each other when approximated.

\subsection{Computational model of AF}

\subsubsection{Anatomical structures in the computer model}

Magnetic resonance imaging (MRI) data of a subject with a normal atrial anatomy was used to reconstruct global atrial shape. Endocardium and epicardium were traced manually and combined into a 'myocardial envelope': a closed surface containing the atrial myocardium. Anatomical features from detailed anatomical studies were added manually to the model using Blender (The Blender Foundation, Amsterdam, The Netherlands) as a 3D editing tool. ${ }^{12-16}$ Twenty pectinate muscles (PM) in the right atrial free wall in addition to Bachmann's Bundle (BB), interatrial bundles, and the crista terminalis (CT) were added based on published anatomical descriptions. ${ }^{12,13,15}$

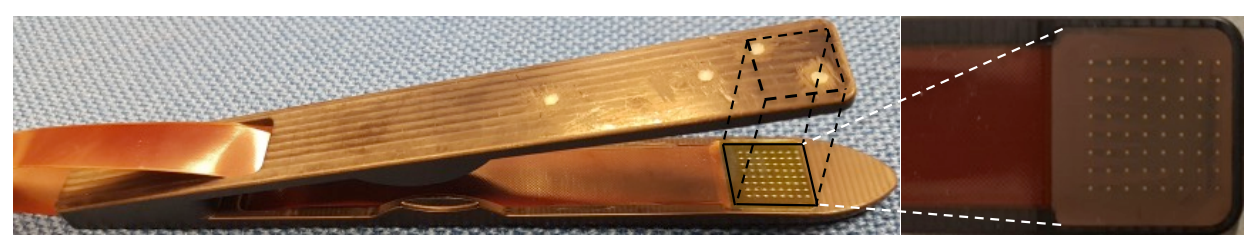

Figure 1. The Endo-epicardial electrode, the endocardial arm is designed in a convex end to facilitate insertion into the right atrium of the beating heart. Both arms contain identical plaques of $8 \times 8$ unipolar electrodes exactly opposing each other when approximated. 
As illustrated in figure 2, the model contained four pulmonary veins, caval veins, left and right atrial appendages (LAA and RAA), and a LAA trabecular network, as well as the coronary sinus. The BB connected regions between superior caval vein and RAA in the right atrium to the superior wall of the left atrium. The coronary sinus (CS) originated in the right atrium and extended along the left atrial posterior wall. A number of fiber tracts connected the CS to the posterior wall of left atrium. These connections were created based on the anatomical study performed by Chauvin et al. ${ }^{14}$ One to three layers of fiber orientations were added to the model based on several anatomical studies (see supplemental material). ${ }^{12,13}$ Comparison with results of a recently published submillimeter diffusion tensor magnetic resonance imaging study showed good agreement of the prevailing local fiber orientations in our model with human atria. ${ }^{9}$

Fibrosis was simulated by zeroing transversal conductivity in a random selection of model elements, while keeping longitudinal conductivity unaltered. It was only introduced in the epicardial layer. Two different degrees of fibrosis (moderate (50\%) and severe (70\%)) were selected, simulated, and compared with no fibrosis (i.e. all adjacent elements transversely coupled, control).

Simulations were performed with the propag-5 software ${ }^{17,18}$ and run on 2560 cores of a Cray XE6 supercomputer. Ionic currents and calcium handling for each model node was described by the Courtemanche-Ramirez-Nattel model. ${ }^{19}$

To exclude possible bias resulting from preferential conduction patterns, caused by $A F$ induction at a certain site, ten episodes of AF were initiated at different locations for each group (see supplemental materials).

\subsection{Signal processing}

In patients, electrograms lasting 30-75 seconds were recorded at a sampling rate of $1 \mathrm{kHz}$ using a band-pass filter of $0.5-500 \mathrm{~Hz}$. To detect local activation times, data were analyzed using an automated algorithm described in detail previously (see supplemental methods). ${ }^{20}$ In simulations, local activation times were calculated using maxima of positive deflections in simulated action potentials (APs) for each model node. From the local activation times obtained, we calculated the atrial fibrillation cycle length $(A F C L)$ and the local conduction velocity (CV). Fibrillation waves were defined as groups of local activations surrounded by lines of block as described previously. ${ }^{20}$ From these data, the number of fibrillation waves and the number of breakthroughs in both endocardial and epicardial layer were calculated.

\subsection{Calculation of endo-epicardial dissociation of electrical activity}

In human recordings, the electrodes on the epicardial and the endocardial planes were directly facing each other, allowing us to quantify activation time differences for each opposing electrode pair. 
To calculate the endo-epicardial activation time differences in simulations, model nodes were categorized as epicardial, endocardial or endocardial bundle. We created pairs of opposing nodes by finding the nearest epicardial node for each endocardial bundle node. In order to obtain data from computer simulations that are comparable with the clinical recordings, an array of 64 segments $(8 \times 8$ with inter-segment distance of $1.5 \mathrm{~mm}$ ) was created in the epicardial and endocardial layers. Activation times were then obtained from the model node that was nearest to each segment centre.

A)

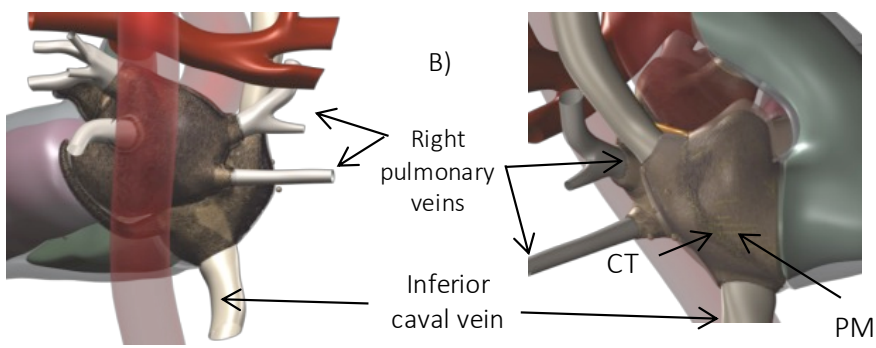

C)

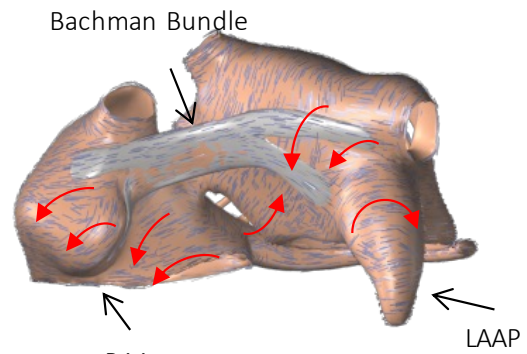

D)

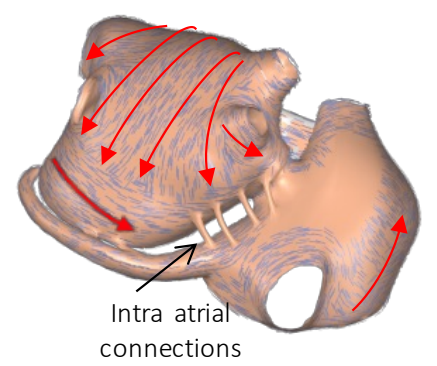

E)

RAA

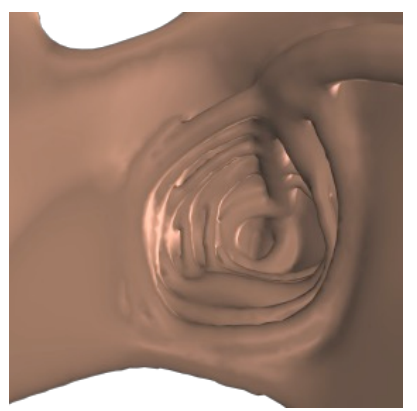

F)

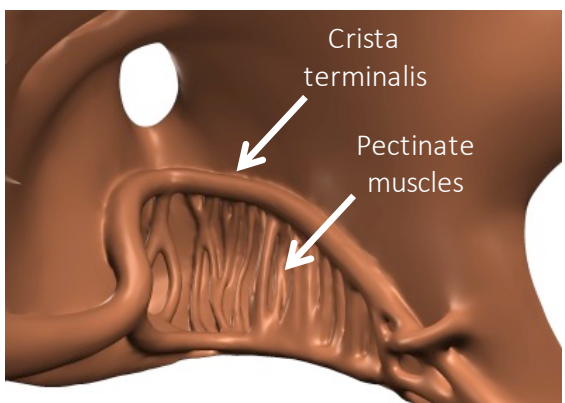

Figure 2. Anatomical model of the atria used for simulations. A) Posterior view B) Sagittal view. C) Fiber orientation in anterior view. D) LA posterior wall fiber orientations. E) Trabeculated network in LAA. F) Trabeculated network of 20 pectinate muscles in the right atrium (interior view)

The extracted activation time differences in both clinical and in-silico recordings were used to assess the degrees of endo-epicardial dissociation of electrical activity. The 
smallest activation time differences of each electrode and either the directly opposing electrode or one of the 8 electrodes surrounding the opposing electrode were considered. For the simulations, quantification was performed using the same algorithm. Endoepicardial dissociation was calculated from histograms of endo-epicardial activation time differences as previously described by Eckstein et al. ${ }^{10}$ Briefly, two distinct populations of activation time differences representing dissociated and non -dissociated activity were identified by fitting a two-component Gaussian function (for activation time differences), or a Gaussian/uniform mixture distribution (for differences in direction) to the histograms. ${ }^{10}$

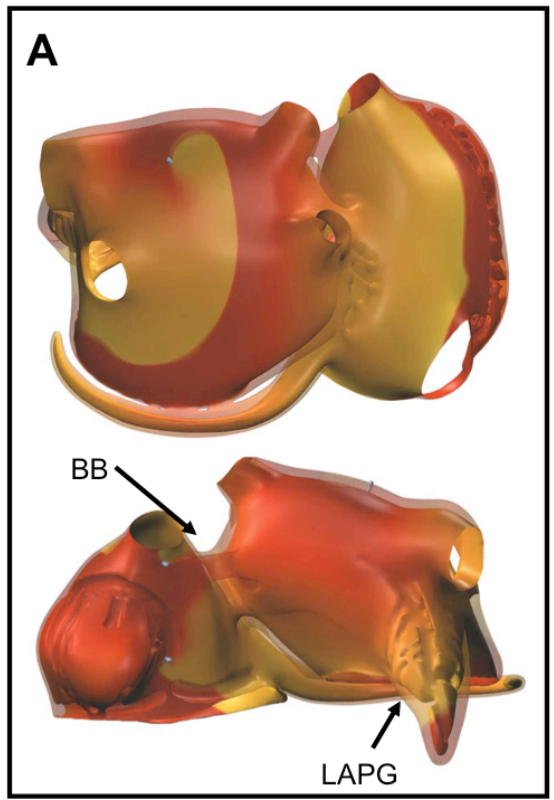

C

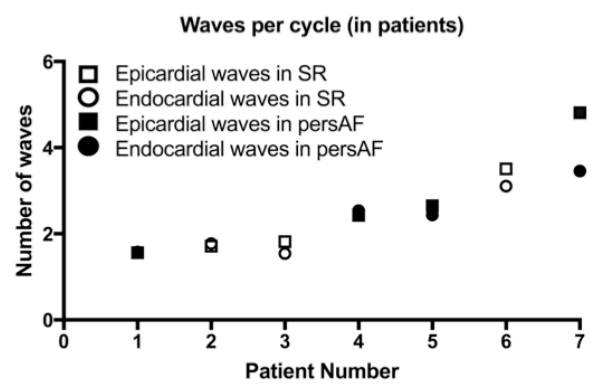

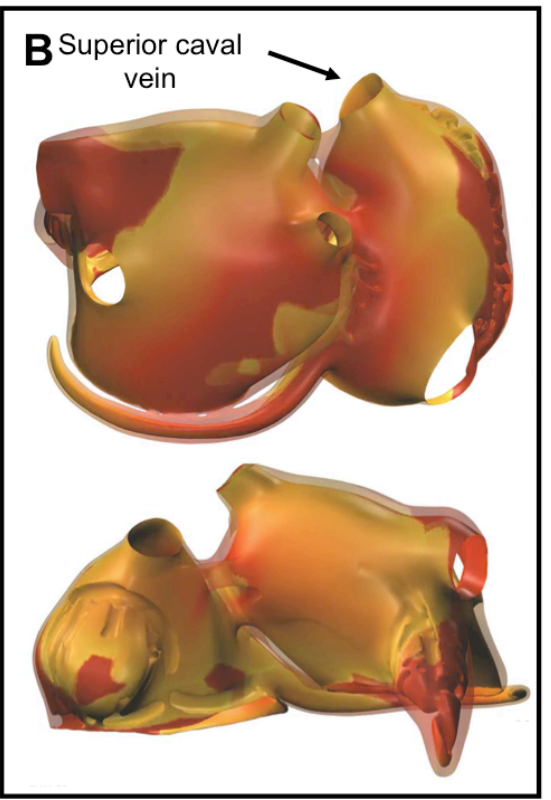

D

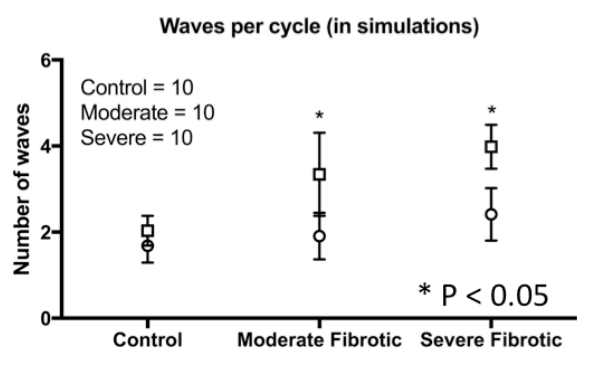

Figure 3. A) Potential map in LA and RA (control). B) Potential map in LA and RA (severe fibrosis). C) Number of waves per cycle in patients recordings ( $N=4$ for persAF patients and $N=3$ for $S R$ patients). D) Averaged number of waves in computer simulations ( $\mathrm{N}=10$ for control, Moderate Fibrotic, and Severe Fibrotic groups). 
A
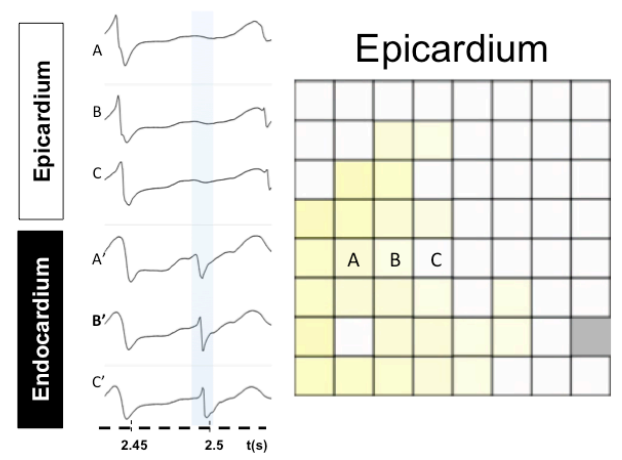

t(s)

B

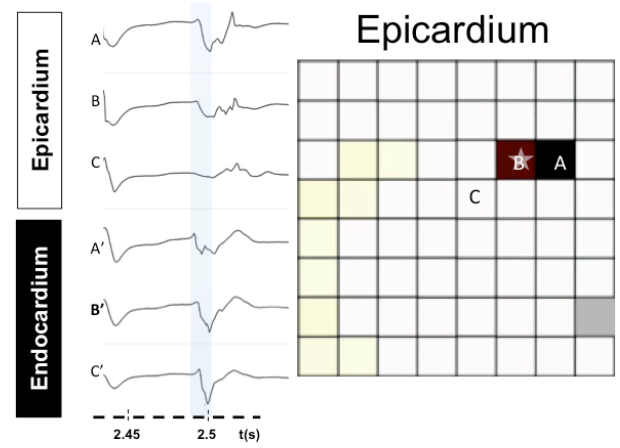

C

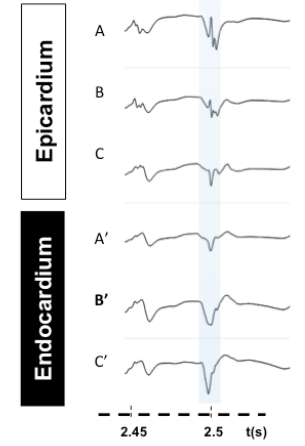

Epicardium

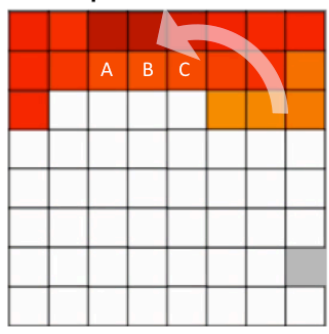

Endocardium
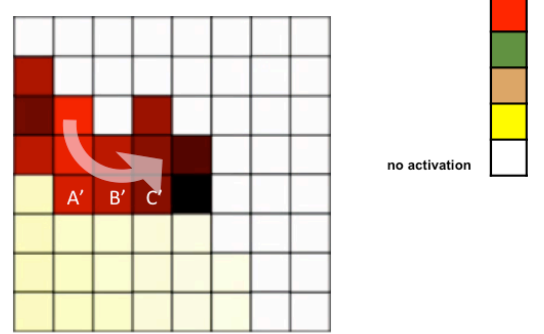

\section{$t=2,490 s$}

Endocardium

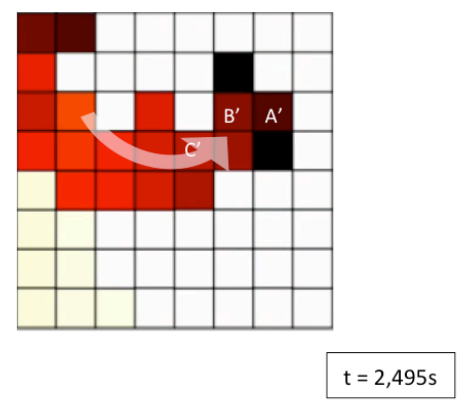

Endocardium

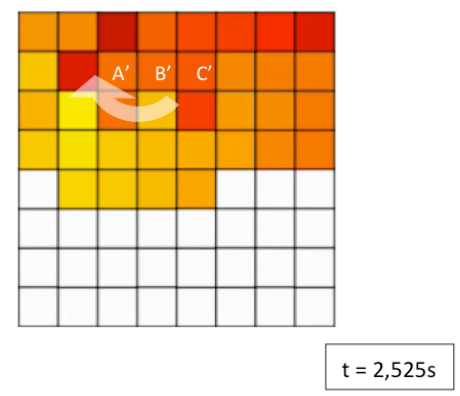

Figure 4. An example of a BT occurrence in the epicardial layer: A) A new wave enters the endocardial layer (Red) $\left(A^{\prime}, B^{\prime}, C^{\prime}\right)$. The epicardium is not activated $(A, B, C)$. The left panels show the local electrograms. $\left.B\right)$ Epicardial breakthrough (b) as a result of endo-epicardial dissociation. C) The breakthrough in the epicardial layer spreads further in an endo-epicardially synchronized manner. 


\section{Results}

\subsection{Patient characteristics}

Simultaneous high-density endo-epicardial mapping of AF was performed in 4 patients with longstanding persistent AF and 3 patients without a history of AF in whom the arrhythmia was acutely induced by rapid pacing. Patient characteristics are presented in table 1. The left atrial diameter was significantly larger in the $A F(P=0.016)$ than in the SR group. We included 13 recordings from the 7 patients, ranging between $30-75$ seconds $(38.34 \pm 15.7 \mathrm{~s})$. Conduction velocity was higher in the endocardial plane compared to the epicardium $(0.66 \pm 0.08 \mathrm{~m} / \mathrm{s}$ vs $0.58 \pm 0.06 \mathrm{~m} / \mathrm{s}$ respectively, $p=0.05)$.

\subsection{Basic AF characteristics in human mapping files and simulations}

Both endocardial and epicardial AFCL were similar in the patient recordings and simulations. The AFCL ranged between $139 \mathrm{~ms}$ to $261 \mathrm{~ms}$ in the patients $(140.3 \pm 6.14$ for SR patients and $194.3 \pm 3.7$ in persAF patients). In the simulations AFCL was $145 \pm 65 \mathrm{~ms}$, $152 \pm 3 \mathrm{~ms}$, and $197 \pm 13 \mathrm{~ms}$ in control, moderate, and severe fibrosis, respectively. The $A F C L$ in severe fibrosis was significantly longer than in control. Endocardial and epicardial CVs ranged between $50.9 \mathrm{~cm} / \mathrm{s}$ and $74.1 \mathrm{~cm} / \mathrm{s}$ in human recordings $(64.2 \pm 4.64 \mathrm{~cm} / \mathrm{s}$ for SR patients and $67.9 \pm 23.38$ for persAF patients), compared to $55.3 \pm 3.5 \mathrm{~cm} / \mathrm{s}$, $49.0 \pm 4.68 \mathrm{~cm} / \mathrm{s}$, and $42.6 \pm 1.7 \mathrm{~cm} / \mathrm{s}$ in control, moderately, and severely fibrotic simulations respectively.

\subsection{AF conduction pattern complexity}

We assessed AF conduction pattern complexity, in terms of number of fibrillation waves in both human recordings and simulations. In Figure $3 A$ and $B$, examples of fibrillation patterns in a control simulation and a severe fibrosis simulation are depicted. In the presence of fibrosis, fibrillation patterns in RA, LA anterior wall, and pulmonary veins area were more complex compared to control.

Quantitative results extracted from 7 patients and 30 simulations are illustrated in figure $3 \mathrm{C}$ and $\mathrm{D}$. The measured number of waves in both endocardium and epicardium in patients corresponded well to each other, with a trend to an increased number of waves in persAF patients compared to SR patients. The average number of waves per cycle was $2.46 \pm 1.11$ in SR patients and $3.07 \pm 0.91$ in persAF patients. The same phenomenon was observed in computational simulations, where the number of waves per cycle in the epicardium increased significantly from $2.03 \pm 0.34$ to $3.34 \pm 0.96$ and $3.98 \pm 0.51$ in control, moderately fibrotic, and severely fibrotic models, respectively. 


\subsection{Endo-epicardial dissociation in human mapping recordings and simulations}

An example of a breakthrough occurrence in the epicardial layer, using simultaneous endo-epicardial recording in a patient, is depicted in figure 4. As illustrated in this figure, a fibrillation wave (red) entered the endocardial layer $\left(A^{\prime}, B^{\prime}, C^{\prime}\right.$ in panel $A$ ) while the epicardial layer was not activated $(A, B, C)$. Five milliseconds later, a breakthrough appeared in the epicardial layer (panel B). During the next 30ms the wave spread simultaneously in the epi- and endocardial layer (panel C). An example of directly opposing electrograms in the endo- and epicardial planes of human right atrium is illustrated in figure 5 .

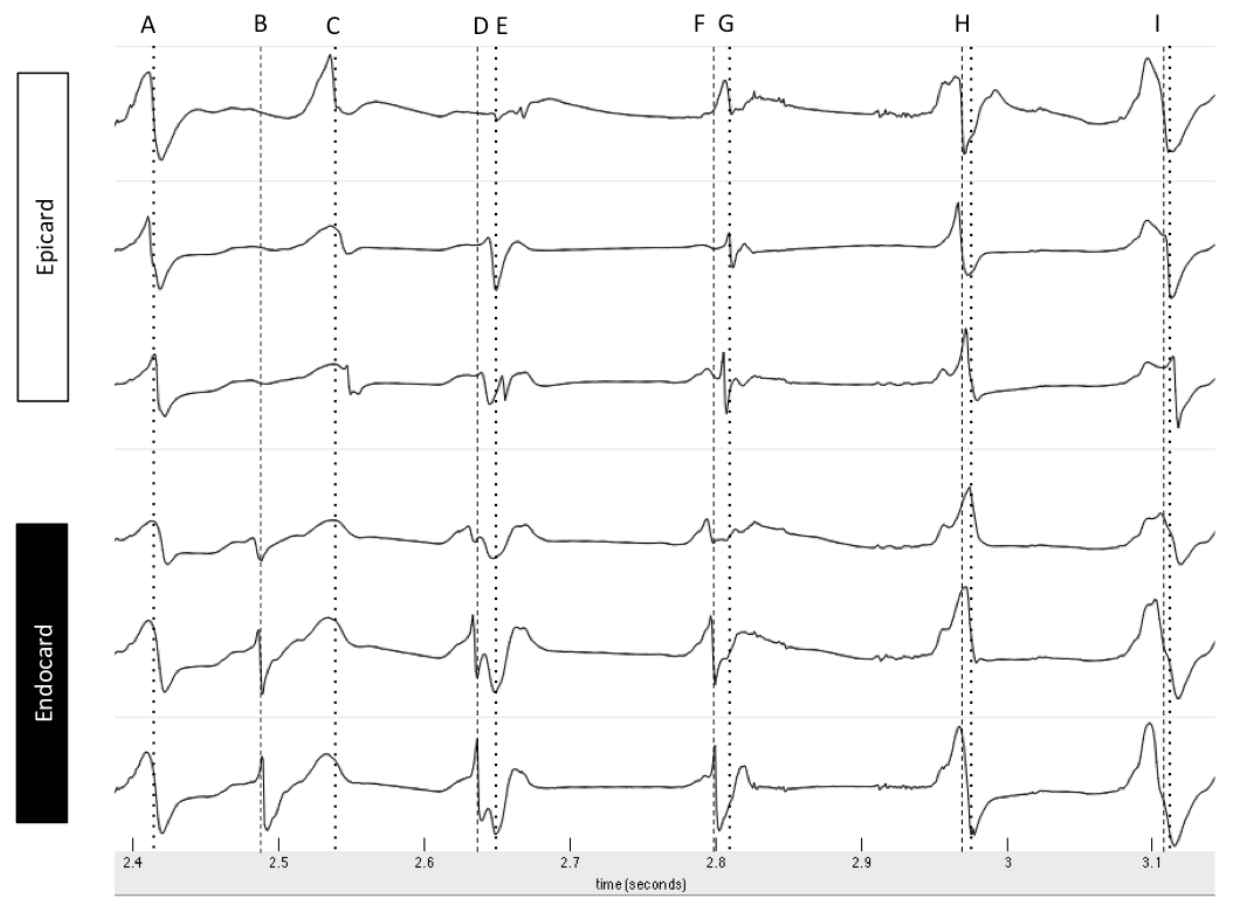

Figure 5. Simultaneous mapping of endo-epicardial layers of human right atrium during AF. Epicardial activation=dotted line, endocardial activation=dashed line. Depicted are 6 electrograms 3 on each side of the atrial wall exactly at the same time and space. While at point $\mathrm{A}, \mathrm{H}$ and $\mathrm{I}$ an almost synchronized activity was seen with earlier activation at the endocardial front, in B and $C$ endo- and epicardial activations are out of phase.

As shown in this figure, at the beginning of the recording endocardial and epicardial deflections occurred simultaneously (A) while $80 \mathrm{~ms}$ later only the endocardial recordings showed steep deflections. It is conceivable that at time point $A$ the deflections in the endocardial layer reflected far field potentials from the epicardial layer. From time point $C$ onwards the deflections occurred nearly simultaneously again in both layers. The same phenomenon was observed in simulated APs where a clear endo-epicardial 
dissociation of electrical activity preceded the breakthroughs, while the endo-epicardial electrical activity synchronized after the breakthrough (figure 6).

A
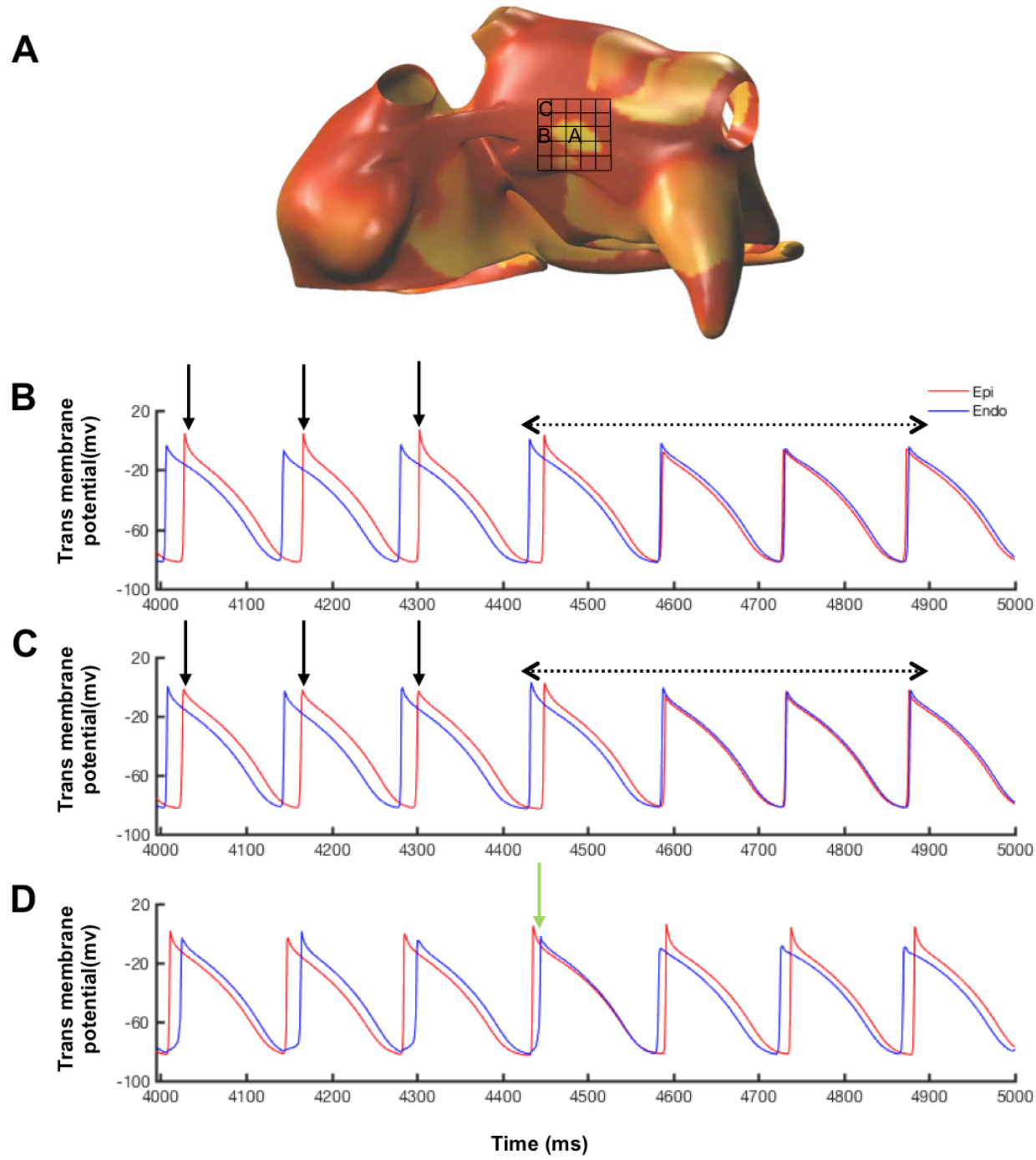

Figure 6. Simultaneous endocardial and epicardial recorded simulated action potentials during occurrence of an epicardial BT. A) An example of a BT and the location of recorded simultaneous endo-epi AP. B) Recorded simultaneous endo-epicardial APs at the center of a BT. Black arrows indicates moments of epicardial BTs occurrence (electrode A). The dotted line shows the disappearance of endo-epicardial electrical dissociation due to the occurrence of the last BT. B) Recorded simultaneous endo-epi AP at a neighboring electrode close to the BT occurrence position (electrode B). C) Recorded simultaneous endo-epi AP at an electrode further from the BT occurrence position. Green arrow shows the effect of the BT on flipping of endo-epi electrical activity dissociation (electrode $\mathrm{C}$ ). 
Histograms of activation time differences in a SR and a persistent AF patient are illustrated in figure $7 \mathrm{~A}$ and $\mathrm{B}$. For each electrode, the shortest activation time differences at the opposing 9 electrodes were considered. The same calculations were performed in the computational studies.

SR

\section{A}

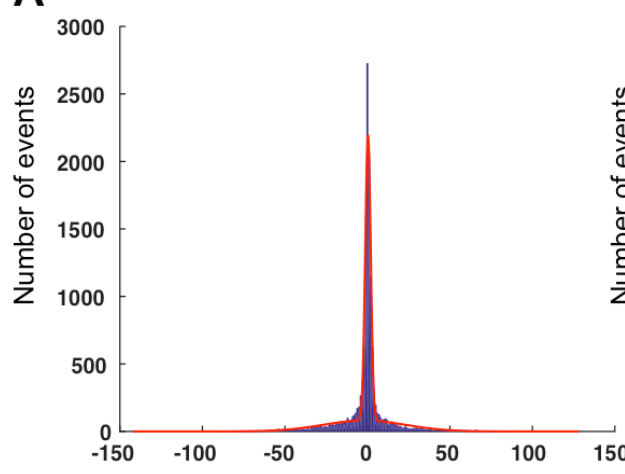

Endo-epicardial activation time difference (ms)

Control (simulation)

C

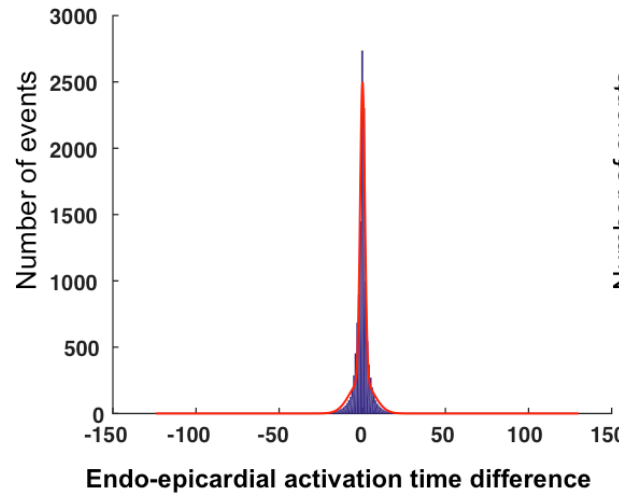

(ms)
persAF

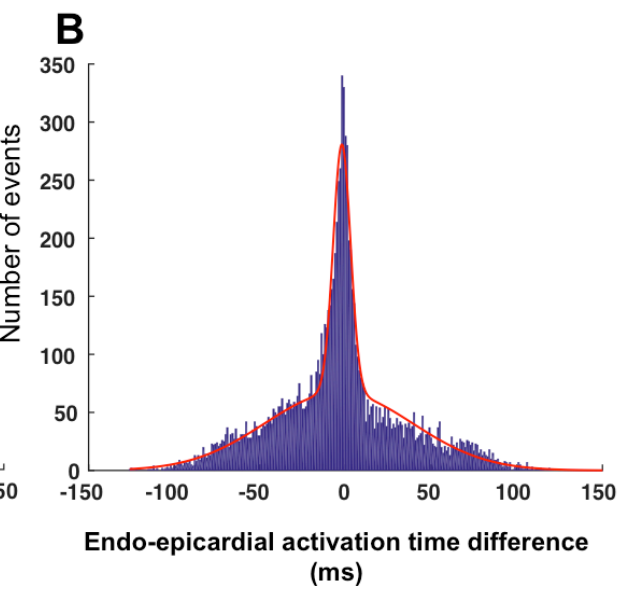

Severe Fibrotic (simulation)

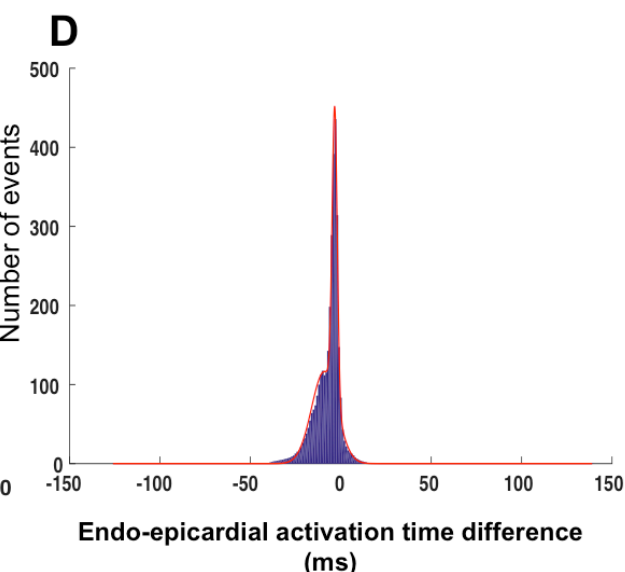

Figure 7. Activation time differences between endo and epicardial layers in patients (upper panels) and simulations (lower panels), A) A histogram of endo-epicardial activation time differences in a SR patient. B) Histogram of endo-epicardial activation time differences in a persAF patient. C) Histogram of endo-epicardial activation time differences in a control simulation. D) Histogram of endo-epicardial activation time differences in a severe fibrotic simulation. X-axis depict difference in activation time (ms) and y axis depict number of events. 
Examples of activation time difference histograms in control and simulations with severe fibrotic tissue are depicted in figure $7 C$ and $D$. Examples of simulated breakthroughs are shown in figure 8 . While most breakthroughs occurred at the location of endocardial bundles (figure $8 \mathrm{~A}$ and $\mathrm{B}$ ), some breakthroughs occurred in areas without underlying endocardial bundles (figure $8 C$ ), suggesting that isolated epicardial fibrosis is sufficient to cause endo-epicardial dissociation even within the thin epicardial surface. Figure $8 \mathrm{D}$ and $\mathrm{E}$ depict the endo-epicardial dissociation in patients and simulations, which ranged from $28.4 \pm 1.52 \%$ to $57 \pm 2.62 \%$ and $60.3 \pm 2.87 \%$ in control, moderately fibrotic, and severely fibrotic models, respectively. Both in the clinical recordings and in the simulations, the degree of endo-epicardial dissociation ranged approximately between $20 \%$ and $80 \%$. In the patients, there was a trend towards more endo-epicardial dissociation in the patients with persistent AF. In the simulations, fibrosis clearly increased the degree of endo-epicardial dissociation.

Interestingly, the increase in endo-epicardial dissociation of electrical activity was associated with an increase in the incidence of breakthroughs both in the patient data as well as in the simulations. In simulations, the average number of breakthroughs per cycle increased from $1.16 \pm 0.45$ to $3.80 \pm 1.13$ and $8.60 \pm 1.75$ in control, moderately fibrotic, and severely fibrotic models, respectively. The calculated numbers of breakthroughs per cycle in all simulation groups were higher than the breakthroughs per cycle in patients (figure 8F and G). This is due to the fact that the breakthroughs in patients' recordings were calculated only within the recording locations, whereas in simulations the whole atrial surface was considered. Both in the mapping recordings and in the simulations, there was a positive correlation between the average number of breakthroughs per cycle and the degree of endo-epicardial dissociated activity (Pearsons correlation $r=0.61$ and $p<0.05$, figure $9 A$ for the patient recordings and $r=0.72, p<0.05$ for the simulations). In the simulations, this correlation was partly driven by the differences between normal and fibrotic groups and partly driven by the differences within the 3 groups $\left(r_{1}=0.61, p<0.05\right.$ and $\left.r_{2}=0.5, p<0.05\right)$.

\section{Discussion}

To the best of our knowledge, this is the first realistic atrial model that can simulate three-dimensional electropathological changes including endo-epicardial dissociation and transmural conduction, closely resembling the human 3D substrate for AF. To implement endo-epicardial dissociation of electrical activity and transmural conduction in a realistic computer model of AF, we developed a highly detailed 3D anatomical model of the human atria. 
A
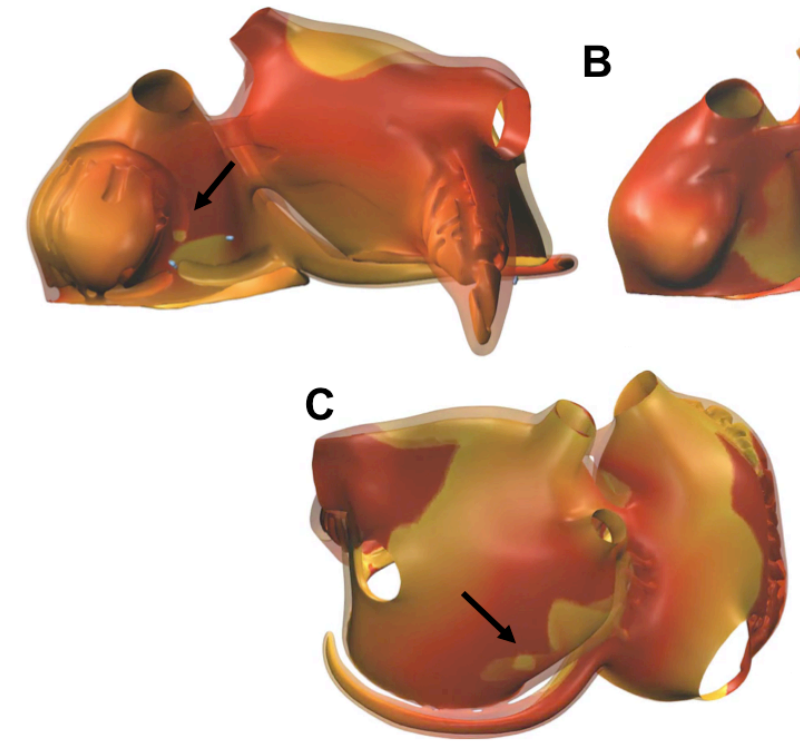

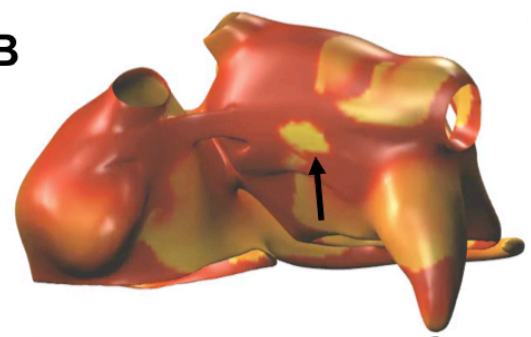

E

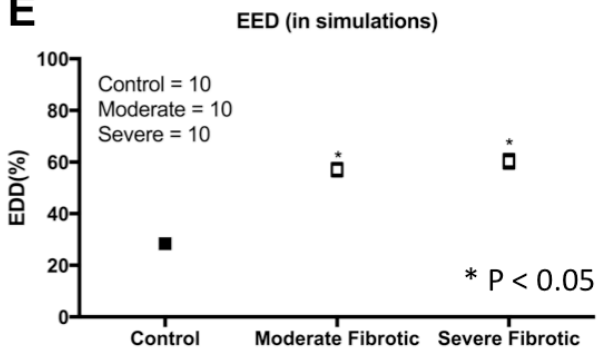

G

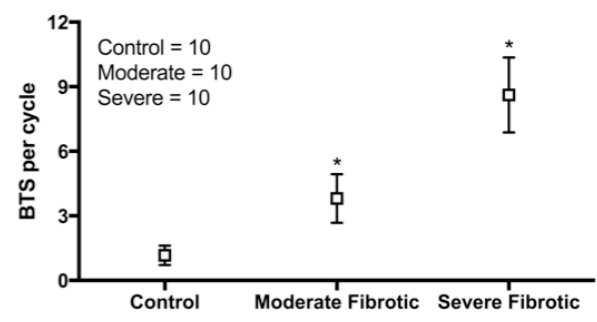

Moderate Fibrotic Severe Fibrotic

$\mathbf{F}$

BTS (in patients)

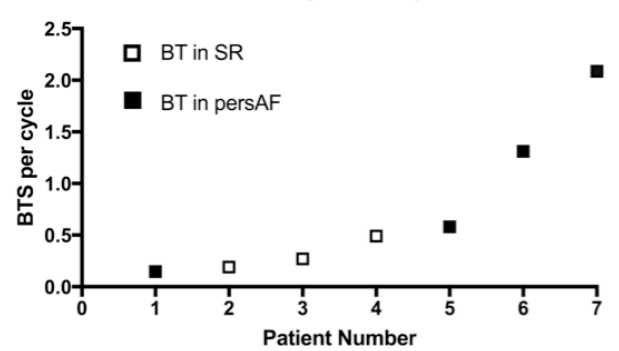

Figure 8. Examples of BTs. A) in control simulation. B) severe fibrosis. C) slight fibrosis. D) Endo-epicardial dissociation (EED) in clinical recordings. E) Endo-epicardial dissociation in simulations. F) Number of BTs per cycle in human recordings. G) Number of BTs per cycle in simulations. 
Our results derived from the new computer model resembled well the basic electrophysiological characteristics obtained from simultaneous endo-epicardial recordings in humans. Parameters such as $\mathrm{AFCL}, \mathrm{CV}$, and degree of endo-epicardial dissociation were very similar in the model as compared to the AF recordings. Importantly, the introduction of isolated atrial fibrosis in the epicardial layer resulted in an increase in endoepicardial dissociation of electrical activity and the incidence of breakthrough. Additionally, breakthroughs and endo-epicardial dissociation of electrical activity showed a good correlation in both patients and simulations. In simulations as well as in patients' recordings, breakthroughs made a significant contribution to AF complexity. These findings confirm the importance of the $3 \mathrm{D}$ electrophysiological substrate contributing to AF perpetuation.
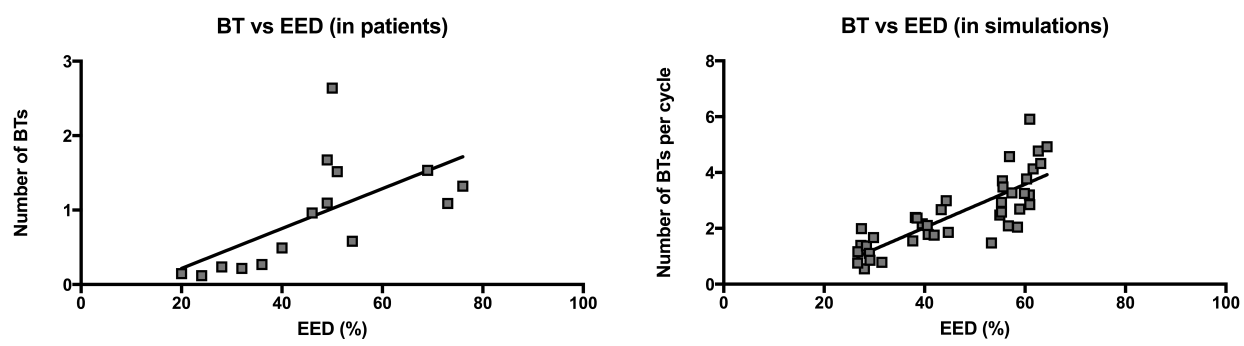

Figure 9. A)(Left) Correlation between EED and breakthrough incidence in patient recordings. Pearsons correlation $r=0,61$ for both endo and epicardial $B T, p<0,05$. B) (Right) Correlation between EED and breakthrough incidence in simulations. Pearsons correlation $r=0,72$ and $p<0.05$.

\subsection{Comparison to other computer models}

Numerous modeling studies have been performed to understand the mechanisms underlying AF. Models developed for this purpose can be divided into two categories with respect to geometrical properties. The first category consists of surface models, which treat the atria as a two-dimensional sheet folded into the shape of the atria. ${ }^{21-23}$ Models in the second category are volumetric models that incorporate a greater degree of detail on regional variation in wall thickness and fiber orientation. ${ }^{24-29}$ Models of both categories have provided valuable insights into AF mechanisms and perpetuation such as ectopy ${ }^{24}$, AP heterogeneity ${ }^{28,30}$ and fibrosis ${ }^{31}$. A few studies have investigated the effect of atrial anatomy, wall thicknesses, and endocardial bundles (modelled by higher local wall thickness) on fibrillatory patterns and AF maintenance. ${ }^{24,29,30}$ Recently, Labarthe et al. investigated the effect of transmural heterogeneities on the complex mechanisms involved during electrical propagation in the atria using a bilayer atrial model. ${ }^{32}$ However, by design, none of these models showed transmural conduction of fibrillation waves driven by endo-epicardial dissociation of electrical activity. The novelty of our 
model is that, due to the presence of the above-mentioned details, it allows us to investigate this phenomenon, and to assess the effect of structural remodeling in this context.

The global anatomy in our model was based on MRI data from a human subject with normal atrial anatomy. Many anatomical details of the atrial bundle structures such as PMs, BB, CT, posterior bundles connecting left and right atrium, CS, and bundles running beneath the LAA were added to this global anatomy based on anatomical and histological observations. ${ }^{12,} 30$ Furthermore, to investigate mechanisms that contribute to AF perpetuation more precisely, a higher level of anatomical detail, such as fiber orientation, must be integrated in the model. ${ }^{13,30}$ Indeed, the integrated fiber orientation in this model was also based on histological studies. ${ }^{9,12,13,33}$ Importantly, based on submillimeter diffusion tensor MRI, Pashakhanloo et al. reported that the main features of fiber orientations were well preserved among subjects. ${ }^{9}$ The preferential fiber directions described in this study are well reflected by our 3D model. All above-mentioned properties, included in this model, have been observed as factors determining the propagation of fibrillation waves. ${ }^{30}$

\subsection{The importance of endo-epicardial dissociation in AF}

The mechanisms underlying AF have complex dynamics and involve tight interactions across multiple temporal and spatial scales. ${ }^{34}$ Electrical remodeling, which occurs in the very early stages of $A F$, facilitates the progression from paroxysmal to permanent AF. This progression is also associated with irreversible structural remodeling such as loss of electrical side-to-side connections due to fibrosis. ${ }^{8}$ Verheule et al. showed that AFinduced structural remodeling in the goat is characterized by an increase in endomysial fibrosis exclusively in the epicardial layer of the atrium. ${ }^{6}$ This loss of connectivity can also occur between endocardial bundle networks and the epicardial layer. Therefore, it leads to endo-epicardial electrical dissociation, which is a prerequisite for transmural conduction. $^{8,10,35}$

Endo-epicardial dissociation of electrical activity has previously been described by Schuessler et al. in isolated canine right atria using simultaneous endo-epicardial mapping. ${ }^{36}$ More recently, optical mapping in isolated right atrial walls from explanted human hearts showed that intramural micro-reentry circuits may drive AF. ${ }^{37}$ Gutbrod et al., in line with our findings in the goat model ${ }^{7,10}$, showed clear evidence of endoepicardial dissociated activity and breakthrough waves in left atria in sheep, also using optical mapping. ${ }^{38}$ De Groot et al. confirmed this with direct contact endo-epicardial mapping in human right atria during cardiac surgery, with $65 \%$ of breakthrough waves explained by activation on the opposing layer. ${ }^{5}$ This is in good agreement with our findings in human right atrium where a higher degree of endo-epicardial dissociation was correlated with a larger number of breakthrough waves resulting in a 3D conduction pattern and enhanced overall complexity of $\mathrm{AF}^{8}$ 


\section{Study Limitations}

First of all, our clinical mapping data were restricted to the right atrial free wall, largely because of safety reasons. In the goat model, however, we did not observe qualitative differences in endo-epicardial dissociation of electrical activity between right and left atria and the data in this study were just used to demonstrate that the data provided by the model are quantitatively comparable to the situation in patients. Secondly, we did not implement ectopic focal discharges as drivers for AF. A previous modeling study of our group has, however, shown that the quantitative relation between endo-epicardial dissociation of electrical activity and breakthrough rate does not critically depend on whether AF is driven by reentrant mechanisms or by ectopic focal discharges. ${ }^{39}$ Finally, simultaneous endo-epicardial mapping would be desirable in a larger number of patients to establish differences in the degree of endo-epicardial dissociation between patients with and without a history of AF.

\section{Conclusion}

We created a novel computer model for AF by implementing an epicardial layer and endocardial bundle network with realistic assumptions on fiber directions based on histological studies and recent MRI studies on the submillimeter level. Simultaneous high-density endo-epicardial mapping in patients with AF confirmed the validity of the main quantitative characteristics of AF and endo-epicardial dissociation during AF in this model. Modeling results showed that isolated epicardial fibrosis is sufficient to explain increasing endo-epicardial dissociation of electrical activity and breakthrough incidence in complex substrate for AF.

\section{Clinical Relevance}

Our findings may have major clinical implications for the interpretation of mapping results to identify targets for AF ablation. Our study demonstrates that conduction patterns recorded on the epicardial or endocardial surface of the atrium does not necessarily reflect the overall conduction pattern in the atrial wall. Also, future computer models of AF will have to account for endo-epicardial dissociation and conduction, particularly when mechanisms of AF are addressed or when used for estimation of efficacy of individualized therapy. 


\section{References}

1. Schotten U, Verheule S, Kirchhof P and Goette A. Pathophysiological mechanisms of atrial fibrillation: a translational appraisal. Physiol Rev. 2011;91:265-325.

2. Verheule $S$, Tuyls E, van Hunnik A, Kuiper M, Schotten $U$ and Allessie M. Fibrillatory conduction in the atrial free walls of goats in persistent and permanent atrial fibrillation. Circ Arrhythm Electrophysiol. 2010;3:590-9.

3. de Groot NM, Houben RP, Smeets JL, Boersma E, Schotten U, Schalij MJ, Crijns H and Allessie MA. Electropathological substrate of longstanding persistent atrial fibrillation in patients with structural heart disease: epicardial breakthrough. Circulation. 2010;122:1674-82.

4. Allessie MA, de Groot NM, Houben RP, Schotten U, Boersma E, Smeets JL and Crijns HJ. Electropathological substrate of long-standing persistent atrial fibrillation in patients with structural heart disease: longitudinal dissociation. Circ Arrhythm Electrophysiol. 2010;3:606-15.

5. de Groot N, van der Does L, Yaksh A, Lanters E, Teuwen C, Knops P, van de Woestijne P, Bekkers J, Kik C, Bogers A and Allessie M. Direct Proof of Endo-Epicardial Asynchrony of the Atrial Wall During Atrial Fibrillation in Humans. Circulation Arrhythmia and electrophysiology. 2016;9.

6. Verheule S, Tuyls E, Gharaviri A, Hulsmans S, van Hunnik A, Kuiper M, Serroyen J, Zeemering S, Kuijpers $\mathrm{NH}$ and Schotten $U$. Loss of continuity in the thin epicardial layer because of endomysial fibrosis increases the complexity of atrial fibrillatory conduction. Circ Arrhythm Electrophysiol. 2013;6:202-11.

7. Eckstein J, Zeemering S, Linz D, Maesen B, Verheule S, van Hunnik A, Crijns H, Allessie MA and Schotten $U$. Transmural conduction is the predominant mechanism of breakthrough during atrial fibrillation: evidence from simultaneous endo-epicardial high-density activation mapping. Circ Arrhythm Electrophysiol. 2013;6:334-41.

8. Verheule S, Eckstein J, Linz D, Maesen B, Bidar E, Gharaviri A and Schotten U. Role of endo-epicardial dissociation of electrical activity and transmural conduction in the development of persistent atrial fibrillation. Prog Biophys Mol Biol. 2014;115:173-85.

9. Pashakhanloo F, Herzka DA, Ashikaga H, Mori S, Gai N, Bluemke DA, Trayanova NA and McVeigh ER. Myofiber Architecture of the Human Atria as Revealed by Submillimeter Diffusion Tensor Imaging. Circ Arrhythm Electrophysiol. 2016;9:e004133.

10. Eckstein J, Maesen B, Linz D, Zeemering S, van Hunnik A, Verheule S, Allessie M and Schotten U. Time course and mechanisms of endo-epicardial electrical dissociation during atrial fibrillation in the goat. Cardiovasc Res. 2011;89:816-24.

11. Kuklik P, Bidar E, Gharaviri A, Maessen J and Schotten U. Application of phase coherence in assessment of spatial alignment of electrodes during simultaneous endocardial-epicardial direct contact mapping of atrial fibrillation. Europace. 2014;16 Suppl 4:iv135-iv140.

12. Ho SY, Anderson RH and Sanchez-Quintana D. Atrial structure and fibres: morphologic bases of atrial conduction. Cardiovasc Res. 2002;54:325-36.

13. Ho SY and Sanchez-Quintana D. The importance of atrial structure and fibers. Clin Anat. 2009;22:52-63.

14. Chauvin M, Shah DC, Haissaguerre M, Marcellin L and Brechenmacher $C$. The anatomic basis of connections between the coronary sinus musculature and the left atrium in humans. Circulation. 2000;101:647-52.

15. Anderson R, Becker AE. Cardiac Anatomy: An Integrated Text and Colour Atlas. Gower Medical Publishing, London.

16. Potse M, Lankveld TA, Zeemering S, Dagnelie PC, Stehouwer CD, Henry RM, Linnenbank AC, Kuijpers NH and Schotten U. P-wave complexity in normal subjects and computer models. J Electrocardiol. 2016;49:545-53.

17. Potse M, Dube B, Richer J, Vinet A and Gulrajani RM. A comparison of monodomain and bidomain reaction-diffusion models for action potential propagation in the human heart. IEEE Trans Biomed Eng. 2006;53:2425-35. 
18. Krause D, Potse M, Dickopf T, Krause R, Auricchio A and Prinzen F. Hybrid Parallelization of a Large-Scale Heart Model. In: R. Keller, D. Kramer and J.-P. Weiss, eds. Facing the Multicore - Challenge II: Springer Berlin Heidelberg; 2012(7174): 120-132.

19. Courtemanche M, Ramirez RJ and Nattel S. Ionic mechanisms underlying human atrial action potential properties: insights from a mathematical model. Am J Physiol. 1998;275:H301-21.

20. Zeemering S, Maesen B, Nijs J, Lau DH, Granier M, Verheule S and Schotten U. Automated quantification of atrial fibrillation complexity by probabilistic electrogram analysis and fibrillation wave reconstruction. Conference proceedings: Annual International Conference of the IEEE Engineering in Medicine and Biology Society IEEE Engineering in Medicine and Biology Society Annual Conference. 2012;2012:635760 .

21. Uldry L, Virag N, Lindemans F, Vesin JM and Kappenberger L. Atrial septal pacing for the termination of atrial fibrillation: study in a biophysical model of human atria. Europace. 2012;14 Suppl 5:v112-v120.

22. Haissaguerre M, Lim KT, Jacquemet V, Rotter M, Dang L, Hocini M, Matsuo S, Knecht S, Jais P and Virag N. Atrial fibrillatory cycle length: computer simulation and potential clinical importance. Europace. 2007;9 Suppl 6:vi64-70.

23. Ruchat P, Dang L, Schlaepfer J, Virag N, von Segesser LK and Kappenberger L. Use of a biophysical model of atrial fibrillation in the interpretation of the outcome of surgical ablation procedures. Eur $J$ Cardiothorac Surg. 2007;32:90-5.

24. Aslanidi OV, Colman MA, Stott J, Dobrzynski H, Boyett MR, Holden AV and Zhang H. 3D virtual human atria: A computational platform for studying clinical atrial fibrillation. Prog Biophys Mol Biol. 2011;107:156-68.

25. Colman MA, Aslanidi OV, Kharche S, Boyett MR, Garratt C, Hancox JC and Zhang H. Pro-arrhythmogenic effects of atrial fibrillation-induced electrical remodelling: insights from the three-dimensional virtual human atria. J Physiol. 2013;591:4249-72.

26. Vigmond EJ, Ruckdeschel R and Trayanova N. Reentry in a morphologically realistic atrial model. J Cardiovasc Electrophysiol. 2001;12:1046-54.

27. Gong Y, Xie F, Stein KM, Garfinkel A, Culianu CA, Lerman BB and Christini DJ. Mechanism underlying initiation of paroxysmal atrial flutter/atrial fibrillation by ectopic foci: a simulation study. Circulation. 2007;115:2094-102.

28. Krueger MW, Severi S, Rhode K, Genovesi S, Weber FM, Vincenti A, Fabbrini P, Seemann G, Razavi R and Dossel O. Alterations of atrial electrophysiology related to hemodialysis session: insights from a multiscale computer model. J Electrocardiol. 2011;44:176-83.

29. Krueger MW, Schulze WH, Rhode KS, Razavi R, Seemann G and Dossel O. Towards personalized clinical in-silico modeling of atrial anatomy and electrophysiology. Med Biol Eng Comput. 2013;51:1251-60.

30. Tobon C, Ruiz-Villa CA, Heidenreich E, Romero L, Hornero F and Saiz J. A three-dimensional human atrial model with fiber orientation. Electrograms and arrhythmic activation patterns relationship. PLoS One. 2013;8:e50883.

31. McDowell KS, Vadakkumpadan F, Blake R, Blauer J, Plank G, MacLeod RS and Trayanova NA. Methodology for patient-specific modeling of atrial fibrosis as a substrate for atrial fibrillation. J Electrocardiol. 2012;45:640-5.

32. Labarthe S, Bayer J, Coudiere Y, Henry J, Cochet H, Jais P and Vigmond E. A bilayer model of human atria: mathematical background, construction, and assessment. Europace. 2014;16 Suppl 4:iv21-iv29.

33. Maesen B, Zeemering S, Afonso C, Eckstein J, Burton RA, van Hunnik A, Stuckey DJ, Tyler D, Maessen J, Grau V, Verheule S, Kohl P and Schotten U. Rearrangement of atrial bundle architecture and consequent changes in anisotropy of conduction constitute the 3-dimensional substrate for atrial fibrillation. Circ Arrhythm Electrophysiol. 2013;6:967-75.

34. Trayanova NA. Mathematical approaches to understanding and imaging atrial fibrillation: significance for mechanisms and management. Circulation research. 2014;114:1516-31.

35. Eckstein J and Schotten U. Rotors and breakthroughs as three-dimensional perpetuators of atrial fibrillation. Cardiovasc Res. 2012;94:8-9. 
36. Schuessler RB, Kawamoto T, Hand DE, Mitsuno M, Bromberg BI, Cox JL and Boineau JP. Simultaneous epicardial and endocardial activation sequence mapping in the isolated canine right atrium. Circulation. 1993;88:250-63.

37. Hansen BJ, Zhao J, Csepe TA, Moore BT, Li N, Jayne LA, Kalyanasundaram A, Lim P, Bratasz A, Powell KA, Simonetti OP, Higgins RS, Kilic A, Mohler PJ, Janssen PM, Weiss R, Hummel JD and Fedorov VV. Atrial fibrillation driven by micro-anatomic intramural re-entry revealed by simultaneous sub-epicardial and sub-endocardial optical mapping in explanted human hearts. European heart journal. 2015;36:2390-401.

38. Gutbrod SR, Walton R, Gilbert S, Meillet V, Jais P, Hocini M, Haissaguerre M, Dubois R, Bernus O and Efimov IR. Quantification of the transmural dynamics of atrial fibrillation by simultaneous endocardial and epicardial optical mapping in an acute sheep model. Circulation Arrhythmia and electrophysiology. 2015;8:456-65.

39. Gharaviri A, Verheule S, Eckstein J, Potse M, Kuklik P, Kuijpers NH and Schotten U. How disruption of endo-epicardial electrical connections enhances endo-epicardial conduction during atrial fibrillation. Europace. 2017;19:308-318. 


\section{Supplemental material}

\section{Simultaneous Endo-epicardial mapping in the patients}

During cardiac surgery, prior to the insertion of the venous cannula in the right atrium, the endocardial arm of the tongs-electrode was introduced into a purse-string suture.

In patients in SR, AF was induced through burst pacing by epicardial pacing wires. When AF was achieved and maintained for 30 seconds, the arms of the electrode were approximated to both sides of the atrial wall and a recording was started. By design, the electrodes were parallel at $3 \mathrm{~mm}$ distance. However, the surgeon could adjust the distance depending on the quality and amplitude of the electrogram signals.

\section{Local activation detection in patient recordings}

To detect local activation time we used automated algorithms described previously. (1) In this method, local deflections are detected after filtering out baseline drift and cancellation of ventricular far fields. Negative deflections in the electrograms were detected using a template matching procedure. Deflections representing local activations were identified by optimizing the match of the obtained intervals to the AF cycle length probability density function using a probabilistic algorithm as described previously. (1)

\section{Fiber orientations in the developed atrial model}

In the editing software, splines were drawn to define fibre orientations in different regions of the atrium. For the left atrial wall, two sets of splines were used to confer different fibre orientations on the endocardial and epicardial half of the wall. Each model element took its orientation from the nearest spline. In the right atrial wall the orientation was governed by the nearest endocardial bundle, and was made perpendicular to it, but parallel to the epicardial surface. An additional set of splines was used to confer a circumferential fiber orientation in the pulmonary and caval vein ostia. Endocardial bundles in the RA wall and LAA received a fiber orientation aligning with the bundle. The bundles consisted of myocardium to which different conduction properties could be assigned. One to three layers of fibre orientations were added to the model based on several anatomical studies. $(2,3)$

\section{Electrophysiological model for the simulations}

Simulations were performed with the propag- 5 software $(6,7)$ and run on 2560 cores of a Cray XE6 supercomputer. Electrical activity was simulated with a mono-domain reaction-diffusion equation. Simulations were performed using an atrial model at $0.2 \mathrm{~mm}$ resolution. Within the myocardial envelope, a $1 \mathrm{~mm}$ layer of myocardium was placed to represent the thin right atrial wall. A $3 \mathrm{~mm}$ layer was used for the thicker left atrium.

Ionic currents and calcium handling for each model node was described by the Courtemanche-Ramirez-Nattel model.(8) To reproduce electrical remodelling as observed in 
atrial fibrillation, conductivities for $I_{\text {to, }} I_{\text {cal }}$, and $I_{k 1}$ were set at $40 \%, 35 \%$, and $200 \%$ of their normal values respectively. (9)

\section{AF initiation}

To initiate $A F$, a single pacing site in combination with an associated temporary block line was used (Figure 1). Ten episodes of AF were initiated at different locations for each group.

A

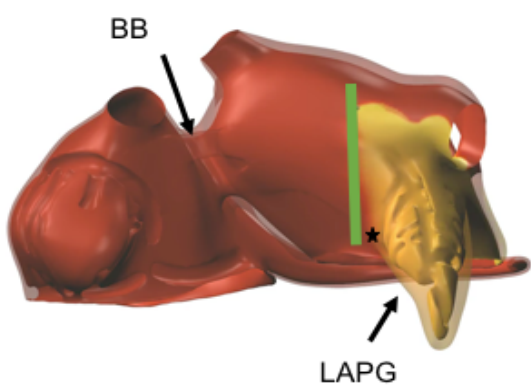

C

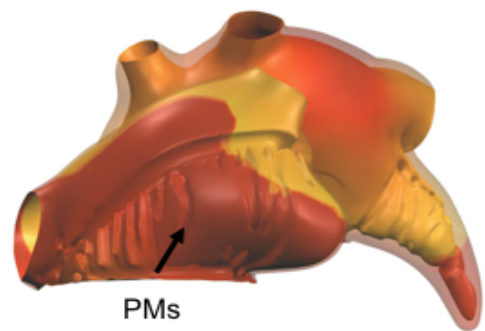

B Superior caval

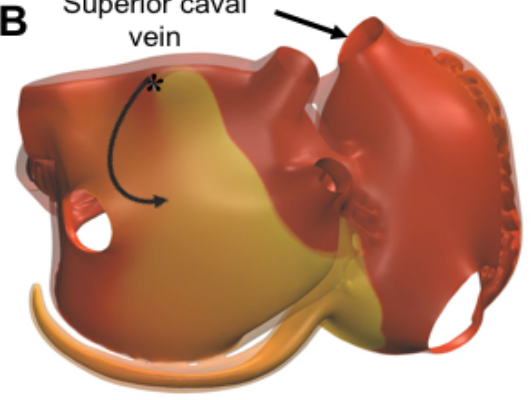

D

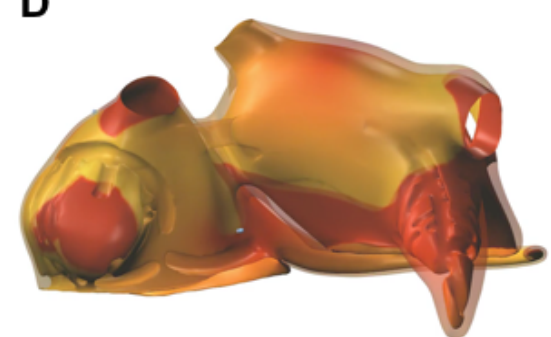

Figure S2. AF initiation. A) An Example of a spiral wave initiation. Pacing point (black star) and temporary line of block (green line). B) Initiated spiral wave (black asteriks) and its trajectory (black arrow). C) Potential map at right atrial free wall. D) Potential map at anterior view.

\section{Detection of Waves in simulations}

A wave was defined as a contiguous area in which all nodes have trans-membrane voltages above a threshold of $-60 \mathrm{mV}$. The number of waves was calculated at each millisecond of simulated time.

\section{Detection of Breakthroughs in the simulations}

A breakthrough (BT) was defined as a wave that appears in the epicardial layer or the endocardial bundle network and cannot be related to the propagation of other waves in that layer. To detect BTs, wave sizes at each time step were calculated. If a wave smaller than a threshold ( 9 nodes in this study) appeared within the opposing layer and this wave had an overlap with a wave in endocardial layer, this was considered as a BT candidate. Each BT candidate was monitored and if its size increased in twofold, it was confirmed as a BT. 


\section{Statistics}

All human data are expressed as means with standard errors ( \pm SE). We used a mixed model analysis (SPSS 20.0) to test for differences between wave characteristics in the endo- and epicardial planes in AF and SR groups.

For the 3D model, all statistical analyses were performed using SPSS software (IBM Corp. Released 2013). Statistical tests were performed to compare the 3 groups of simulations (control, moderate, and severe fibrosis). The average number of waves, breakthroughs, and EED percentage during the whole simulation period were calculated for each individual simulation. The results of the 3 groups were compared using oneway ANOVA with a Bonferroni correction. 


\section{References:}

1. Zeemering S, Maesen B, Nijs J, Lau DH, Granier M, Verheule S, Schotten U. Automated quantification of atrial fibrillation complexity by probabilistic electrogram analysis and fibrillation wave reconstruction. Conf Proc IEEE Eng Med Biol Soc 2012; 2012:6357-6360.

2. Ho SY, Anderson RH, Sanchez-Quintana D. Atrial structure and fibres: morphologic bases of atrial conduction. Cardiovasc Res 2002; 54(2):325-336.

3. Ho SY, Sanchez-Quintana D. The importance of atrial structure and fibers. Clin Anat 2009; 22(1):52-63.

4. Lindgren F, Rue $\mathrm{H}$, Lindstrom J. An explicit link between Gaussian fields and Gaussian Markov random fields: the stochastic partial differential equation approach. J R Stat Soc Ser B 2011;73:423-98.

5. Quaglino A, Pezzuto S, Koutsourelakis P-S, Auricchio A, Krause R. Fast uncertainty quantification of activation sequences in patient-specific cardiac electrophysiology meeting clinical time constraints. Int J Num Meth Bion Engng 2018;1-28.

6. Potse M, Dube B, Richer J, Vinet A, Gulrajani RM. A comparison of monodomain and bidomain reactiondiffusion models for action potential propagation in the human heart. IEEE Trans Biomed Eng 2006; 53(12 Pt 1):2425-2435.

7. Krause D, Potse M, Dickopf T, Krause R, Auricchio A, Prinzen F. Hybrid Parallelization of a Large-Scale Heart Model. In: Keller R, Kramer D, Weiss J-P, eds. Facing the Multicore - Challenge II: Springer Berlin Heidelberg; 2012. p. 120-132.

8. Courtemanche M, Ramirez RJ, Nattel S. Ionic mechanisms underlying human atrial action potential properties: insights from a mathematical model. Am J Physio/ 1998; 275(1 Pt 2):H301-321.

9. Gharaviri A, Verheule S, Eckstein J, Potse M, Kuklik P, Kuijpers NH, Schotten U. How disruption of endoepicardial electrical connections enhances endo-epicardial conduction during atrial fibrillation. Europace 2016. 
Endo-Epicardial Dissociation and Conduction during AF 


\section{Application of Phase Coherence in Assessment of Spatial Alignment of Electrodes during Simultaneous Endo- epicardial Direct Contact Mapping of Atrial}

Fibrillation 


\section{Abstract}

Aims: Mapping and interpretation of wave conduction patterns recorded during simultaneous mapping of the electrical activity on both endocardial and epicardial surfaces is challenging because of the difficulty of reconstruction of reciprocal alignment of electrodes in space. Here, we suggest a method to overcome this difficulty using a concept of maximized endo-epicardial phase coherence.

Methods: Endo-epicardial mapping was performed in six humans during induced atrial fibrillation $(A F)$ in right atria using two sets of $8 \times 8$ electrode plaques. For each electrode, mean phase coherence (MPC) with all electrodes on the opposite side of the atrial wall was calculated. Localization error was defined as a distance between the directly opposing electrode and the electrode with the maximal MPC.

Results: Overall, there was a linear correlation between MPC and distance between electrodes with $R^{2}=0.34$. Localization error obtained for electrodes of the plaque in 6 patients resulted in a mean $2.3 \pm 1.9 \mathrm{~mm}$ for $25 \mathrm{~s}$ electrogram segment length. $84 \%$ of the measurements resulted in error smaller than $3.4 \mathrm{~mm}$. The duration of the recording used to compute MPC was negatively correlated with localization error, however the effect reached plateau for segment durations longer than $15 \mathrm{~s}$.

Conclusion: Application of the concept of maximized endo-epicardial phase coherence to electrograms during AF allows reconstruction of reciprocal alignment of the electrodes on the opposite side of the atrial wall. This approach may be especially useful in settings where the spatial position of endo- and epicardial electrodes for intracardiac mapping cannot otherwise be determined. 


\section{What's new?}

Phase coherence between electrograms recorded during AF decays with a distance between electrodes.

This property may be used to localize the closest electrode to an electrode with known position by calculating its coherence with remaining electrodes and locating the position of maximum coherence.

This technique may also be used to localize an electrode with respect to a set of electrodes with known positions by calculation of the relative distances between the electrodes by using phase coherence as a surrogate distance parameter.

Localization of an electrode located on other side of the atrial wall in RA during AF can be achieved with a mean error of $2.3 \pm 1.9 \mathrm{~mm}$ (recording length at least $25 \mathrm{sec}$ ). The duration of AF recordings should be at least 15 s to minimize localization error.

\section{Introduction}

Despite decades of intense research efforts, detailed mechanism of Atrial Fibrillation (AF) initiation, perpetuation and termination remain unclear ${ }^{1}$. Most of the findings revealing patterns of wave conduction perpetuating $\mathrm{AF}$ regard atrial wall as a two dimensional medium, measuring electrical activity either on epicardial or endocardial surface of the chamber. However, complexity of atrial architecture augmented by structural remodeling of the atrial wall has been demonstrated to cause dissociation of electrical activity between endocardial bundle network and epicardial layer ${ }^{2-7}$. This threedimensional complexity of electrical activity during AF requires development of novel methods of mapping and wave conduction analysis.

Simultaneous mapping of endocardial and epicardial electrical activity was already achieved in experimental setting using epicardial plaques of electrodes along with intraatrial balloon arrays ${ }^{4}$ or 'clamp like' devices comprising two plaques of electrodes for mapping of both surfaces of the atria ${ }^{3}$. The latter solution enables mapping of the wave conduction on both epicardial and endocardial surface providing information about relative spatial position of the electrodes on both sides of the atrial wall. However, requirement of the incision in order to introduce the clamp limits its experimental utility. The former approach doesn't require an incision of the atrial wall for mapping, however is limited with respect to positioning of the electrodes (location of the electrodes of the intracardiac array with respect to electrodes of epicardial plaques). This limitation makes assessment of the endo-epicardial dissociation and interpretation of the wave conduction patterns challenging. Exact spatial positioning of the electrodes could be achieved using impedance-based three-dimensional anatomical mapping systems, however their effectiveness may be limited in open chest experiment due to exposure of the heart hampering impedance measurement. Here, we suggest a simple method to 
reconstruct reciprocal spatial alignment of the electrodes during AF using a concept of maximized endo-epicardial phase coherence ${ }^{8}$.

\section{Methods}

\section{Data acquisition}

Electrical activity of endocardial and epicardial surface of atria was recorded using clamplike mapping tool (see Figure 1). The device has two jaws ending in a square plaque $(1.5 \times 1.5 \mathrm{~cm})$ carrying $64(8 \times 8)$ unipolar electrodes that directly oppose each other when the device is closed. Using this device, we conducted simultaneous endo-epicardial mapping of the right atrial wall in 6 patients with persistent AF undergoing open chest surgery. Prior to the insertion of the venous cannula for the cardiopulmonary bypass in the right atrial appendage, the endocardial jaw of the electrode was introduced into the purse-string suture that was placed for the venous cannula. By design, the electrode arrays were parallel to each other at a $3 \mathrm{~mm}$ distance between the arrays. However, the surgeon was able to adjust the distance guided by the quality and amplitude of the electrograms. In the beating heart, a 25 -second endo-epicardial recording was made before the electrode was extracted and the venous cannula was inserted for cardiopulmonary bypass. Unipolar electrograms were recorded at $1 \mathrm{kHz}$ sampling rate, band-pass filtered between 0.1 and $500 \mathrm{~Hz}$, digitized and stored for off-line analysis.

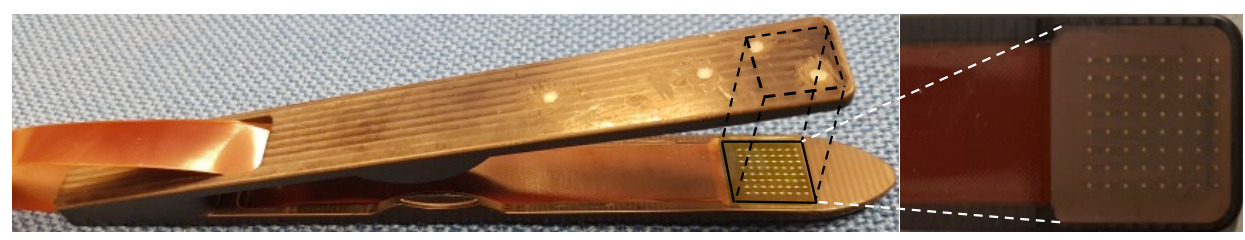

Figure 1 Clamp-like mapping device used in the study to simultaneously map both endocardial and epicardial electrical activity of the atria during AF.

\section{Calculation of electrograms phase}

Electrograms phase of was obtained using a concept of sinusoidal recomposition (see online Appendix A) followed by Hilbert transform. Phase of the electrogram was defined as:

$$
\varphi(t)=\arctan \left(\frac{-u(t)}{H(u)(t)}\right)
$$

where $\mathrm{u}(\mathrm{t})$ is recomposed electrogram and $\mathrm{H}(\mathrm{u})(\mathrm{t})$ is a recomposed electrogram after application of Hilbert transform. 


\section{Assessment of coherence of two electrograms using a concept of mean phase} coherence

Mean phase coherence (MPC) ${ }^{8}$ between an electrogram at position (i,j) on endocardial surface and electrogram at position $(m, n)$ on epicardial surfaces was defined as:

$$
M P C=\left|\frac{1}{T} \sum_{t=1}^{T} e^{j\left(\varphi_{i, j}^{E n d o}(t)-\varphi_{m, n}^{E p i}(t)\right)}\right|
$$

where $t$ is a time index, $\mathrm{T}$ is a number of time samples of the electrogram, $\phi_{i, j}^{\text {Endo }}(t)$ is a phase of the electrogram on endocardial surface and $\phi_{m, n}^{E p i}(t)$ is a phase of the corresponding electrode on epicardial surface. In a case both electrograms have identical phase in time, MPC is equal to one. In case of uncorrelated electrical activity between electrograms, MPC will be close to zero ${ }^{8}$. Schematic and an example of mean phase coherence (MPC) calculation are shown in Figure 5.

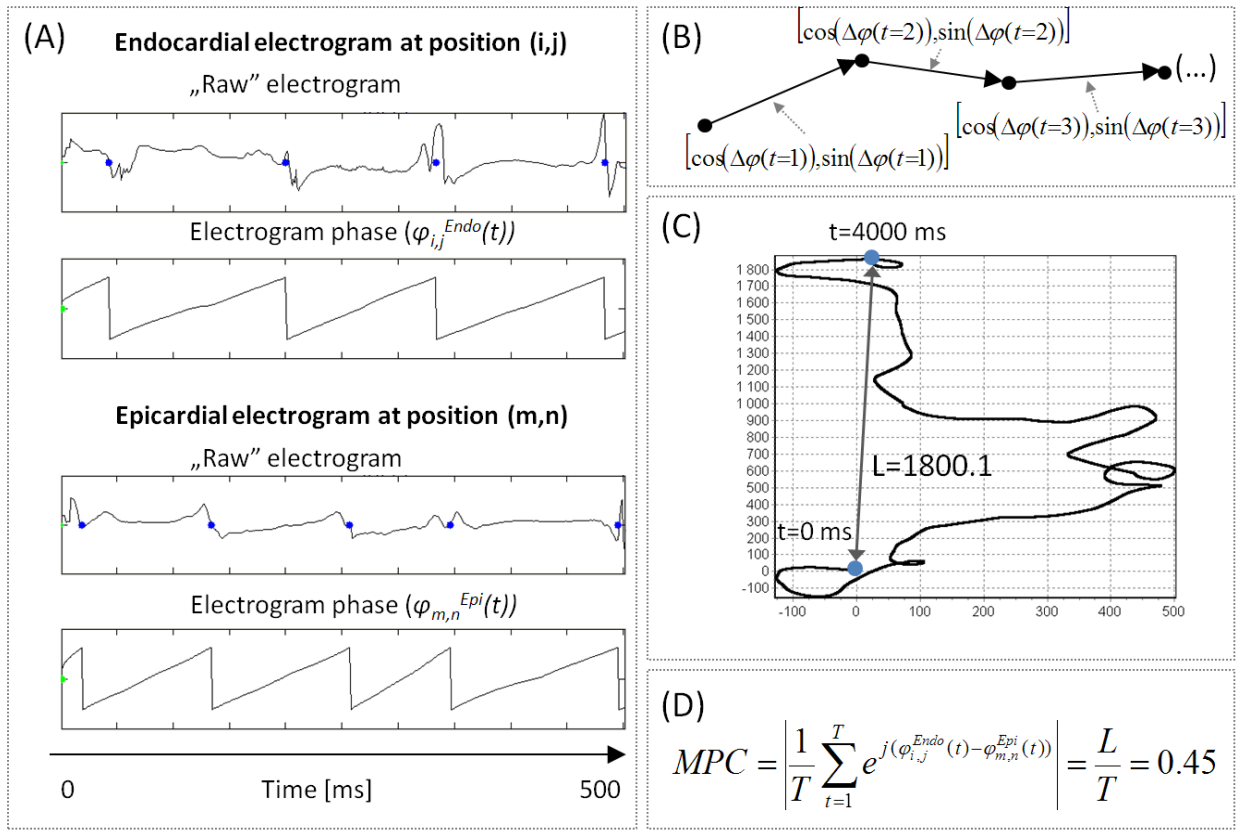

Figure 2 Schematic and an example of MPC calculation. Electrograms with corresponding phases recorded on endocardium and epicardium $(A)$. For each timepoint, a unit vector with orientation set by phase difference between both signals is added in the complex plane plot $(B)(\Delta \phi$ denotes the phase difference between electrograms at a given timepoint). Such constructed curve for $4 \mathrm{~s}$ of example electrogram (C). Mean phase coherence is defined as a distance (denoted as $L$ ) between starting point of the curve $(0,0)$ and an endpoint divided by a number of time samples $(D)$. Such defined parameter ranges from 0 if the endpoint is at the same location as a starting point, to 1 in case all contributing vectors are aligned along straight line (which corresponds with a constant phase difference) 


\section{Determination of the electrode position based on mean phase coherence}

For each electrode of the plaque, MPC was calculated between an electrogram of given electrode and all electrograms recorded at electrodes on the opposite surface. Positioning error was defined as a distance between actual position of the electrode within a plaque and the position of the maximum in obtained distribution of MPC values (see Figure 3.a).
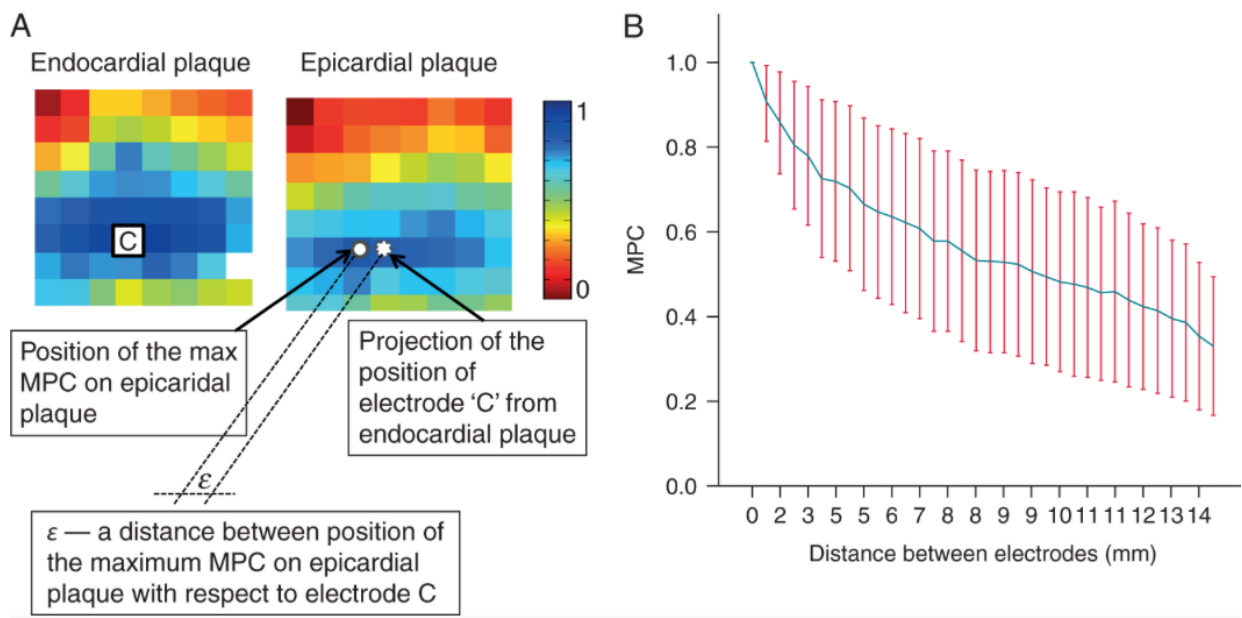

Figure $3(A)$ : Spatial distribution of mean phase coherence between arbitrarily selected electrode on endocardial plaque (marked as C). Each square corresponds with a measurement electrode. MPC decays with a distance from reference electrode C. Maximum of the MPC on epicardial plaque and projection of the electrode $\mathrm{C}$ marked with white circles. A distance between position of the maximum and position of the projected electrode is interpreted as a measurement error. (B): MPC value as a function of distance from electrode calculated or all pairs of electrodes for all patients ( $N=48140$ electrode pairs). Despite significant spread of values (error bars denote one standard deviation) MPC exhibits a decay with increasing distance between electrodes.

\section{Results}

In order to assess relationship between MPC and a distance between electrodes, MPC was calculated between all pairs of the electrodes within the plaque (with electrode pairs belonging to either endocardial or epicardial plaque). Combined result for all patients ( $N=48140$ pairs of electrodes) and length of the analyzed electrogram segment 25 sec is shown in Figure 3.b. Overall, there was a linear correlation between MPC and the distance between electrodes with $\mathrm{R}^{2}=0.34$

Mean localization error at an electrode (see Figure 3.a for definition) was defined as the distance between the electrode with the maximum endo-apicardial mean phase coherence and the directly opposing electrode. The result for each patient is shown in 
Figure 4.a (result for analyzed electrogram segment length $25 \mathrm{sec}$ ). The mean error varied between patients with lowest for patient \#5 with $\varepsilon=1.2 \pm 1.1 \mathrm{~mm}$ and highest for patient \#6 with $\varepsilon=3.8 \pm 2.0 \mathrm{~mm}$. On average, the localization error was $2.3 \pm 1.9 \mathrm{~mm}$.

The duration of the electrogram used to compute MPC was negatively correlated with localization error (see Figure 4.b). However, the effect reached plateau for segment lengths longer than $15 \mathrm{~s}$.
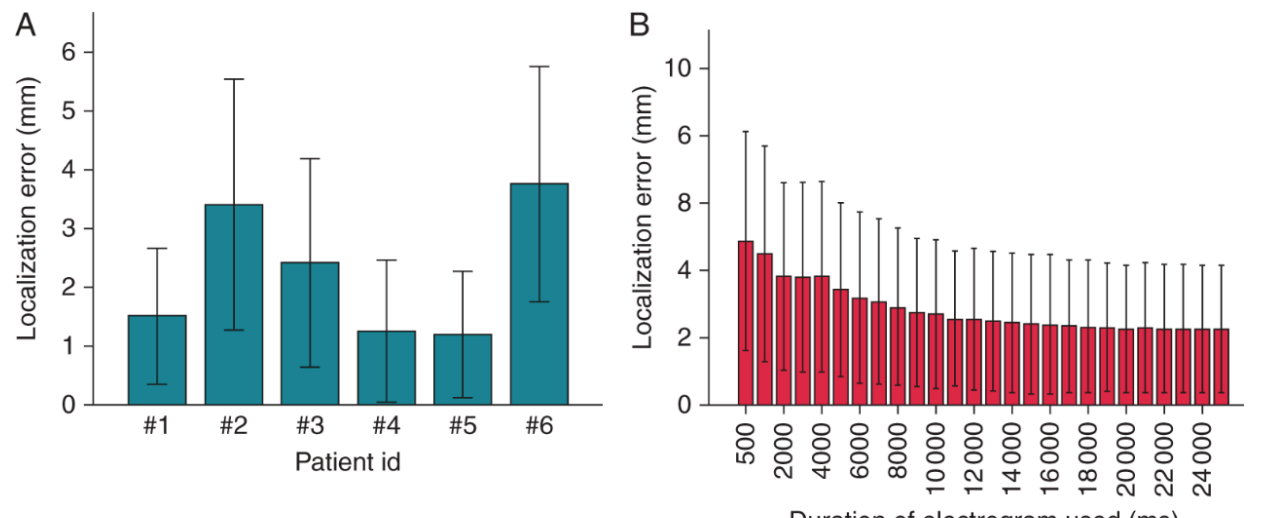

Figure $4(\mathrm{~A})$ : Electrode localization error (a distance between position of reference electrode and a maximum MPC on the other side of the atrial wall) for all 6 patients included in this study and electrogram segment length $25 \mathrm{sec}$. (B): Electrode localization error for various lengths of the analyzed electrograms segment.
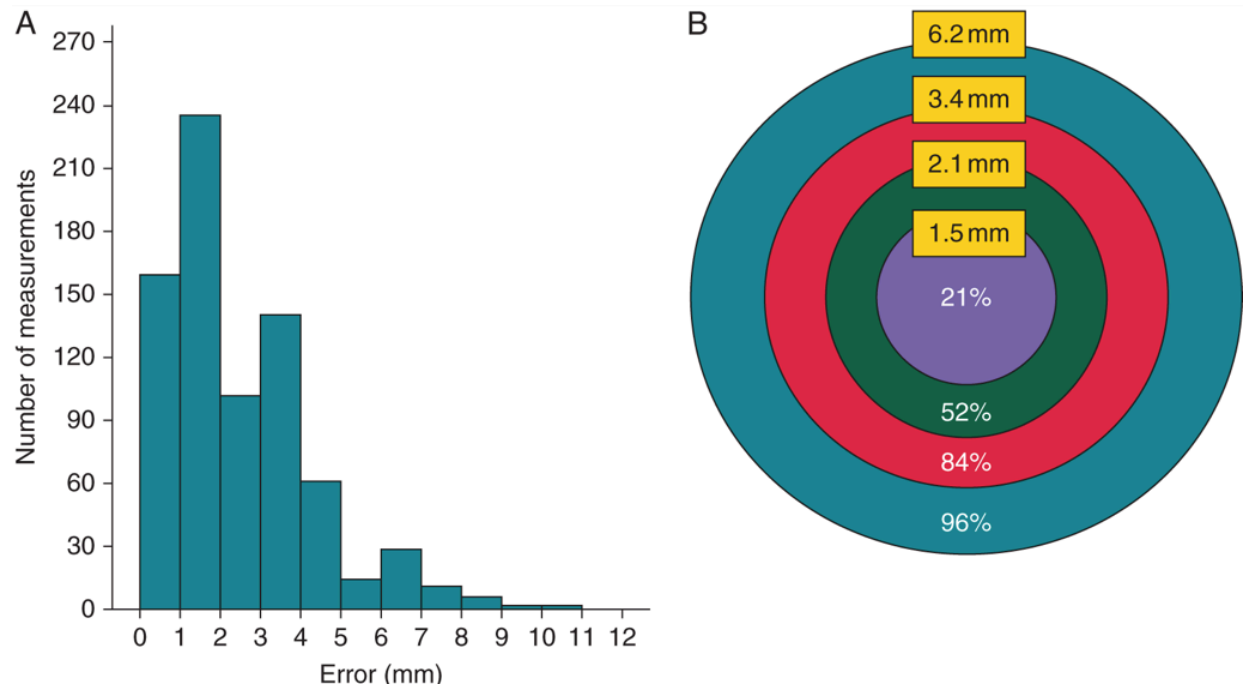

Figure 5 (A): Histogram of localization error $\varepsilon$. (B): cumulative frequency of the localization error $\varepsilon$ falling within a circles of specified radius with respect to reference electrode. In $21 \%$ percent of cases, $\varepsilon$ was be- 
tween 0-1.5 mm, in $52 \%$ of cases $\varepsilon$ was between $0-2.1 \mathrm{~mm}$, etc. Results for analyzed electrogram segment duration $25 \mathrm{~s}$.

The histogram of localization error $\varepsilon$ for all patients combined is shown in Figure 5.a. Majority of the measurements were related with error $\varepsilon<5 \mathrm{~mm}$. A schematic presenting cumulative frequency of the localization error $\varepsilon$ falling within a circles of specified radius with respect to reference electrode is shown in Figure 5.b. $84 \%$ of the measurements resulted in error smaller than $3.4 \mathrm{~mm}$.

\section{Discussion and conclusions}

The main findings of the study may be summarized as follows:

Phase coherence between electrograms recorded during AF decays with a distance between electrodes (see Figure 3.b).

This property may be used to localize the closest electrode to an electrode with known position by calculating its coherence with remaining electrodes and locating the position of maximum coherence.

This technique may also be used to localize an electrode with respect to a set of electrodes with known positions by calculation of the relative distances between the electrodes by using phase coherence as a surrogate distance parameter.

Localization of an electrode located on other side of the atrial wall in RA during AF can be achieved with a mean error of $2.3 \pm 1.9 \mathrm{~mm}$ (recording length at least $25 \mathrm{sec}$ ).

The duration of AF recordings should be at least $15 \mathrm{~s}$ to minimize localization error.

The presented technique may be particularly useful during detailed contact mapping of the atrial electrical activity with plaques of electrodes covering the epicardial surface, and arrays of the intracardiac electrodes covering endocardial surface (such as described in ${ }^{4}$ ). This configuration might be used in an experimental setting in which endoepicardial dissociation and conduction is investigated. Also, during endo-epicardial approaches for AF ablation in hybrid electrophysiology labs this technique might prove useful to merge electrograms recording data sets recorded from various arrays of electrodes. These procedures require an open chest or at least a minimal invasive epicardial approach, making usage of 3D mapping systems or fluoroscopy to localize the electrodes difficult ${ }^{9}$. We suggest, in such setting, application of the proposed method to localize electrodes of the intracardiac catheter with respect to epicardial plaques of electrodes. Thus, for each electrode of the intracardiac catheter, the closest corresponding electrode of epicardial plaques will be located enabling proper spatial mutual positioning of the endocardial and epicardial electrodes. The relative distances between electrodes determined from the relative differences in phase coherence may further facilitate electrode alignment. 
Since proposed method is based on the decay of electrogram phase coherence with distance between electrodes, robust results may only be achieved in case of irregular atrial activity. Organized arrhythmia (such as atrial flutter) may result in lack of relationship between coherence and distance thus rendering the method inapplicable.

\section{Limitations}

This study has following limitations: (i) due to difficulty in obtaining simultaneous endoepicardial, high density recordings in human atria, electrograms were recorded only in one location in right atria. Measurements at different locations may have yield different coherence decay distributions, due to different myocardial architecture and presence of fibrosis, (ii) proposed method works best if intracardiac electrode is located in the area below epicardial plaque. In case electrode is located in a location falling into a gap between two different epicardial plaques, reconstruction of its exact positioning may require interpolation using the locations of maximum coherence on both plaques.

\section{Acknowledgments}

This work was supported by the European Network for Translational Research in AF (FP7 collaborative project EUTRAF, No 261057) and CTMM COHFAR. 


\section{References}

1. Calkins H, Kuck KH, Cappato R, Brugada J, Camm AJ, Chen SA, Crijns HJ, Damiano RJ, Jr., Davies DW, DiMarco J, Edgerton J, Ellenbogen K, Ezekowitz MD, Haines DE, Haissaguerre M, Hindricks G, lesaka Y, Jackman W, Jalife J, Jais P, Kalman J, Keane D, Kim YH, Kirchhof P, Klein G, Kottkamp H, Kumagai K, Lindsay BD, Mansour M, Marchlinski FE, McCarthy PM, Mont JL, Morady F, Nademanee K, Nakagawa H, Natale A, Nattel S, Packer DL, Pappone C, Prystowsky E, Raviele A, Reddy V, Ruskin JN, Shemin RJ, Tsao HM, Wilber D, Heart Rhythm Society Task Force on C and Surgical Ablation of Atrial F. 2012 HRS/EHRA/ECAS expert consensus statement on catheter and surgical ablation of atrial fibrillation: recommendations for patient selection, procedural techniques, patient management and follow-up, definitions, endpoints, and research trial design: a report of the Heart Rhythm Society (HRS) Task Force on Catheter and Surgical Ablation of Atrial Fibrillation. Developed in partnership with the European Heart Rhythm Association (EHRA), a registered branch of the European Society of Cardiology (ESC) and the European Cardiac Arrhythmia Society (ECAS); and in collaboration with the American College of Cardiology (ACC), American Heart Association (AHA), the Asia Pacific Heart Rhythm Society (APHRS), and the Society of Thoracic Surgeons (STS). Endorsed by the governing bodies of the American College of Cardiology Foundation, the American Heart Association, the European Cardiac Arrhythmia Society, the European Heart Rhythm Association, the Society of Thoracic Surgeons, the Asia Pacific Heart Rhythm Society, and the Heart Rhythm Society. Heart Rhythm. 2012;9:632-696 e21.

2. Eckstein J, Maesen B, Linz D, Zeemering S, van Hunnik A, Verheule S, Allessie M and Schotten U. Time course and mechanisms of endo-epicardial electrical dissociation during atrial fibrillation in the goat. Cardiovascular research. 2011;89:816-24.

3. Eckstein J, Zeemering S, Linz D, Maesen B, Verheule S, van Hunnik A, Crijns H, Allessie MA and Schotten $U$. Transmural conduction is the predominant mechanism of breakthrough during atrial fibrillation: evidence from simultaneous endo-epicardial high-density activation mapping. Circulation Arrhythmia and electrophysiology. 2013;6:334-41.

4. Derakhchan K, Li D, Courtemanche M, Smith B, Brouillette J, Page PL and Nattel S. Method for simultaneous epicardial and endocardial mapping of in vivo canine heart: application to atrial conduction properties and arrhythmia mechanisms. Journal of cardiovascular electrophysiology. 2001;12:548-55.

5. Schuessler RB, Kawamoto T, Hand DE, Mitsuno M, Bromberg BI, Cox JL and Boineau JP. Simultaneous epicardial and endocardial activation sequence mapping in the isolated canine right atrium. Circulation. 1993;88:250-63.

6. Yamazaki M, Mironov S, Taravant C, Brec J, Vaquero LM, Bandaru K, Avula UM, Honjo H, Kodama I, Berenfeld $\mathrm{O}$ and Kalifa J. Heterogeneous atrial wall thickness and stretch promote scroll waves anchoring during atrial fibrillation. Cardiovascular research. 2012;94:48-57.

7. Everett THt, Wilson EE, Hulley GS and Olgin JE. Transmural characteristics of atrial fibrillation in canine models of structural and electrical atrial remodeling assessed by simultaneous epicardial and endocardial mapping. Heart rhythm : the official journal of the Heart Rhythm Society. 2010;7:506-17.

8. Mormann F, Lehnertz K, David P and Elger CE. Mean phase coherence as a measure for phase synchronization and its application to the EEG of epilepsy patients. Physica D. 2000;144:358-369.

9. Pison L, La Meir M, van Opstal J, Blaauw Y, Maessen J and Crijns HJ. Hybrid thoracoscopic surgical and transvenous catheter ablation of atrial fibrillation. Journal of the American College of Cardiology. 2012;60:54-61. 
Assessment of Spatial Alignment of Electrodes During Endo-Epicardial Mapping 
Chapter 6 
Chapter 7

General Discussion

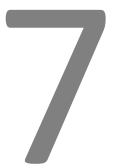

General Discussion 
Chapter 7 
In the first 3 chapters of this thesis we aimed to determine the long-term incidence of postoperative atrial fibrillation (POAF) using prolonged rhythm-monitoring strategies. We hypothesized that while the incidence of early POAF peaks during the first postoperative days following the operation, suggesting an important causative role of acute inflammatory or autonomic alterations, late POAF also occurs frequently thereafter and might be more dependent on pre-existing organ damage. To exclude confounding electrophysiological effects of AF itself we included patients without a history of AF. We found that patients with a specific risk profile show mostly subclinical AF episodes lasting up to 1.5 hours per episode in the months to years after surgery. We divided the postoperative period into an early and late phase considering enhanced effects of the acute postoperative triggers in the first days after surgery. This early phase coincides with the hospitalization period of most patients undergoing cardiac surgery, which is reflected by the follow-up period in most previous studies on POAF. However, identifying the risk profile and the underlying substrate of late POAF contributes to prediction and prevention strategies of these episodes. Thus the presence of an underlying substrate for AF and the possible range of substrate complexity in AF should be thoroughly studied (Figure 1). For this purpose, electrophysiological mapping techniques are very useful. In Chapters 5 and 6 we carried out an in-depth analysis of the effects of fibrosis on the 3-dimensional propagation properties of the atria, which is an important contributor to AF maintenance in diverse AF substrates with different co-morbidities.

It is important to recognize that there are differences in AF substrates resulting from different underlying diseases. We further tested this hypothesis by assessing the electrophysiological characteristics of POAF patients as a reflection of a preexisting atrial structural substrate.

\section{Acute postoperative triggers for POAF}

POAF is the most common complication after cardiac surgery, affecting up to $60 \%$ of patients. To fully understand the high prevalence of POAF, it is very important to consider the multitude of pro-arrhythmic mechanisms after cardiac surgery.

AF initiation and perpetuation are facilitated by a complex interplay between triggers and an underlying structural substrate. ${ }^{1-3}$ In other words there are specific proarrhythmic areas in the atria causing focal discharges (triggers), while structural changes influencing impulse propagation may perpetuate AF (substrate). While triggers can initiate an AF episode, the AF substrate determines the stability and duration of an AF episode after initiation. In structurally normal atria, a single trigger is likely to cause only a short AF episode, and maintenance of AF requires a high frequency of triggering events. In contrast, in atria with extensive structural remodelling, a single ectopic beat can initiate an AF episode that does not terminate spontaneously, ${ }^{4}$ because it is maintained by the AF substrate. 


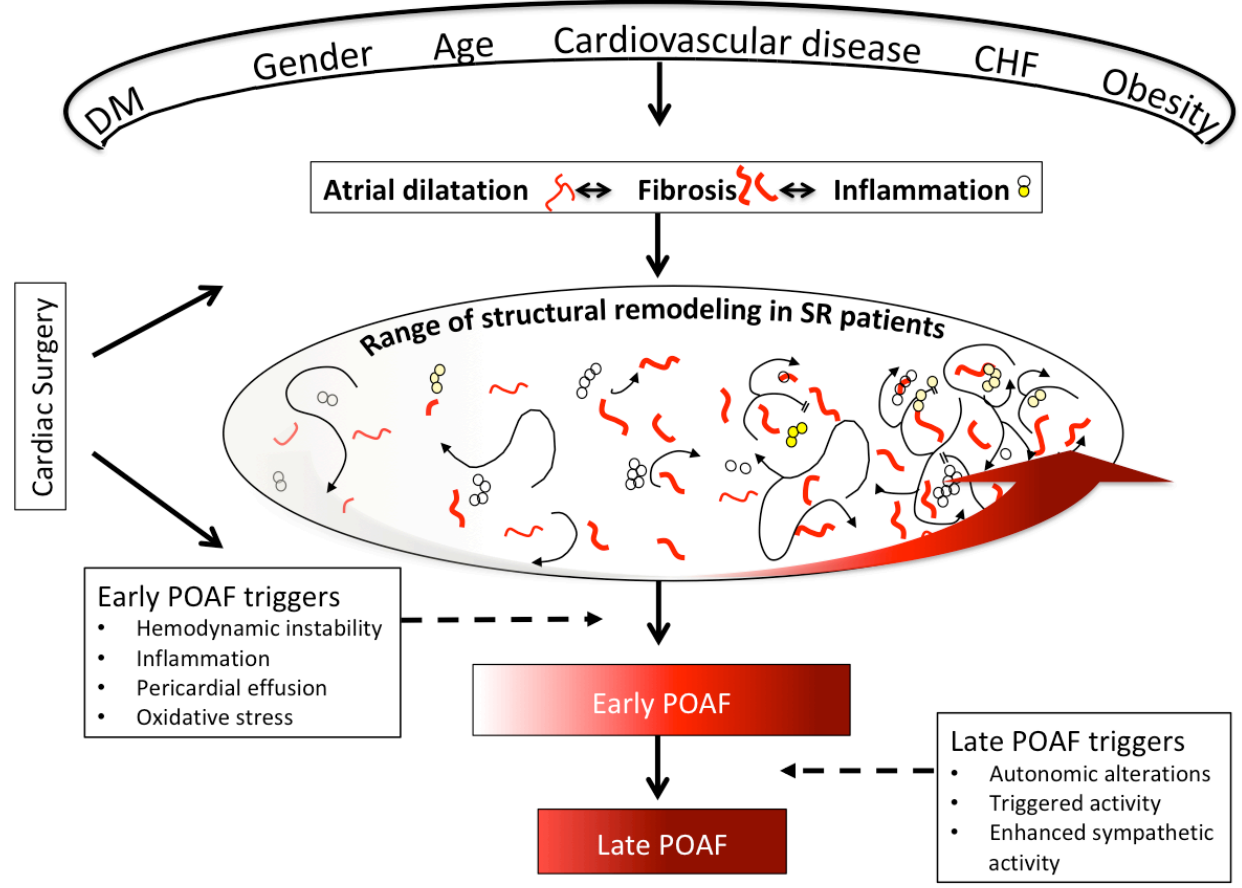

Figure 1. Schematic depiction of the pathophysiology of early and late POAF, effect of co-morbidities on development of a structural and electrophysiological substrate (curved arrows) for POAF and the subsequent triggers in the acute postoperative phase and later on. DM: diabetes mellitus; CHF: congestive heart failure; POAF: postoperative atrial fibrillation; SR: sinus rhythm.

The triggers for AF often originate in specific regions, most notably the muscular sleeves of the pulmonary veins, but also the ligament of Marshall, the coronary sinus, and the ostia of the caval veins. These regions may have specific pro-arrhythmic characteristics (i.e. differences in cellular electrophysiology, autonomic ganglia, overlapping and complex myofiber orientation), ${ }^{1,5-7}$ but the mechanism underlying ectopic activity (i.e. triggered activity vs. micro reentry) is not certain. Triggered activity often results from calcium $\left(\mathrm{Ca}^{2+}\right)$ oscillations. Calcium overload or abnormal $\mathrm{Ca}^{2+}$ handling causes these oscillations, which are mediated by $\mathrm{Ca}^{2+}$-induced-Ca ${ }^{2+}$ release from the sarcoplasmic reticulum and lead to delayed after depolarisations (DADs) after a normal action potential as a result of activity of the sodium-calcium exchanger (NCX). ${ }^{8}$ Specific conditions increasing the likelihood of these events are enhanced sympathetic activity, tachycardia and ischemia. ${ }^{1,4,8}$ Furthermore pericarditis, ${ }^{9}$ acute atrial stretch and oxidative stress ${ }^{10}$ can all cause abnormalities in $\mathrm{Ca}^{2+}$ handling that may provoke afterdepolarisations.

As discussed in chapter 2, many of these conditions are present during the acute postoperative phase. Common examples include volume overload with increased right atrial pressures, which may last for days and sometimes weeks before euvolemia is achieved. Other examples are infections, pericardial effusions, systemic inflammation as 
a result of cardio-pulmonary bypass, possibly leading to hypovolemia, and proarrhythmic inotropic agents such as Dobutamine or Milrinone used to stabilize hemodynamics in the intensive care unit. Hence the first few days after cardiac surgery contain an agglomerate of triggers for AF. Notably, the incidence of arrhythmias after cardiac surgery attributable to the surgical process or postoperative period is much lower for ventricular arrhythmias than for atrial arrhythmias. This may be due to the differences in ion-channel expression between the atrium and ventricle. Expression of the inward rectifier potassium channel $I_{\mathrm{K} 1}$ for example, is 5-10 fold higher in the ventricles, which makes atrial myocytes more excitable than ventricular myocytes. ${ }^{1}$

While during the acute postoperative phase, patients are continuously under medical supervision, after discharge the effectiveness of medical treatment heavily depends on patient compliance. It is plausible that modulators increasing risk for late POAF such as heart rate variability and autonomic dysregulation ${ }^{11}$ may be enhanced in case of non-adherence of the patient to beta-blockers ${ }^{12,13}$ or other antihypertensive and antiarrhythmic drugs.

\section{Substrate for POAF}

Considering the acute postoperative phase, it is easily conceivable that early POAF may occur because the high incidence of triggers acts as 'a stress test' on the underlying AF substrate. However, we also demonstrated that POAF is not confined to the acute postoperative phase and a large number of patients are at risk of developing late POAF after discharge from the hospital. In addition, we propose that a pre-existing AF substrate predisposes patients to late POAF development. We demonstrated that predictors of POAF and late POAF include: obesity and diabetes mellitus (DM), smoking and aortic valve disease, male gender, $\mathrm{C}$-reactive protein (CRP) levels combined with myocardial infarction (chapter 3), advanced age, higher $\mathrm{CHA}_{2} \mathrm{DS}_{2} \mathrm{VASc}$ (Congestive heart failure (CHF), hypertension (HT), age, DM, sex, vascular disease) and HATCH (i.e. HT, age >75 years, transient ischemic attack/stroke, COPD, and HF) scores and right atrial dilatation (chapter 4). We also investigated the pre-existing substrate for POAF by quantifying the atrial electrical propagation during AF using direct contact high-density mapping of the right atrial wall. To examine the complexity of fibrillation in patients developing POAF, we compared our results in chapter 4 to previously published data. Figure 2 illustrates the RA waves/cycle/ $\mathrm{cm}^{2}$ in patients described in chapter 4 (i.e. patients with comorbidities, but no AF history) compared to patients undergoing Wolf-Parkinson-White ablation (i.e. no risk factors for $A F$ ) and persistent AF. ${ }^{14,15}$ As expected, due to several co-morbidities, patients undergoing cardiac surgery showed more complex fibrillation patterns compared to WPW-patients, also when they did not develop subsequent POAF (figure 2). 
Hence the range of atrial remodelling depends on the underlying co-morbidities. Predictors of late POAF are similar to those in AF patients in the general population. The Framingham study, following 2090 men and 2641 women without a history of AF, showed that independent predictors of AF after 38 years of follow-up were diabetes, $\mathrm{HT}, \mathrm{CHF}$ and valvular disease. ${ }^{16}$ Accordingly, almost $60 \%$ of incident AF in general population has been attributed to the same elevated risk factors in addition to obesity and smoking. ${ }^{17}$ Furthermore higher HATCH-scores are associated with an increased risk of new onset $A F^{18}$ and $A F$ progression. ${ }^{19}$ Indeed, aggressive management of factors such as weight, blood pressure, and lipid management, glycemic control, breathing management during sleep, smoking and alcohol cessation beneficially affect outcome as demonstrated by higher success rates of AF ablation compared to a control group. ${ }^{20}$

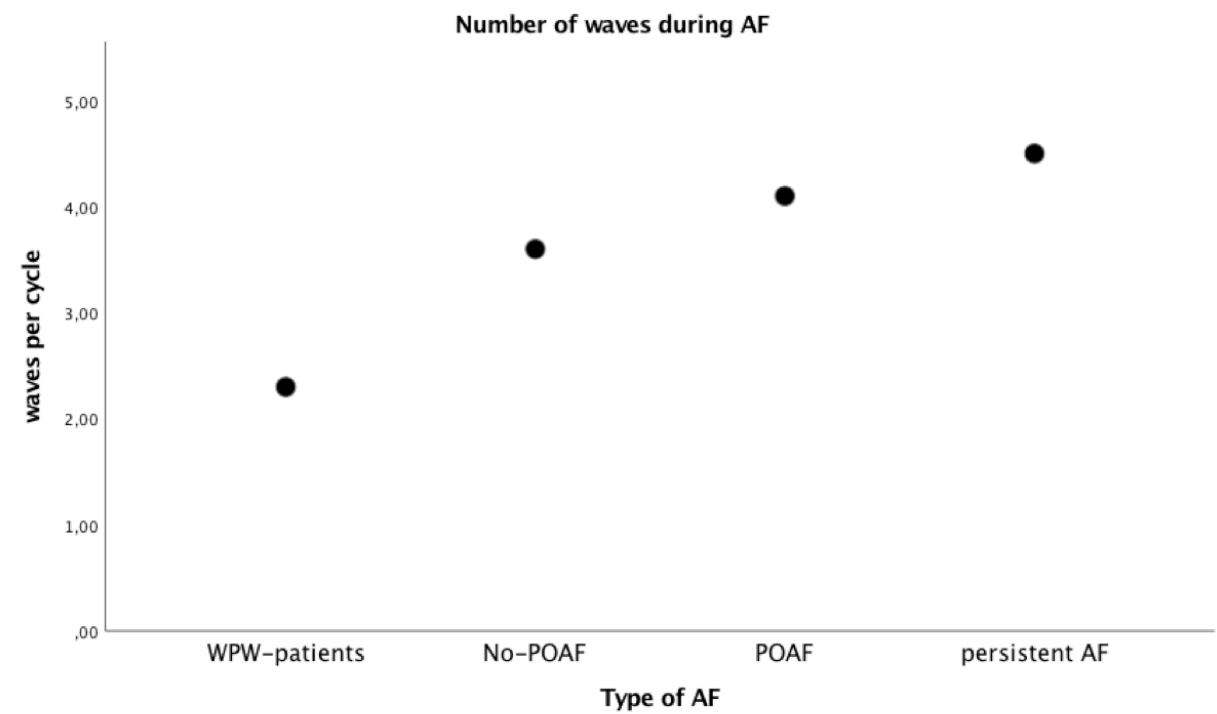

Figure 2. The median number of waves $/ \mathrm{cycle} / \mathrm{cm}^{2}$ as measured by Allessie et al. ${ }^{15}$ was 2.3 waves $/ \mathrm{cm}^{2}$ in WPW patients and 4.5 waves $/ \mathrm{cm}^{2}$ in persistent AF patients. In comparison recordings from patients with hypertension undergoing cardiac surgery showed a median of 4.1 waves $/ \mathrm{cm}^{2}$ in patients who developed POAF compared to 3.6 waves $/ \mathrm{cm}^{2}$ in those without subsequent POAF (see Chapter 4).

On the structural level, there are important proarrhythmic changes resulting from comorbidities. One key structural abnormality demonstrated in different models of AF has been increased connective tissue deposition and fibroblast proliferation leading to fibrosis. The reaction of the myocardium to stressors such as pressure or volume overload and ischemia is mediated through cardiac fibroblast activation, synthesis of extracellular matrix proteins as a protective mechanism which in its turn disrupts electrical coupling between myocytes. ${ }^{21}$ Fibrosis can display several distinct patterns. ${ }^{22}$ As an 
adaptive mechanism in response to increased stretch or wall stress due to volume or pressure overload, a type of fibrosis occurs that has been named reactive, interstitial or endomysial fibrosis, characterized by an increase in extracellular matrix volume surrounding individual myocytes. This type of fibrosis occurs in the absence of increased myocyte apoptosis or necrosis. By contrast, replacement fibrosis or scar formation occurs in response to myocyte death. In the ventricular myocardium, the exact distribution pattern of fibrous tissue strongly determines the impact on conduction. ${ }^{23}$ Accordingly patients with AF also have enhanced level of both types of fibrosis. ${ }^{21,24}$

Nevertheless the relation between AF and atrial fibrosis remains highly complex and non-linear. ${ }^{25-27}$ Perpetuation of AF is not solely determined by fibrosis; another structural abnormality that has been recognized in recent studies is fatty infiltration. ${ }^{28}$ Adipocytes intermingling with myocytes are likely to lead to a disruption of propagation similar to fibrous tissue. Many areas of fatty infiltration are also surrounded by fibrous tissue. ${ }^{29}$ In addition, adipocytes release factors that can be profibrotic, but can also be protective, for example by reducing production of reactive oxygen species in myocytes. ${ }^{30}$ Finally, mechanical stress resulting from pressure overload (concentric) and volume overload (eccentric), alongside profibrotic stimuli such as transforming growth factor (TGF)- $\beta$ and macrophage mediated inflammation all contribute to myocyte hypertrophy. ${ }^{31}$ Myocyte hypertrophy may compromise contractile function and become proarrhythmic. ${ }^{32}$

However, direct causality of diseases in AF is difficult to prove due to co-existence of morbidities, especially in the elderly population. For this purpose, animal models (discussed below) have been useful, assessing the relation between each disease and the specific structural changes at the atrial level.

\section{'Lone $A F^{\prime}$}

'Lone $A F$ ', i.e. AF without underlying structural heart disease can be mimicked in animal models by rapid atrial pacing (RAP), in which a burst pacemaker stimulates the atria at high frequency. The goat model of RAP illustrated the progressive nature of AF, as evidenced by the gradual loss of efficacy of anti-arrhythmic drugs ${ }^{33}$ paralleling observations in AF patients. During the first hours to days of RAP in goats, electrical remodeling, i.e. shortening of effective refractory period (ERP) occurs. ${ }^{34}$ In the ensuing weeks to months, atrial structural remodeling slowly develops including myocyte hypertrophy and structural changes ${ }^{35}$ hallmarked by gradual endomysial fibrosis in the outer epicardial layer of the atria. ${ }^{36}$ Electrical propagation during AF in this model is characterized by multiple simultaneously propagating wavelets. Over time, fibrillation patterns become more complex and dissociated, with a larger number of waves. We have previously demonstrated that conduction does not only become more dissociated within the epicardial plane ${ }^{36}$ but also between the epicardial layer and the underlying endocardial trabecular network. ${ }^{37}$ In the goat model of AF, endo-epicardial dissociation explains a majority of breakthrough (BT) events, i.e. waves which suddenly appear on the surface 
of one layer are conducted transmurally from the opposing layer. An increased incidence of BTs had also been described in patients with longstanding AF. ${ }^{38}$

In chapter 5, we demonstrate with simultaneous epi-endocardial mapping that epiendocardial dissociation, leading to BTs, also occurs in patients. Interestingly, while there was a clear correlation between transmural electrical uncoupling and increased BT, these changes were not observed only in persistent AF patients but also in patients without a history of AF. This further underscores the range of atrial structural remodeling resulting from underlying cardiovascular diseases. Notably, previous mathematical models of atrial propagation have not been able to replicate this behavior. ${ }^{39,}{ }^{40}$ After taking the 3-dimensional structure of the atrial wall including fiber orientation into account, we present in Chapter 5 a computer model that, for the first time, was able to demonstrate endo-epicardial dissociated activation closely related to increased BT with enhanced levels of endomysial fibrosis. Indeed, this computer model replicated the propagation pattern observed in animal models and our patient population.

\section{Heart Failure}

Heart failure (HF) is also strongly associated with AF development in patients and ${ }^{41}$ atrial fibrosis is significantly more pronounced in patients with heart failure. ${ }^{42}$ In a canine model, Li et al, compared 6-8 week of RAP (with controlled ventricular rate) to CHF induced by 5 weeks of rapid ventricular pacing (RVP). They found that in contrast to the RAP group, HF led to slow and heterogeneous conduction with pronounced atrial fibrosis. ${ }^{43}$ The pattern of fibrosis in this model suggests replacement fibrosis, and indeed, in the first days after the initiation of RVP, a dramatic phase of apoptosis, necrosis and inflammatory infiltration was observed. After cessation of ventricular pacing for 5 weeks in the same model, although recovery of clinical symptoms of heart failure and hemodynamics occurred, tissue fibrosis remained unchanged with consistently enhanced vulnerability to $\mathrm{AF}^{44}$

Interestingly, in patients with ventricular hypertrophy and diastolic heart failure due to aortic valve stenosis, a similar effect is seen. In these patients, both focal replacement fibrosis (scar) resulting from necrosis as well as cellular hypertrophy and connective tissue deposition (reactive fibrosis) are present and can be quantified by cardiovascular magnetic resonance. ${ }^{45}$ However, 1 year after aortic valve surgery, contrary to the replacement fibrosis, cellular hypertrophy and diffuse reactive fibrosis regress accompanied by functional and structural changes. ${ }^{45}$ These findings alongside the abovementioned findings from HF and AF models, suggest that reactive extracellular matrix deposition and myocyte hypertrophy are reversible while fibrosis replacing necrotic tissue remains present after treatment, as a potential substrate for AF. 


\section{Mitral regurgitation and atrial dilatation}

Atrial dilatation without $\mathrm{HF}$ is another pro-arrhythmic entity in the pathophysiology of $\mathrm{AF}$, which is common to many animal models of $\mathrm{AF}$ (e.g. RAP, CHF) and has also been examined as a separate factor in several models. In patients with atrial septal defect RA dilatation is accompanied by electrophysiological changes such as conduction slowing and double potentials in the terminal crest. ${ }^{46}$ Furthermore, in a canine model of left atrial dilatation due to mitral valve avulsion, increased atrial size correlated to AF inducibility and duration with histological findings including chronic inflammation and fibrosis. ${ }^{47}$ These structural changes were not associated with altered conduction during pacing at slow rates. However, during extra-stimulation protocols, the dilated LA displayed direction-dependent conduction abnormalities that were not observed in the non-dilated RA of the same animals, nor in either atrium of a control and RAP comparison group. ${ }^{48}$ Also in a model of AV block without HF in goats, atrial dilatation with local conduction disturbances was associated with myocyte hypertrophy. Interestingly no fibrosis or Cx re-distribution was found ${ }^{49,50}$ suggesting that in this model fibrosis was not a prerequisite for AF perpetuation.

In both MR and AV block models, atrial effective refractory period (ERP) was prolonged, which also contrasts the RAP and HF models described above. To further elucidate, Sparks et al. investigated the effects of atrio-ventricular (AV) asynchrony and consequent atrial dilatation in humans. ${ }^{51}$ They compared patients with implanted pacemakers who were first paced in VVI mode (ventricular pacing only) for 3 months followed by DDD mode (atrio-ventricular pacing) to patients who were paced in DDD mode continuously. In line with previous findings, they found that after 3 months of VVI pacing, both atria increased in size and showed prolongation of ERP and P-wave duration. ${ }^{51}$ All these changes were transient and normalized after 3 months of DDD pacing comparable to baseline and the control group. ${ }^{51}$

In this thesis, RA volume was an independent predictor of late POAF (chapter 4), which may have contributed to a substrate for AF beyond the effects of other predictors such as age and $\mathrm{CHA}_{2} \mathrm{DS}_{2} \mathrm{VASc}$ score. Interestingly, an indirect effect from the pericardium may also contribute to the right atrial dilating properties. There is a close correlation between the right atrial pressure and pericardial pressure before pericardium is opened..$^{52}$ In this sense, the pericardium is a determinant of RA contractility and stiffness as a response to RV afterload. ${ }^{53}$ In a rabbit model of passive pericardial constraint, increasing atrial volume only resulted in ERP shortening and AF perpetuation when the pericardium was removed contrary to when the pericardium was still intact, ${ }^{54}$ suggesting that atrial stretch as opposed to atrial pressure contributes to vulnerability to AF. During cardiac surgery, closing the pericardium is not always required and depends on the preference of the surgeon. Although closure of the sternum itself constraints cardiac dilatation, the direct pericardial support potentially contributes to normalizing RA function by preventing stretch. 


\section{Advanced age}

In general $\mathrm{AF}$ is known to be age-dependent ${ }^{1,3,55}$ and advanced age is one of the most important predictors of POAF, as discussed in chapters 2, 3 and 4. In animal models of aging, changes in cellular electrophysiology have been described ${ }^{56,57}$, along with a redistribution of gap junctional proteins, interstitial/ endomysial fibrosis, and fatty infiltration. ${ }^{58}$ Thus, aging can lead to an accumulation of structural changes that can lead to pro-arrhythmic propagation patterns.

\section{Hypertension}

Hypertension has also been shown to correlate with interstitial fibrosis leading to heterogeneous atrial conduction. ${ }^{59,60}$ In a sheep model of longstanding hypertension (15 months), inflammatory infiltrates in the atrial wall correlated with increased AF inducibility and interstitial fibrosis. ${ }^{59}$ Accordingly, renal denervation for uncontrolled hypertension increases atrial conduction velocity and reduces fractionated activity ${ }^{61} \mathrm{~A}$ previous study from our group suggests, however, that a protective effect of renal denervation also occurs in the absence of hypertension. ${ }^{62}$

\section{Obesity}

In a sheep model of obesity, animals were fed a high-calorie diet over 36 weeks and underwent electrophysiological and histological study. ${ }^{63}$ In this model, obesity led to left atrial enlargement, increased tissue levels of transforming growth factor- $\beta 1$ (TGF- $\beta 1$ ) with increased fibrosis and left atrial fatty infiltration and subsequent pro-arrhythmic effects with heterogeneous conduction and enhanced susceptibility to AF. ${ }^{63}$

\section{Inflammation}

Another important AF substrate modifier in the context of cardiac surgery is local and systemic inflammation. Inflammation may be pro-arrhythmic through several profibrotic cytokines and atrial structural changes. ${ }^{64}$ Increased inflammatory biomarkers such as tumornecrosis factor- $\alpha$ (TNF- $\alpha$ ) have been associated with AF and notably with lone AF. ${ }^{65}$ TNF- $\alpha$ has been shown to increase fibrosis and the profibrotic TGF- $\beta$ activity in the atrial wall. ${ }^{66}$

During cardiac surgery, spatial non-uniformity in refractoriness caused by hypoxia and oxidative stress due to insufficient cardioplegic support and insufficient cooling of the atria has been hypothesized as an important substrate for development of POAF. ${ }^{67}$ In line with this, we found prolonged aortic cross clamp time as an independent predictor of late POAF (chapter 3). Notably, the source of inflammation in patients undergoing cardiac surgery is not only the surgical procedure including cardiopulmonary bypass, but additional low-grade inflammation may co-exist with the underlying cardiac disease itself. For example, in the pathophysiology of coronary artery disease, inflammation particularly with increased CRP level plays an essential role contributing to plaque de- 
stabilisation following endothelial dysfunction. ${ }^{68,69}$ Also chronic inflammation is a major component in the cascade of native aortic valve degeneration. ${ }^{70}$ Hence low-grade systemic inflammation goes hand-in-hand with several cardiovascular diseases in the setting of cardiac surgery. In accordance, we found baseline CRP levels combined with myocardial infarction as an independent predictor of POAF (Chapter 3).

In canine sterile pericarditis models, which resemble the acute post cardiac surgery setting, dispersion in gap junction distribution with heterogeneous conduction properties has been demonstrated. ${ }^{9,} 71$ Also comparable to the systemic effect of cardiopulmonary bypass, ${ }^{72}$ systemic inflammation has been associated with early AF recurrences after rhythm control in patients with recent onset persistent AF. ${ }^{73}$ As expected, corticosteroids have been shown to reduce POAF incidence in a meta-analysis of 50 randomised controlled trials ${ }^{74}$ indicating the role of inflammation in POAF. However, in a large randomised controlled trial, administration of a statin perioperatively reduced postoperative low-density lipoprotein and CRP levels but did not affect early POAF incidence. ${ }^{75}$

Although these animal models provide insight into pathophysiological mechanisms contributing to a structural substrate for AF, it is important to recognize that animal models have been used to study a single disease with a sudden onset for a limited duration, whereas patients most often have several disease factors developing gradually and with a more extended duration.

\section{Conclusion}

Patients without a history of AF with several co-morbidities may still carry a complex underlying substrate for AF as a result of atrial structural changes. In patients undergoing cardiac surgery, specific co-morbidities aggravating AF susceptibility already co-exist with the underlying cardiac diseases. Both $\mathrm{CHA}_{2} \mathrm{DS}_{2}$ VASc as well as $\mathrm{HATCH}$ score are important predictors of POAF. In the acute postoperative phase after cardiac surgery, this AF substrate is unmasked due to a strong agglomeration of triggers leading to early POAF. On the other hand, patients with underlying substrates, perhaps depending on the duration of the underlying diseases and treatment compliance, also develop late POAF. Importantly, different underlying diseases may affect propagation properties differently and complex AF substrates are an accumulation of different co-morbidities and their intensity. It is therefore plausible that atrial propagation is negatively affected by progressive atrial structural changes towards a critical amount of substrate formation, which then maintains AF when initiated by triggers. These factors show a high inter-individual variability contributing to the difficulty to develop relevant classifications for AF. This variable and progressive AF substrate also indicates the desirability of minimally invasive characterization of the AF substrate, such as by P-wave analysis (Chapter4) for an optimal, individualized treatment strategy. 


\section{References}

1. Schotten U, Verheule S, Kirchhof P and Goette A. Pathophysiological mechanisms of atrial fibrillation: a translational appraisal. Physiol Rev. 2011;91:265-325.

2. January CT, Wann LS, Alpert JS, Calkins H, Cigarroa JE, Cleveland JC, Jr., Conti JB, Ellinor PT, Ezekowitz MD, Field ME, Murray KT, Sacco RL, Stevenson WG, Tchou PJ, Tracy CM, Yancy CW and American College of Cardiology/American Heart Association Task Force on Practice G. 2014 AHA/ACC/HRS guideline for the management of patients with atrial fibrillation: a report of the American College of Cardiology/American Heart Association Task Force on Practice Guidelines and the Heart Rhythm Society. J Am Coll Cardiol. 2014;64:e1-76.

3. Kirchhof P, Benussi S, Kotecha D, Ahlsson A, Atar D, Casadei B, Castella M, Diener HC, Heidbuchel H, Hendriks J, Hindricks G, Manolis AS, Oldgren J, Popescu BA, Schotten U, Van Putte B, Vardas P, Agewall S, Camm J, Baron Esquivias G, Budts W, Carerj S, Casselman F, Coca A, De Caterina R, Deftereos S, Dobrev D, Ferro JM, Filippatos G, Fitzsimons D, Gorenek B, Guenoun M, Hohnloser SH, Kolh P, Lip GY, Manolis A, McMurray J, Ponikowski P, Rosenhek R, Ruschitzka F, Savelieva I, Sharma S, Suwalski P, Tamargo JL, Taylor CJ, Van Gelder IC, Voors AA, Windecker S, Zamorano JL and Zeppenfeld K. 2016 ESC Guidelines for the management of atrial fibrillation developed in collaboration with EACTS. Europace. 2016;18:1609-1678.

4. Brundel BJ, Henning RH, Kampinga HH, Van Gelder IC and Crijns HJ. Molecular mechanisms of remodeling in human atrial fibrillation. Cardiovasc Res. 2002;54:315-24.

5. Calkins H, Kuck KH, Cappato R, Brugada J, Camm AJ, Chen SA, Crijns HJ, Damiano RJ, Jr., Davies DW, DiMarco J, Edgerton J, Ellenbogen K, Ezekowitz MD, Haines DE, Haissaguerre M, Hindricks G, lesaka $Y$, Jackman W, Jalife J, Jais P, Kalman J, Keane D, Kim YH, Kirchhof P, Klein G, Kottkamp H, Kumagai K, Lindsay BD, Mansour M, Marchlinski FE, McCarthy PM, Mont JL, Morady F, Nademanee K, Nakagawa H, Natale A, Nattel S, Packer DL, Pappone C, Prystowsky E, Raviele A, Reddy V, Ruskin JN, Shemin RJ, Tsao HM and Wilber D. 2012 HRS/EHRA/ECAS Expert Consensus Statement on Catheter and Surgical Ablation of Atrial Fibrillation: recommendations for patient selection, procedural techniques, patient management and follow-up, definitions, endpoints, and research trial design. Europace. 2012;14:528-606.

6. Wit AL and Boyden PA. Triggered activity and atrial fibrillation. Heart Rhythm. 2007;4:S17-23.

7. Corradi D, Maestri R, Macchi E and Callegari S. The atria: from morphology to function. J CardiovasC Electrophysiol. 2011;22:223-35.

8. Katra RP and Laurita KR. Cellular mechanism of calcium-mediated triggered activity in the heart. Circ Res. 2005;96:535-42.

9. Ishii Y, Schuessler RB, Gaynor SL, Yamada K, Fu AS, Boineau JP and Damiano RJ, Jr. Inflammation of atrium after cardiac surgery is associated with inhomogeneity of atrial conduction and atrial fibrillation. Circulation. 2005;111:2881-8.

10. Schonleitner P, Schotten $U$ and Antoons $G$. Mechanosensitivity of microdomain calcium signalling in the heart. Prog Biophys Mol Biol. 2017.

11. Pokushalov E, Kozlov B, Romanov A, Strelnikov A, Bayramova S, Sergeevichev D, Bogachev-Prokophiev A, Zheleznev S, Shipulin V, Lomivorotov VV, Karaskov A, Po SS and Steinberg JS. Long-Term Suppression of Atrial Fibrillation by Botulinum Toxin Injection Into Epicardial Fat Pads in Patients Undergoing Cardiac Surgery: One-Year Follow-Up of a Randomized Pilot Study. Circ Arrhythm Electrophysiol. 2015;8:133441.

12. Osterberg $L$ and Blaschke T. Adherence to medication. N Eng/J Med. 2005;353:487-97.

13. Kurlansky P, Herbert M, Prince S and Mack M. Coronary Artery Bypass Graft Versus Percutaneous Coronary Intervention: Meds Matter: Impact of Adherence to Medical Therapy on Comparative Outcomes. Circulation. 2016;134:1238-1246.

14. Konings KT, Kirchhof $\mathrm{CJ}$, Smeets JR, Wellens HJ, Penn OC and Allessie MA. High-density mapping of electrically induced atrial fibrillation in humans. Circulation. 1994;89:1665-80. 
15. Allessie MA, de Groot NM, Houben RP, Schotten U, Boersma E, Smeets JL and Crijns HJ. Electropathological substrate of long-standing persistent atrial fibrillation in patients with structural heart disease: Iongitudinal dissociation. Circ Arrhythm Electrophysiol. 2010;3:606-15.

16. Benjamin EJ, Levy D, Vaziri SM, D'Agostino RB, Belanger AJ and Wolf PA. Independent risk factors for atrial fibrillation in a population-based cohort. The Framingham Heart Study. JAMA. 1994;271:840-4.

17. Huxley RR, Lopez FL, Folsom AR, Agarwal SK, Loehr LR, Soliman EZ, Maclehose R, Konety S and Alonso A. Absolute and attributable risks of atrial fibrillation in relation to optimal and borderline risk factors: the Atherosclerosis Risk in Communities (ARIC) study. Circulation. 2011;123:1501-8.

18. Chen K, Bai R, Deng W, Gao C, Zhang J, Wang X, Wang S, Fu H, Zhao Y, Zhang J, Dong J and Ma C. HATCH score in the prediction of new-onset atrial fibrillation after catheter ablation of typical atrial flutter. Heart Rhythm. 2015;12:1483-9.

19. de Vos CB, Pisters R, Nieuwlaat R, Prins MH, Tieleman RG, Coelen RJ, van den Heijkant AC, Allessie MA and Crijns HJ. Progression from paroxysmal to persistent atrial fibrillation clinical correlates and prognosis. Journal of the American College of Cardiology. 2010;55:725-31.

20. Pathak RK, Middeldorp ME, Lau DH, Mehta AB, Mahajan R, Twomey D, Alasady M, Hanley L, Antic NA, McEvoy RD, Kalman JM, Abhayaratna WP and Sanders P. Aggressive risk factor reduction study for atrial fibrillation and implications for the outcome of ablation: the ARREST-AF cohort study. Journal of the American College of Cardiology. 2014;64:2222-31.

21. Travers JG, Kamal FA, Robbins J, Yutzey KE and Blaxall BC. Cardiac Fibrosis: The Fibroblast Awakens. Circ Res. 2016;118:1021-40.

22. Weber KT and Brilla CG. Pathological hypertrophy and cardiac interstitium. Fibrosis and reninangiotensin-aldosterone system. Circulation. 1991;83:1849-65.

23. Kawara T, Derksen R, de Groot JR, Coronel R, Tasseron S, Linnenbank AC, Hauer RN, Kirkels $H$, Janse MJ and de Bakker JM. Activation delay after premature stimulation in chronically diseased human myocardium relates to the architecture of interstitial fibrosis. Circulation. 2001;104:3069-75.

24. Platonov PG, Mitrofanova LB, Orshanskaya V and Ho SY. Structural abnormalities in atrial walls are associated with presence and persistency of atrial fibrillation but not with age. J Am Coll Cardiol. 2011;58:2225-32.

25. Dzeshka MS, Lip GY, Snezhitskiy V and Shantsila E. Cardiac Fibrosis in Patients With Atrial Fibrillation: Mechanisms and Clinical Implications. Journal of the American College of Cardiology. 2015;66:943-59.

26. Trayanova NA, Boyle PM, Arevalo HJ and Zahid S. Exploring susceptibility to atrial and ventricular arrhythmias resulting from remodeling of the passive electrical properties in the heart: a simulation approach. Frontiers in physiology. 2014;5:435.

27. Burstein B and Nattel S. Atrial fibrosis: mechanisms and clinical relevance in atrial fibrillation. Journal of the American College of Cardiology. 2008;51:802-9.

28. Venteclef N, Guglielmi V, Balse E, Gaborit B, Cotillard A, Atassi F, Amour J, Leprince P, Dutour A, Clement $\mathrm{K}$ and Hatem SN. Human epicardial adipose tissue induces fibrosis of the atrial myocardium through the secretion of adipo-fibrokines. Eur Heart J. 2015;36:795-805a.

29. Hatem SN, Redheuil A and Gandjbakhch E. Cardiac adipose tissue and atrial fibrillation: the perils of adiposity. Cardiovasc Res. 2016;109:502-9.

30. Antonopoulos AS, Margaritis M, Verheule S, Recalde A, Sanna F, Herdman L, Psarros C, Nasrallah $H$, Coutinho P, Akoumianakis I, Brewer AC, Sayeed R, Krasopoulos G, Petrou M, Tarun A, Tousoulis D, Shah AM, Casadei B, Channon KM and Antoniades C. Mutual Regulation of Epicardial Adipose Tissue and Myocardial Redox State by PPAR-gamma/Adiponectin Signalling. Circ Res. 2016;118:842-55.

31. Samak M, Fatullayev J, Sabashnikov A, Zeriouh M, Schmack B, Farag M, Popov AF, Dohmen PM, Choi YH, Wahlers T and Weymann A. Cardiac Hypertrophy: An Introduction to Molecular and Cellular Basis. Med Sci Monit Basic Res. 2016;22:75-9.

32. Wiegerinck RF, Verkerk AO, Belterman CN, van Veen TA, Baartscheer A, Opthof T, Wilders R, de Bakker $\mathrm{JM}$ and Coronel R. Larger cell size in rabbits with heart failure increases myocardial conduction velocity and QRS duration. Circulation. 2006;113:806-13. 
33. Verheule S, Tuyls E, van Hunnik A, Kuiper M, Schotten $U$ and Allessie M. Fibrillatory conduction in the atrial free walls of goats in persistent and permanent atrial fibrillation. Circ Arrhythm Electrophysiol. 2010;3:590-9.

34. Wijffels MC, Kirchhof CJ, Dorland R and Allessie MA. Atrial fibrillation begets atrial fibrillation. A study in awake chronically instrumented goats. Circulation. 1995;92:1954-68.

35. Ausma J, Wijffels M, Thone F, Wouters L, Allessie M and Borgers M. Structural changes of atrial myocardium due to sustained atrial fibrillation in the goat. Circulation. 1997;96:3157-63.

36. Verheule S, Tuyls E, Gharaviri A, Hulsmans S, van Hunnik A, Kuiper M, Serroyen J, Zeemering S, Kuijpers $\mathrm{NH}$ and Schotten U. Loss of continuity in the thin epicardial layer because of endomysial fibrosis increases the complexity of atrial fibrillatory conduction. Circ Arrhythm Electrophysiol. 2013;6:202-11.

37. Eckstein J, Zeemering S, Linz D, Maesen B, Verheule S, van Hunnik A, Crijns H, Allessie MA and Schotten $U$. Transmural conduction is the predominant mechanism of breakthrough during atrial fibrillation: evidence from simultaneous endo-epicardial high-density activation mapping. Circ Arrhythm Electrophysiol. 2013;6:334-41.

38. de Groot N, van der Does L, Yaksh A, Lanters E, Teuwen C, Knops P, van de Woestijne P, Bekkers J, Kik C, Bogers A and Allessie M. Direct Proof of Endo-Epicardial Asynchrony of the Atrial Wall During Atrial Fibrillation in Humans. Circ Arrhythm Electrophysiol. 2016;9.

39. Everett THt, Wilson EE, Hulley GS and Olgin JE. Transmural characteristics of atrial fibrillation in canine models of structural and electrical atrial remodeling assessed by simultaneous epicardial and endocardial mapping. Heart Rhythm. 2010;7:506-17.

40. Eckstein J, Maesen B, Linz D, Zeemering S, van Hunnik A, Verheule S, Allessie M and Schotten U. Time course and mechanisms of endo-epicardial electrical dissociation during atrial fibrillation in the goat. Cardiovasc Res. 2011;89:816-24.

41. Santhanakrishnan R, Wang N, Larson MG, Magnani JW, McManus DD, Lubitz SA, Ellinor PT, Cheng S, Vasan RS, Lee DS, Wang TJ, Levy D, Benjamin EJ and Ho JE. Atrial Fibrillation Begets Heart Failure and Vice Versa: Temporal Associations and Differences in Preserved Versus Reduced Ejection Fraction. Circulation. 2016;133:484-92.

42. Ohtani K, Yutani C, Nagata S, Koretsune Y, Hori M and Kamada T. High prevalence of atrial fibrosis in patients with dilated cardiomyopathy. J Am Coll Cardiol. 1995;25:1162-9.

43. Li D, Fareh S, Leung TK and Nattel S. Promotion of atrial fibrillation by heart failure in dogs: atrial remodeling of a different sort. Circulation. 1999;100:87-95.

44. Shinagawa K, Shi YF, Tardif JC, Leung TK and Nattel S. Dynamic nature of atrial fibrillation substrate during development and reversal of heart failure in dogs. Circulation. 2002;105:2672-8.

45. Treibel TA, Kozor R, Schofield R, Benedetti G, Fontana M, Bhuva AN, Sheikh A, Lopez B, Gonzalez A, Manisty C, Lloyd G, Kellman P, Diez J and Moon JC. Reverse Myocardial Remodeling Following Valve Replacement in Patients With Aortic Stenosis. J Am Coll Cardiol. 2018;71:860-871.

46. Morton JB, Sanders P, Vohra JK, Sparks PB, Morgan JG, Spence SJ, Grigg LE and Kalman JM. Effect of chronic right atrial stretch on atrial electrical remodeling in patients with an atrial septal defect. Circulation. 2003;107:1775-82.

47. Verheule S, Wilson E, Everett Tt, Shanbhag S, Golden C and Olgin J. Alterations in atrial electrophysiology and tissue structure in a canine model of chronic atrial dilatation due to mitral regurgitation. Circulation. 2003;107:2615-22.

48. Verheule S, Wilson E, Banthia S, Everett THt, Shanbhag S, Sih HJ and Olgin J. Direction-dependent conduction abnormalities in a canine model of atrial fibrillation due to chronic atrial dilatation. $\mathrm{Am}$ Physiol Heart Circ Physiol. 2004;287:H634-44.

49. Neuberger HR, Schotten U, Blaauw Y, Vollmann D, Eijsbouts S, van Hunnik A and Allessie M. Chronic atrial dilation, electrical remodeling, and atrial fibrillation in the goat. J Am Coll Cardiol. 2006;47:644-53.

50. Neuberger HR, Schotten U, Verheule S, Eijsbouts S, Blaauw Y, van Hunnik A and Allessie M. Development of a substrate of atrial fibrillation during chronic atrioventricular block in the goat. Circulation. 2005;111:30-7. 
51. Sparks PB, Mond HG, Vohra JK, Jayaprakash S and Kalman JM. Electrical remodeling of the atria following loss of atrioventricular synchrony: a long-term study in humans. Circulation. 1999;100:1894-900.

52. Tyberg JV, Taichman GC, Smith ER, Douglas NW, Smiseth OA and Keon WJ. The relationship between pericardial pressure and right atrial pressure: an intraoperative study. Circulation. 1986;73:428-32.

53. Maniar HS, Prasad SM, Gaynor SL, Chu CM, Steendijk P and Moon MR. Impact of pericardial restraint on right atrial mechanics during acute right ventricular pressure load. Am J Physiol Heart Circ Physiol. 2003;284:H350-7.

54. Ninio DM and Saint DA. Passive pericardial constraint protects against stretch-induced vulnerability to atrial fibrillation in rabbits. Am J Physiol Heart Circ Physiol. 2006;291:H2547-9.

55. Hijazi Z, Oldgren J, Siegbahn A, Granger CB and Wallentin L. Biomarkers in atrial fibrillation: a clinical review. Eur Heart J. 2013;34:1475-80.

56. Anyukhovsky EP, Sosunov EA, Chandra P, Rosen TS, Boyden PA, Danilo P, Jr. and Rosen MR. Ageassociated changes in electrophysiologic remodeling: a potential contributor to initiation of atrial fibrillation. Cardiovasc Res. 2005;66:353-63.

57. Anyukhovsky EP, Sosunov EA, Plotnikov A, Gainullin RZ, Jhang JS, Marboe CC and Rosen MR. Cellular electrophysiologic properties of old canine atria provide a substrate for arrhythmogenesis. Cardiovasc Res. 2002;54:462-9.

58. Koura T, Hara M, Takeuchi S, Ota K, Okada Y, Miyoshi S, Watanabe A, Shiraiwa K, Mitamura H, Kodama I and Ogawa S. Anisotropic conduction properties in canine atria analyzed by high-resolution optical mapping: preferential direction of conduction block changes from longitudinal to transverse with increasing age. Circulation. 2002;105:2092-8.

59. Lau DH, Mackenzie L, Kelly DJ, Psaltis PJ, Brooks AG, Worthington M, Rajendram A, Kelly DR, Zhang Y, Kuklik P, Nelson AJ, Wong CX, Worthley SG, Rao M, Faull RJ, Edwards J, Saint DA and Sanders P. Hypertension and atrial fibrillation: evidence of progressive atrial remodeling with electrostructural correlate in a conscious chronically instrumented ovine model. Heart Rhythm. 2010;7:1282-90.

60. Medi C, Kalman JM, Spence SJ, Teh AW, Lee G, Bader I, Kaye DM and Kistler PM. Atrial electrical and structural changes associated with longstanding hypertension in humans: implications for the substrate for atrial fibrillation. J Cardiovasc Electrophysiol. 2011;22:1317-24.

61. McLellan AJ, Schlaich MP, Taylor AJ, Prabhu S, Hering D, Hammond L, Marusic P, Duval J, Sata Y, Ellims A, Esler M, Peter K, Shaw J, Walton A, Kalman JM and Kistler PM. Reverse cardiac remodeling after renal denervation: Atrial electrophysiologic and structural changes associated with blood pressure lowering. Heart Rhythm. 2015;12:982-90

62. Linz D, van Hunnik A, Hohl M, Mahfoud F, Wolf M, Neuberger HR, Casadei B, Reilly SN, Verheule S, Bohm $\mathrm{M}$ and Schotten $\mathrm{U}$. Catheter-based renal denervation reduces atrial nerve sprouting and complexity of atrial fibrillation in goats. Circ Arrhythm Electrophysiol. 2015;8:466-74.

63. Mahajan R, Lau DH, Brooks AG, Shipp NJ, Manavis J, Wood JP, Finnie JW, Samuel CS, Royce SG, Twomey DJ, Thanigaimani S, Kalman JM and Sanders P. Electrophysiological, Electroanatomical, and Structural Remodeling of the Atria as Consequences of Sustained Obesity. J Am Coll Cardiol. 2015;66:1-11.

64. Hu YF, Chen YJ, Lin YJ and Chen SA. Inflammation and the pathogenesis of atrial fibrillation. Nat Rev Cardiol. 2015;12:230-43

65. Li J, Solus J, Chen Q, Rho YH, Milne G, Stein CM and Darbar D. Role of inflammation and oxidative stress in atrial fibrillation. Heart Rhythm. 2010;7:438-44.

66. Liew R, Khairunnisa K, Gu Y, Tee N, Yin NO, Naylynn TM and Moe KT. Role of tumor necrosis factor-alpha in the pathogenesis of atrial fibrosis and development of an arrhythmogenic substrate. Circ J. 2013;77:1171-9.

67. Cox JL. A perspective of postoperative atrial fibrillation in cardiac operations. The Annals of thoracic surgery. 1993;56:405-9.

68. Marzilli M, Merz CN, Boden WE, Bonow RO, Capozza PG, Chilian WM, DeMaria AN, Guarini G, Huqi A Morrone D, Patel MR and Weintraub WS. Obstructive coronary atherosclerosis and ischemic heart disease: an elusive link! Journal of the American College of Cardiology. 2012;60:951-6. 
69. Koenig $W$ and Khuseyinova N. Biomarkers of atherosclerotic plaque instability and rupture. Arteriosclerosis, thrombosis, and vascular biology. 2007;27:15-26.

70. Mazzone A, Epistolato MC, Gianetti J, Castagnini M, Sassi C, Ceravolo R, Bevilacqua S, Glauber M, Biagin $A$ and Tanganelli P. Biological features (inflammation and neoangiogenesis) and atherosclerotic risk factors in carotid plaques and calcified aortic valve stenosis: two different sites of the same disease? Am J Clin Pathol. 2006;126:494-502.

71. Tselentakis EV, Woodford E, Chandy J, Gaudette GR and Saltman AE. Inflammation effects on the electrical properties of atrial tissue and inducibility of postoperative atrial fibrillation. J Surg Res. 2006;135:68-75.

72. Maesen B, Nijs J, Maessen J, Allessie M and Schotten U. Post-operative atrial fibrillation: a maze of mechanisms. Europace. 2012;14:159-74.

73. Smit MD, Maass AH, De Jong AM, Muller Kobold AC, Van Veldhuisen DJ and Van Gelder IC. Role of inflammation in early atrial fibrillation recurrence. Europace. 2012;14:810-7.

74. Ho KM and Tan JA. Benefits and risks of corticosteroid prophylaxis in adult cardiac surgery: a doseresponse meta-analysis. Circulation. 2009;119:1853-66.

75. Zheng Z, Jayaram R, Jiang L, Emberson J, Zhao Y, Li Q, Du J, Guarguagli S, Hill M, Chen Z, Collins R and Casadei B. Perioperative Rosuvastatin in Cardiac Surgery. N Eng/ J Med. 2016;374:1744-53. 
Chapter 7 
Valorization 
This thesis highlights the incidence and clinical relevance of late POAF and adds evidence to the notion of opportunities for intensified monitoring of postoperative patients to increase their health and avoid complication related costs.

\section{Late POAF}

Atrial fibrillation after cardiac surgery is the most prevalent complication adding to substantial morbidity and clinical costs. ${ }^{1}$ Patients developing POAF shorter than 48 hours are discharged without oral anticoagulation and usually without prolonged rhythm monitoring. Although symptomatic late POAF episodes may be diagnosed due to patient's complaints, short subclinical episodes are often left undiagnosed and untreated. Two important clinical questions regarding POAF recurrences are relevant for late POAF, namely the importance of continuous rhythm monitoring and treatment of short lasting AF episodes with oral anticoagulation.

The importance of prolonged continuous rhythm monitoring in AF has recently been emphasized in several reports. Intermittent rhythm monitoring strategies such as Holter monitoring or periodical electrocardiograms is insufficient to uncover the true AF burden. ${ }^{2,3}$ Duration of AF per episode and AF density (i.e temporal clustering of the episodes) are highly unpredictable in all types of $A F{ }^{2}$ This is clearly reflected in clinical misclassification of AF, where only $47 \%$ of paroxysmal AF and $32 \%$ of persistent $A F$ are correctly categorized. ${ }^{4}$ In addition, a large amount of silent strokes result from AF. To quantify the incidence of silent stroke in AF patients, one study conducted cerebral magnetic resonance imaging (MRIC) of AF patients and compared them to sinus rhythm patients. ${ }^{5}$ The authors showed that $89 \%$ of patients with pAF and $92 \%$ of pers AF patients ( $\mathrm{n}=90$ in each group) had underlying silent cerebral ischemia (SCl). Interestingly, $46 \%$ of SR group also had $\mathrm{SCl}$. Although significantly less than AF patients, this remains a high percentage of undiagnosed subtle brain damage, which at least partly may correlate to asymptomatic AF. ${ }^{5}$ 6, 7 Indeed, asymptomatic AF is usually detected after a stroke episode ${ }^{8}$ and using continuous monitoring, asymptomatic AF has been shown to explain a large group of cryptogenic strokes with a median AF detection rate of 41 days after the stroke, ${ }^{9}$ further emphasizing the importance of long-term continuous monitoring due to heterogeneous AF density. In line with these findings, we found that the majority of patients without a history of AF also show recurrences of POAF lasting minutes to hours, after discharge from the hospital.

Interestingly, patients with late POAF in addition to early POAF had higher $\mathrm{CHADS}_{2} \mathrm{VAS}_{2} \mathrm{C}$ scores. This raises the question of treating short lasting AF episodes, which is still debated. However, accumulating evidence inclines towards anticoagulation treatment for patients with short lasting subclinical AF episodes. First, AF maintains a systemic hypercoagulable state ${ }^{10}$ and considering the trias of Virchow, at least in patients with endothelial damage, even short paroxysm of AF may expose the patient to 
risk of stroke. In accordance, subclinical AF episodes in diabetic patients doubled the chances of subclinical infarct (up to 60\%) and stroke compared to diabetics without AF. ${ }^{11}$ Also, recent studies have shown higher hypercoagulability markers, a so called "pro-thrombotic" state, in young paroxysmal AF patients with $\mathrm{CHADS}_{2} \mathrm{VAS}_{2} \mathrm{C}$ of 0 compared to patients without AF emphasizing the hypercoagulable state caused by $A F{ }^{12}$ Furthermore, 15 minutes of AF in paroxysmal AF patients significantly increases the levels of platelet activation, thrombin activation and inflammation in the atria compared to patients without AF. ${ }^{13}$ In addition, as discussed in chapter 4 , subclinical AF episodes detected by continuous rhythm monitoring lasting more than 5-6 minutes are associated with ischemic stroke or systemic embolization. ${ }^{3,14}$ These findings imply that both clinical AF, as well as clinical ischemic stroke, are not sufficient or reliable outcomes for decision making regarding patients long-term treatment. For this reason it is desirable to closely follow patients prone to AF during the months and years after the operation. If $A F$ is detected, intensified monitoring may be adequate and as soon as an AF episode is diagnosed on ECG or Holter anticoagulant therapy should be considered. Furthermore, rhythm follow-up enables to investigate the effects of therapy on individual patients. This is nowadays possible because of the ease and efficiency level of continuous rhythm monitoring devices. Interestingly, detecting AF episodes using an i-phone electrocardiogram application was recently shown to be very feasible and effective and may be the next step in the evolution of effective arrhythmia management. ${ }^{15}$ In addition, important outcomes such as silent stroke should also be considered in the decision making process.

\section{Minimal invasive substrate detection in AF}

In addition to continuous rhythm monitoring, adequate substrate quantification may contribute to patient selection for further follow up, treatment and perhaps in tailored treatment aimed at underlying substrate. We found that patients developing early and late POAF carry underlying structural substrate as a result of several co-morbidities making minimal invasive techniques to quantify this substrate very attractive. In chapter 4 we used the electrocardiogram to determine P-wave characteristics predicting POAF. Contrary to the direct contact epicardial mapping, the P-wave derived from the ECG gives a reflection of propagation of the entire atrial activation. Lower P-wave amplitude and duration was a characteristic of patients developing early and late POAF. Implementing signal averaged $\mathrm{P}$-wave analysis to detect and predict AF episodes is a low cost low invasive and potentially very accurate technique. Still more research is required to expand the field of ECG based P-wave guided risk stratification in detection and prevention of POAF and AF in general.

In addition, transmural electrical conduction and a 3D substrate is pronounced in remodelled atria and is an important measure of substrate complexity for AF (chapter 
5). In chapter 6 we describe a method to simplify endo-epicardial mapping during AF using phase analysis. Phase analysis of electrograms does not require the timeconsuming process of activation time annotation and is more and more used to analyse fibrillation electrograms. The coherence of phase between neighboring electrodes allows quantifying the degree of electrical dissociation between these electrodes and thus this technique can also be used for quantifying endo-epicardial electrical dissociation. By calculating the phase of the unipolar electrograms for each electrode, we found that during a measurement of at least 15 seconds, maximum mean phase coherence is highest between closest electrodes on the opposing side (average of 2,3 mm localization error). As expected, we found that there was almost never complete phase coherence between endo-epicardially opposing electrodes, (figure 4 of chapter 6 ) further emphasizing our findings in chapter 5 where endo-epicardial activation time differences were never completely zero. We also found that phase coherence decays with distance between electrodes. This suggests that dissociated activity is heterogeneously distributed between endo- and epicardium and is not a temporary phenomenon (considering at least the mapped area). If dissociation would be a transient phenomenon, then phase coherence at least with distant electrodes (further than the dissociated region) would reach a plateau and remain constant. This is clearly not the case as seen in figure 3 of chapter 6. Nevertheless, maximum mean phase coherence detects the opposing electrode in longstanding AF patients with endo-epicardial files lasting 15 seconds or longer. In other words, there is a correlation between phase of electrograms and the distance between the electrodes. This technique may contribute to electrode localization on the opposing sites of the atrial wall even in electrically remodeled areas and thus become particularly of interest in quantifying individual substrates for AF for tailored treatment approaches.

In conclusion, for an effective and tailored AF treatment, detection of the severity of the underlying substrate correlating with true AF burden is mandatory. Future research should take primary outcomes such as subclinical short lasting AF episodes and silent strokes into consideration. Modern technology offers solutions for these challenges including enhanced rhythm follow-up with low burden devices independent of patient compliance (ILRs) and minimal-invasive substrate detection and stratification based on low cost low burden diagnostic systems (ECGs). 


\section{References}

1. LaPar DJ, Speir AM, Crosby IK, Fonner E, Jr., Brown M, Rich JB, Quader M, Kern JA, Kron IL, Ailawadi G and Investigators for the Virginia Cardiac Surgery Quality I. Postoperative atrial fibrillation significantly increases mortality, hospital readmission, and hospital costs. Ann Thorac Surg. 2014;98:527-33; discussion 533.

2. Charitos El, Stierle U, Ziegler PD, Baldewig M, Robinson DR, Sievers HH and Hanke T. A comprehensive evaluation of rhythm monitoring strategies for the detection of atrial fibrillation recurrence: insights from 647 continuously monitored patients and implications for monitoring after therapeutic interventions. Circulation. 2012;126:806-14.

3. Botto GL, Padeletti L, Santini M, Capucci A, Gulizia M, Zolezzi F, Favale S, Molon G, Ricci R, Biffi M, Russo $G$, Vimercati $M$, Corbucci $G$ and Boriani $G$. Presence and duration of atrial fibrillation detected by continuous monitoring: crucial implications for the risk of thromboembolic events. I Cardiovasc Electrophysiol. 2009;20:241-8.

4. Charitos El, Purerfellner H, Glotzer TV and Ziegler PD. Clinical classifications of atrial fibrillation poorly reflect its temporal persistence: insights from 1,195 patients continuously monitored with implantable devices. J Am Coll Cardiol. 2014;63:2840-8.

5. Gaita F, Corsinovi L, Anselmino M, Raimondo C, Pianelli M, Toso E, Bergamasco L, Boffano C, Valentini $M C$, Cesarani $F$ and Scaglione M. Prevalence of silent cerebral ischemia in paroxysmal and persistent atrial fibrillation and correlation with cognitive function. J Am Coll Cardiol. 2013;62:1990-7.

6. Flaker GC, Belew K, Beckman K, Vidaillet H, Kron J, Safford R, Mickel M, Barrell P and Investigators A. Asymptomatic atrial fibrillation: demographic features and prognostic information from the Atrial Fibrillation Follow-up Investigation of Rhythm Management (AFFIRM) study. Am Heart J. 2005;149:65763.

7. Sposato LA, Klein FR, Jauregui A, Ferrua M, Klin P, Zamora R, Riccio PM and Rabinstein A. Newly diagnosed atrial fibrillation after acute ischemic stroke and transient ischemic attack: importance of immediate and prolonged continuous cardiac monitoring. J Stroke Cerebrovasc Dis. 2012;21:210-6.

8. Freedman B, Camm J, Calkins H, Healey JS, Rosenqvist M, Wang J, Albert CM, Anderson CS, Antoniou S, Benjamin EJ, Boriani G, Brachmann J, Brandes A, Chao TF, Conen D, Engdahl J, Fauchier L, Fitzmaurice DA, Friberg L, Gersh BJ, Gladstone DJ, Glotzer TV, Gwynne K, Hankey GJ, Harbison J, Hillis GS, Hills MT, Kamel H, Kirchhof P, Kowey PR, Krieger D, Lee VWY, Levin LA, Lip GYH, Lobban T, Lowres N, Mairesse GH, Martinez C, Neubeck L, Orchard J, Piccini JP, Poppe K, Potpara TS, Puererfellner H, Rienstra M, Sandhu RK, Schnabel RB, Siu CW, Steinhubl S, Svendsen JH, Svennberg E, Themistoclakis S, Tieleman RG, Turakhia MP, Tveit A, Uittenbogaart SB, Van Gelder IC, Verma A, Wachter R, Yan BP and Collaborators AF-S. Screening for Atrial Fibrillation: A Report of the AF-SCREEN International Collaboration. Circulation. 2017;135:1851-1867.

9. Sanna T, Diener HC, Passman RS, Di Lazzaro V, Bernstein RA, Morillo CA, Rymer MM, Thijs V, Rogers T, Beckers F, Lindborg K, Brachmann J and Investigators CA. Cryptogenic stroke and underlying atrial fibrillation. N Eng/ J Med. 2014;370:2478-86.

10. Chung NA, Belgore F, Li-Saw-Hee FL, Conway DS, Blann AD and Lip GY. Is the hypercoagulable state in atrial fibrillation mediated by vascular endothelial growth factor? Stroke. 2002;33:2187-91.

11. Marfella R, Sasso FC, Siniscalchi M, Cirillo M, Paolisso P, Sardu C, Barbieri M, Rizzo MR, Mauro C and Paolisso G. Brief episodes of silent atrial fibrillation predict clinical vascular brain disease in type 2 diabetic patients. J Am Coll Cardiol. 2013;62:525-30.

12. Hobbelt AH, Spronk HM, Crijns H, Ten Cate H, Rienstra M and Van Gelder IC. Prethrombotic State in Young Very Low-Risk Patients With Atrial Fibrillation. J Am Coll Cardiol. 2017;69:1990-1992.

13. Lim HS, Willoughby SR, Schultz C, Gan C, Alasady M, Lau DH, Leong DP, Brooks AG, Young GD, Kistler PM, Kalman JM, Worthley $\mathrm{MI}$ and Sanders P. Effect of atrial fibrillation on atrial thrombogenesis in humans: impact of rate and rhythm. J Am Coll Cardiol. 2013;61:852-60. 
14. Healey JS, Connolly SJ, Gold MR, Israel CW, Van Gelder IC, Capucci A, Lau CP, Fain E, Yang S, Bailleul C, Morillo CA, Carlson M, Themeles E, Kaufman ES, Hohnloser SH and Investigators A. Subclinical atrial fibrillation and the risk of stroke. N Eng/ J Med. 2012;366:120-9.

15. Lowres N, Mulcahy G, Gallagher R, Ben Freedman S, Marshman D, Kirkness A, Orchard J and Neubeck L. Self-monitoring for atrial fibrillation recurrence in the discharge period post-cardiac surgery using an iPhone electrocardiogram. Eur J Cardiothorac Surg. 2016;50:44-51. 


\section{Summary}


Atrial fibrillation occurs in the first few days after cardiac surgery (postoperative atrial fibrillation, POAF) as a result of acute-phase triggers. Although historically thought of as a transient arrhythmia, accumulating evidence suggests that POAF is an independent predictor of poor survival years after surgery. In addition, there is an association between POAF occurring in the acute postoperative phase and thromboembolic complications such as stroke occurring months to years after discharge. This suggests that POAF may not be confined to the acute postoperative phase but may be a recurrent subclinical arrhythmia.

To determine the incidence of AF episodes after discharge, we used continuous rhythm monitoring devices to follow patients without a history of AF following their open chest cardiac surgical procedure. In Chapter 3 and 4, we describe our results from continuous rhythm monitoring for a month and for 3 years respectively. Firstly, we found that more than $25 \%$ of patients developed AF in the month following discharge form hospital, the so-called late POAF (Chapter 3). Predictors of late POAF included comorbidities such as prior myocardial infarction, diabetes mellitus, obesitas and baseline CRP levels. In chapter 4 we further extended the rhythm-monitoring period to 3 years with an implantable loop recorder in patients without a history of AF. We demonstrated that up to $50 \%$ of patients developed AF episodes lasting 1,5 hours on average during the months to years following surgery. Patients who developed late POAF were older and had higher $\mathrm{CHA}_{2} \mathrm{DS}_{2}$ VASC and $\mathrm{HATCH}$ scores with right atrial volume as an independent predictor of late POAF. Our findings in these chapters suggest that the risk profile for POAF and notably for late POAF resembles the risk profile of AF in general including a structural substrate for AF.

The complexity of the atrial structural substrate is reflected by the complexity of electrical conduction during induced AF. Patients with several cardiovascular comorbidities (high $\mathrm{CHA}_{2} \mathrm{DS}_{2}$ VASc scores), show enhanced level of pathological atrial wall changes leading to complex fibrillating patterns during AF. To explore the electrophysiological substrate for POAF, we measured the complexity of fibrillating patterns of electrically induced AF on the right atrial wall (Chapter 4). For this purpose we induced AF during cardiac surgery by burst pacing and mapped the electrical activation of the right atrium using a 256 unipolar electrode plaque. In line with the previous findings, we found more complex activation patterns (i.e. higher number of waves and fractionation index) in patients who subsequently developed POAF and also those with late-POAF. This illustrates the effects of age and several co-morbidities on the atrial wall, which may not have led to (symptomatic) AF prior to surgery but may be prone to development of a stronger substrate with time.

Interestingly, enhanced complexity of the electrophysiological substrate in animal models involves higher number of wavelets and higher number of breakthrough waves, i.e. waves migrating to the opposing layer of the atrial wall due to dyssynchronous activation of the endocardium compared with epicardium. To investigate the mechanism of transmural propagation of the atrial wall described in animal models, we developed a 
highly detailed 3 dimensional computer model of the human atria. In this computer model, specific atrial anatomical structures were implemented and the mechanism of fibrosis related dissociation between endo-epicardial layers was demonstrated. We found a clear association between endo-epicardial dissociated activity due to increased levels of fibrosis and the number of breakthrough waves. To validate this model, we developed a crocodile shaped clamp electrode containing a double layer of unipolar electrode plaques. The electrode was designed to be inserted into the right atrium with one arm and to be approximated on the atrial wall on both sides. Using this technique, we were able to quantify for the first time in human, the amount of electrical uncoupling between the two layers of the atrial wall. We found that the endo-epicardial dissociation is enhanced with complex substrates for AF. In addition, there is indeed a clear correlation between endo-epicardial dissociation and the number of waves migrating to the opposing layer of the atrial wall, the so-called breakthrough waves. To further elucidate on these findings, we describe in Chapter 6 a method to detect the location of electrodes on the opposing side of the atrial wall by measuring the phase of depolarization during AF. We were able to demonstrate that mean-phase coherence between 2 electrodes, decays with distance between them. This method may be helpful in detecting the 3-D substrate of AF less invasively.

In conclusion, using continuous rhythm monitoring strategies combined with baseline substrate quantification in patients without a history of AF we found up to $50 \%$ late POAF recurrences. Patients developing late POAF were older with additional comorbidities and showed a more complex fibrillation pattern during electrically induced AF compared to those who did not develop POAF. In addition, we sought for the effects of atrial structural substrate on endo-epicardial dissociation and found a correlation between enhanced electrical dyssynchrony and breakthrough waves in a computer model of human atria. We also demonstrated the 3D substrate for AF in human by direct contact endo-epicardial mapping. Future research should determine the clinical consequences of late POAF and the range of the underlying structural substrate, which predisposes patients to AF development. 
Samenvatting 
Het hart bestaat uit 2 boezems en 2 kamers. De boezems vullen de kamers van bloed waarna de kamers bloed rondpompen naar de rest van het lichaam. Een ritmestoornis waarbij de boezems (atria) niet meer contraheren en het bloed niet meer adequaat naar de kamers kunnen pompen wordt boezemfibrilleren of atrium fibrilleren (AF) genoemd. De klachten die hiermee samenhangen zijn hartkloppingen, kortademigheid en pijn op de borst. Boezemfibrilleren is soms ook aanwezig zonder enige symptomen en wanneer het niet ontdekt en niet behandeld wordt, verhoogt het de risico op herseninfarcten en hartfalen.

$\mathrm{Na}$ een open hartoperatie ontstaat AF met name in de eerste paar dagen na de operatie. Dit wordt postoperatief AF (POAF) genoemd. Hoewel altijd gedacht werd dat POAF van voorbijgaande aard was, bleken patiënten die de ritmestoornis wel ontwikkelen, in de jaren na ontslag uit het ziekenhuis ook eerder te overlijden vergeleken met patiënten die dit niet ontwikkelen. Om te achterhalen waarom patiënten die POAF ontwikkelen slechtere overleving laten zien, hebben wij in dit proefschrift onder andere onderzoek gedaan naar 2 vragen.

Ten eerste is de vraag of POAF een voorbijgaande ritmestoornis is, of komt het maanden tot jaren na ontslag uit het ziekenhuis toch weer terug, een zogenaamde late POAF. Ten tweede is de vraag welke patiënten hier het meest vatbaar voor zijn.

De eerste vraag hebben wij onderzocht door patiënten die niet bekend waren met boezemfibrilleren te volgen nadat zij een open hartoperatie hadden ondergaan. Dit hebben wij gedaan op twee manieren. Eerst hebben wij speciaal ontworpen draagbare apparaten gebruikt die het ritme van de patiënten continu kunnen detecteren gedurende een maand (Hoofdstuk 3). Daarnaast hebben wij een tweede groep patiënten gedurende 3 jaar gevolgd via een chip die onder de huid werd geïmplanteerd met dezelfde ritme detectie functie (Hoofdstuk 4). In hoofdstukken 3 en 4 hebben wij de resultaten van deze twee technieken beschreven. Continue ritme monitoring liet in beide studies zien dat meer dan $30 \%$ van de patiënten die nooit tevoren symptomen van AF hadden, na ontslag uit het ziekenhuis alsnog POAF ontwikkelden. Nadat wij patiënten 3 jaar gevolgd hadden, zagen wij dat maar liefst 50\% van de patiënten jaren na de operatie wederom kortdurende episoden van POAF ontwikkelden. De conclusie van deze studies was dat POAF geen voorbijgaande ritmestoornis is zoals vooraf gedacht werd.

Een tweede vraag die logischerwijs op de eerste vraag volgt, is welke kenmerken bepalend zijn voor late POAF ontwikkeling. Wij hebben dus uitgebreid onderzoek gedaan naar de zogenaamde voorspellers van POAF en de vatbaarheid van patiënten hiervoor.

De belangrijkste voorspeller van POAF en late POAF is hogere leeftijd (Hoofdstuk 4). Het is bekend dat door hogere leeftijd de structuur van de boezemwand langzaam verandert wat een belangrijk effect heeft op de regelmaat van boezem activatie en dus de ritme van het hart. Oudere patiënten hebben bovendien specifieke ziektebeelden zoals hypertensie, suikerziekte en overgewicht, ziektebeelden die ook rechtstreeks effecten uitoefenen op de kans op AF. 
Een belangrijk neveneffect van de structuur veranderingen van de boezems is dat de elektrische geleiding over de boezems ook onregelmatig en chaotisch verloopt ten opzichte van een relatief eenvoudige patroon van activatie bij normale boezems. Om deze elektrische eigenschappen van de "zieke" boezems te achterhalen hebben wij gebruik gemaakt van speciaal ontworpen elektrodes die tijdens open hartoperaties op of in het hart werden gepositioneerd terwijl boezemfibrilleren werd opgewekt met behulp van een pacemaker. Wij vonden dat vooral in patiënten met POAF, de elektrische geleiding veel complexer en meer chaotisch was dan bij patiënten zonder POAF. Met andere woorden, door ouderdom en de ziektebeelden die ermee samengaan, hebben patiënten dusdanig beschadigde boezems ontwikkeld (een zogenaamd substraat voor AF), die (onder stimulatie) vatbaar kunnen zijn voor het ontwikkelen van boezemfibrilleren. Dit betekent dus ook dat gezien de vatbaarheid, deze patiënten niet alleen boezemfibrilleren ontwikkelen tijdens opname in het ziekenhuis, maar eveneens het risico lopen om later na ontslag uit het ziekenhuis opnieuw boezemfibrilleren te ontwikkelen.

Om de effecten van ouderdom en ziektebeelden op de elektrische geleiding van de boezems verder te onderzoeken hebben wij een anatomisch computer model ontwikkeld waarin wij deze eigenschappen konden nabootsen. We vonden dat afhankelijk van de ernst van de beschadiging van de boezems er ook een toenemend asynchrone geleiding plaatsvindt over de binnen en buitenwand van de boezems. Dit leidt er vervolgens toe dat steeds meer elektrische activatie vanuit de binnenzijde van de boezemwand ook naar buitenzijde kan geleiden en andersom. Hoe minder synchroon de buiten- en binnenzijde van de boezems geactiveerd worden, hoe meer elektrische activatie tussen de twee lagen wordt voortgeleid. Met andere woorden, naar mate de boezems beschadigd raken als gevolg van verschillende ziektebeelden (substraat), verbreekt de synchronisatie tussen de binnen en buitenwand van de boezems en ontstaat een 3 dimensionale elektrische geleiding die bijdraagt aan de complexe patroon van de elektrische geleiding.

In hoofdstukken 4 en 6 beschrijven wij enkele technieken waarin met behulp van minimaal invasieve methodes een eventueel substraat voor boezemfibrilleren gedetecteerd kan worden. Zo werden in hoofdstuk 4, P-golf eigenschappen in een standaard ECG besproken die kenmerkend waren voor patiënten die late POAF ontwikkelden. Deze technieken kunnen relatief eenvoudig voorspellen bij welke patiënten reeds een substraat bestaat en aldus behandeling voor late POAF aan te bevelen is. Uiteraard zijn deze technieken nog in kinderschoenen en zou meer onderzoek hiernaar de klinische toepasbaarheid ervan kunnen vergroten.

Concluderend kunnen wij stellen dat boezemfibrilleren na een hartoperatie een uiting is van de onderliggende ernst van de beschadiging van de boezemwand (substraat). Dit leidt ertoe dat boezemfibrilleren na een open hartoperatie zich niet beperkt tot het ziekenhuisopname maar in de maanden tot jaren na ontslag uit het ziekenhuis ook kan terugkeren. Verder onderzoek zal moeten uitwijzen op welke wijze de uitingen van dit substraat behandeld of zelfs voorkomen zouden kunnen worden. 
Dankwoord 
De Universiteit Maastricht onderscheidt zich door een innovatief onderwijs model, het probleem gestuurd onderwijs, waarin de student al vroeg in de studie gefaciliteerd wordt om in aanraking te komen met de kliniek en het wetenschap. Ik heb deze mogelijkheden gekregen binnen Cardiovascular Research Institute Maastricht een van de grootste cardiovasculaire onderzoeksinstellingen binnen Europa. Hierbinnen bestaan unieke samenwerkingen tussen verschillende specialismen, onder andere de afdelingen Fysiologie (Prof Schotten), Cardiologie (Prof Crijns) en Cardio-Thoracale Chirurgie (Prof Maessen) wat een platform heeft gecreëerd voor open en innovatief wetenschappelijk onderzoek en hier begint het voor velen.

Op de eerste plaats gaat mijn dank uit naar Prof Schotten, Uli ("Niet bang zijn voor je negatieve resultaten"..."Het gaat om de boodschap") die mij niet alleen het belang van kwaliteit heeft bijgebracht, maar nog belangrijker, het belang van mijden van concessies doen aan kwaliteit, hetgeen bewerkstelligd wordt door informatie onbevooroordeeld en onafhankelijk op zijn waarde te schatten. De weg leidt dan automatisch naar creativiteit, zorgvuldigheid en meer inzicht. Ik hoop van harte dit proces met zijn hulp verder te mogen uitdiepen.

Alweer 10 jaar geleden heb ik kennis gemaakt met Prof Maessen ("blijf op het juiste vlak"... "wees niet zuinig op de lat") die mij in de loop der jaren gestimuleerd heeft om verder te kijken en geïnspireerd heeft om grenzeloos te denken m.n. rondom innovatie en opleiding. Het vereist hoge mate van kennis om zijn helikopter view voor te stellen maar gelukkig gaat dat samen met veel betrokkenheid en staat zijn deur altijd open (en zijn GSM)! Ik hoop ook met name op een voortzetting van onze muzikale avonturen.

Ik ben Sander Verheule ("maar... je kan het ook anders zien...") dankbaar voor zijn ingenieus non-conformistische inbreng welke onmisbaar is in ieder project. Dit betekent dat hij vaak als enige het lichtpuntje ziet. Zijn Maverick status wordt alleen al bevestigd door het feit dat hij in 2018 zijn eerste smartphone heeft aangeschaft en ik ben blij dat hij mijn co-promotor wilde zijn.

Ik zou graag de leden van de leescommissie Prof Crijns, Prof Van Gelder, Prof Suyker en Prof La Meir willen bedanken voor het kritisch beoordelen van dit werk en voor het afleggen van lange afstanden om bij de verdediging aanwezig te zijn.

Diepgaande discussies en een open feedback cultuur kenmerken de geweldige researchgroep waarin onder andere Stef Zeemering, Arne van Hunnik, Ali Gharaviri, Theo Lankveld, Dennis Lau en Pawel Kuklik mij hebben begeleid...We'll always have Denver!

Ik ben de staf Cardio-Thoracale Chirurgie van Maastricht UMC+ dankbaar voor hun toegankelijkheid en geduld, kwaliteiten die keer op keer op de proef werden gesteld tijdens wetenschappelijke activiteiten maar ook tijdens opleidingsmomenten. Daarnaast ben ik erg verwend geraakt in mijn opleiding door de verfrissend moderne opvattingen met name van mijn opleidster Dr Suzanne Kats ("kom op...even flink zijn!"), Dr Ehsan 
Natour ("nooit compromissen accepteren tijdens opereren!"), Dr Peyman Sardari Nia ("Het draait altijd om perfectie!"), Dr Patrique Segers ("als je iets efficiënter had gewerkt waren wij nu allang thuis"), Dr Gijs Geskes ( "De betere chirurg weet wie hij niet moet opereren."), Prof. dr. Bas Mochtar ("communiceren en documenteren!') en Prof. dr. Roberto Lorusso ("remember...it's all about details!"), allen met een eigen heldere filosofie betreffende cardiochirurgie dat mij altijd zal bijblijven.

In het diepe werd er voor verlichting gezorgd door Marcel van der Linden, Bart Maesen, Reinier Zandbergen en Ryan Accord, allen als mijn begeleiders als medisch student en later arts-assistent en ik waardeer de vriendschappen die hieruit zijn ontstaan. Hetzelfde geldt voor Stefan Verstraeten, Pieter Lozekoot, Lars van Middendorp, Rick Schreurs, Sam Heuts en Martijn Gilbers, allen wil ik bedanken voor hun inzet en bijdrage ook na het werk, vaak tot in de kleine uurtjes. Ellen Heerdt en Martijne Tromp hebben op het gebied van patiënt contacten en Reveal implantaties het meeste werk verricht! Daarnaast hebben vele studenten bijgedragen aan het verzamelen van data.

Mijn dank gaat verder uit naar de betrokken anesthesiologen voor hun geduld tijdens rapid-pacing op de operatiekamer en de intensivisten tijdens pacing op de intensive care. Ik ben erg veel geholpen door de creatieve oplossingen geboden door de operatieverpleegkundigen tijdens mapping op de OK. Sylvia, Nicole, Lucien en Anja ben ik dankbaar voor hun onmisbare ervaring en inzet in de planning. Alle secretaressen o.a. Bianca, Vivian, Lysette, Nadine en Monique hebben gezorgd voor de onvermijdelijke logistiek. Tussen 2010 en 2015 hebben meer dan 250 patiënten toestemming gegeven om mee te doen aan een onderzoek. Zonder deze vrijwilligers was dit onderzoek onmogelijk geweest.

De horizon werd steeds breder met vrienden als Parwez \& Farnaz, Ehsan \& Nargis en Eduard \& Bernice!

Door de onvoorwaardelijke liefde van mijn ouders, ondanks de vele uitdagingen in hun leven, sta ik waar ik sta en is dit boekje uiteraard aan hun opgedragen. Ik ben bijzonder trots op mijn broertje Bahram en zusjes Elaha en Sadaf en de nieuwste leden Jorrin en de kleine Naeva...zij zijn de veilige thuisbasis waar ik altijd kan landen.

Finally, I would like to thank my wife, Karina who has ben a constant support and a true motivation, with an unconditional smile on her face...я люблю тебя!

Milan en Amir zijn zonder twijfel de belangrijkste inspiratiebronnen in mijn leven. 


\section{About the Author}

Elham Bidar (Born August $4^{\text {th }}$ 1986) became a refugee of war at the age of 6 when he fled Kabul, Afghanistan with his family travelling to Peshawar, Pakistan (1992). He attended several primary schools and after 3 years, he moved to Saint Petersburg, Russia where he lived until Feb-1998, subsequently migrating to The Netherlands. After acquiring the Dutch citizenship he obtained the secondary school diploma from Trevianum School in Sittard, The Netherlands (1999-2005, Gymnasium $\beta$ ). He studied medicine at the Medical Faculty of Maastricht University and graduated with Honours in 2011. During his internship he joined the research group of Cardio-Thoracic Surgery under the supervision of Prof. Dr. J. G. Maessen and after graduation he started a joint PhD program between the dept. Cardio-Thoracic Surgery and Physiology under supervision of Prof. Dr. U. Schotten, which resulted in this thesis. He started his training of CardioThoracic Surgery in Maastricht (Jan-2014) en is currently in the final year of his training (until May-2019) under the supervision of Dr. S Kats and Prof. Dr. J.G. Maessen. He is married to Karina Kambulova and has 2 sons ( 6 and 4 years). 
List of publications 
Bidar E, Accord RE Een man met een intermitterende thoracale zwelling. Nederlands Tijdschrift voor Geneeskunde. Aug 2010

Van Breugel NH, Bidar E, Essers BE, Nieman F, Accord RE, Severens J L, Vrakking R, Maessen JG Cost-effectiveness of ablation surgery in patients with atrial fibrillation undergoing cardiac surgery. Interactive CardioVascular and Thoracic Surgery 2011.

Bidar E, Bramer S, Maesen B, Maessen JG, Schotten U. Post-operative Atrial Fibrillation - Pathophysiology, Treatment and Prevention. J Atr Fibrillation. 2013

Bidar E, Maesen B, Nieman F, Verheule S, Schotten U, Maessen JG A prospective randomized controlled trial on the incidence and predictors of latephase postoperative atrial fibrillation up to 30 days and the preventive value of biatrial pacing. Heart Rhythm. 2014

Kuklik P, Bidar E, Gharaviri A, Maessen J, Schotten U. Application of phase coherence in assessment of spatial alignment of electrodes during simultaneous endocardial-epicardial direct contact mapping of atrial fibrillation. Europace. 2014

Verheule S, Eckstein J, Linz D, Maesen B, Bidar E, Gharaviri A, Schotten U. Role of endo-epicardial dissociation of electrical activity and transmural conduction in the development of persistent atrial fibrillation. Prog Biophys Mol Biol. 2014

Lau DH, Maesen B, Zeemering S, Kuklik P, van Hunnik A, Lankveld TA, Bidar E, Verheule $S$, Nijs J, Maessen J, Crijns H, Sanders P, Schotten U. Indices of bipolar complex fractionated atrial electrograms correlate poorly with each other and atrial fibrillation substrate complexity. Heart Rhythm. 2015

Gharaviri A*, Bidar E*, Potse M, Zeemering S, Verheule S, Krause R, Maessen JG, Auricchio A and Schotten U, A Novel Computer Model of Endo-epicardial Electrical Dissociation and Conduction during Human Atrial Fibrillation, *Authors contributed equally, Submitted 
Raffa GM, Gelsomino S, Sluijpers N, Meani P, Alenizy K, Natour E, Bidar E, Johnson DM, Makhoul M, Heuts S, Lozekoot P, Kats S, Schreurs R, Delnoij T, Montalti A, Sels JW, Poll MV, Roekaerts P, Maessen J, Lorusso R.In-hospital outcome of post-cardiotomy extracorporeal life support in adult patients: the 2007-2017 Maastricht experience. Critical Care Resuscitation. 2017

Bidar E, Gelsomino S, Lorusso R, Johnson D, Jainandunsing JS, Tielliu Ignace FJ, Maessen JG, Natour E Modified Gott Shunt for Spinal Cord and Brain Perfusion During Off-Pump Distal Aortic Arch Repair. Submitted

Meani P, Gelsomino S, Natour E, Johnson DM, Brunner LRHP, Pappalardo F, Bidar E, Makhoul M, Raffa G, Heuts S, Lozekoot P, Kats S, Stuijpers N, Schreurs R, Delnoij T, Montalti A, Sels JW, Van de Poll M, Roekaerts P, Korver E, Babar Z, Maessen JG and Lorusso R Modalities and Effects of Left Ventricle Unloading on Extracorporeal Life support: a Review of the Current Literature. European Journal of Heart Failure 2017

Dudink E, Bidar E, Weijs B, Luermans J, Schotten U, Maessen J, Crijns H, Verheule S, Age and extent of coronary artery disease are associated with complexity of induced atrial fibrillation, Submitted

Meani P, Natour E, Johnson D, Pappalardo F, Bidar E, Makhoul M, Raffa G, Heuts S, Gelsomino S, Lozekoot P, Kats S, Stuijpers N, Schreurs R, Delnoij T, Montalti A, Sels JW, Van de Poll M, Roekaerts P, Weerwind P, Ganushchak Y, Korver E, Babar Z, Maessen JG, Lorusso R Left ventricle unloading in Veno-Arterial ECMO support: literature review for an unanswered dilemma European Journal of Heart Failure, 2017

Bidar E, Folliguet T, Kluin J, Muneretto C, Parolari A, Barili F, Suwalski P, Bonaros N, Punjabi P, Sadaba R, De Bonis M, Al-Attar N, Obadia JF, Czerny M, Shrestha M, Zegdi R, Natour E, Lorusso R, Postimplant Biological Aortic Prosthesis Degeneration: Challenges in Trans-catheter Valve Implant, European Journal of Cardiothoracic Surgery, 2018 in Press

Gelsomino S, Bidar E, Johnson D, Maessen JG, Natour E, Open Repair of Type la Endoleak in the Aortic Arch: Three Tailored Approaches. Journal of Thoracic Disease, 2018 
Lorusso R, Barili F, Bidar E, Di Mauro M, Gelsomino M, Miceli A, Parolari A; Daprati A, Myasoedova $V$, Alamanni $F$ et al. on behalf of the GIROC Investigators Prolonged pacemaker dependency is associated with increased mortality: a 12-year follow-up of 909 patients with permanent pacemaker implant after cardiac surgery. Submitted

Lorusso R, Vizzardi E, Johnson DM, Mariscalco G, Sciatti E, Maessen J, Bidar E, Gelsomino $S$. Cardiac surgery in adult patients with remitted or active malignancies: a review of preoperative screening, surgical management and short- and long-term postoperative results. European Journal of Cardiothorac Surgery 2018

Bidar E, Arrigoni SC, Accord RE, Resection of Kommerell Diverticulum and Transposition of Aberrant Left Subclavian Artery in Right Aortic Arch Vascular Ring Submitted

Meani P, Delnoij T, Raffa GM, Morici N, Sacco A, Oliva F, Sels JW, Driessen R, Roekaerts P, Gilbers M, Bidar E, Schreurs R, Natour E, Maessen JG, Venstra L, Kats S, Lorusso R Permanent aortic valve closure during peripheral veno-arterial extracorporeal-life support: is intra-aortic balloon pump an effective solution?, Perfusion, 2018

Lorusso R, Bidar E, Natour E, Heuts S, Minimally invasive Extra Corporeal Membrane Oxygenator removal, Submitted

\section{Abstracts}

E Bidar, JG Maessen, Robot Assisted Thoracic Surgery vs Video assisted thoracic surgery, Oral presentation, RAMSES: The Robotic Assisted Microsurgical \& Endoscopic Society Conference 3-4 March 2017, Chair Session: Robot Assisted Vascular Surgey

P Podziemski, S Zeemering, E Bidar, P Kuklik, A Van Hunnik, U Schotten Far-field effect in unipolar electrograms recorded from epicardial and endocardial surface: quantification of epi-endo dissociation during atrial Fibrillation in Humans (2015) Computing in Cardiology DOI: 10.1109/CIC.2015.7410956 
E Bidar, B Maesen, F Niemann, S Verheule, U Schotten, J G Maessen Incidence and predictors of "Late phase" versus "Early phase" post-operative atrial fibrillation, Heart rhythm Scientific Sessions, 2013, Denver Colorado, US

M Gilbers, B Maesen, E Bidar, J G Maessen, U Schotten, Postoperative atrial fibrillation after isolated corornary artery bypass graft surgery, oral presentation, European association of cardiothoracic surgery, October 2017, Vienna, Austria

E Bidar, E Natour, M Makhoul, et al. Cannula Position in Post-Cardiotomy ECMO: Configurations Options for a Better Patient Management. European journal of heart failure, Vol. 19, p.12-12. ISSN 1388-9842.

E.A.M.P. Dudink, J. Jacobs, E. Bidar, B. Weijs, J.G.L.M. Luermans, B. Maesen, E.C. Cheriex, U. Schotten, J.G. Maessen, J.C.A. Hoorntje, H.J.G.M. Crijns, S. Verheule, Age and extent of coronary artery disease are associated with complexity of induced atrial fibrillation August 2017 European Heart Journal 38 DOI: 10.1093/eurheartj/ehx504.P3628

E Bidar, B Maesen, U Schotten, J G Maessen, Add-on value of Bi-Atrial Pacing in combination with standardized Sotalol treatment for the prevention of postoperative Atrial Fibrillation after Cardiovascular Surgery Best oral presentation at Antwerp Medical Students' congress (AMSC) 2009, European Medical Students' Association; Antwerpen, Belgium

A Gharaviri, E Bidar, M Potse, S Verheule, S Zeemering, R Krause, A Auricchio, U Schotten Validation of a novel computer model of endo-epicardial electrical dissociation and transmural conduction during atrial fibrillation, EP Europace, Issue suppl_1, https://doi.org/10.1093/europace/euy015.256

M Gilbers, E Bidar, B Maesen, J G Maessen, U Schotten, Translational research: the use of our current knowledge in understanding postoperative atrial fibrillation' Oral presentation, European association of cardiothoracic surgery, October 2018, Milan, Italy 